OPEN ACCESS

Edited by: Isabella Zanella,

University of Brescia, Italy

Reviewed by:

James C. Vickers,

University of Tasmania, Australia

Ronald Booth

University of Ottawa, Canada

*Correspondence:

Aidong Yuan

yuan@nki.rfmh.org

Ralph A. Nixon

nixon@nki.rfmh.org

Specialty section:

This article was submitted to

Neurodegeneration,

a section of the journal

Frontiers in Neuroscience

Received: 01 April 2021

Accepted: 02 September 2021

Published: 27 September 2021

Citation:

Yuan $A$ and Nixon RA (2021)

Neurofilament Proteins as Biomarkers

to Monitor Neurological Diseases

and the Efficacy of Therapies.

Front. Neurosci. 15:689938.

doi: 10.3389/fnins.2021.689938

\section{Neurofilament Proteins as Biomarkers to Monitor Neurological Diseases and the Efficacy of Therapies}

\author{
Aidong Yuan ${ }^{1,2 *}$ and Ralph A. Nixon ${ }^{1,2,3 *}$ \\ ${ }^{1}$ Center for Dementia Research, Nathan Kline Institute, Orangeburg, NY, United States, ${ }^{2}$ Department of Psychiatry, NYU \\ Neuroscience Institute, New York, NY, United States, ${ }^{3}$ Department of Cell Biology, New York University Grossman School \\ of Medicine, (NYU), Neuroscience Institute, New York, NY, United States
}

Biomarkers of neurodegeneration and neuronal injury have the potential to improve diagnostic accuracy, disease monitoring, prognosis, and measure treatment efficacy. Neurofilament proteins (NfPs) are well suited as biomarkers in these contexts because they are major neuron-specific components that maintain structural integrity and are sensitive to neurodegeneration and neuronal injury across a wide range of neurologic diseases. Low levels of NfPs are constantly released from neurons into the extracellular space and ultimately reach the cerebrospinal fluid (CSF) and blood under physiological conditions throughout normal brain development, maturation, and aging. NfP levels in CSF and blood rise above normal in response to neuronal injury and neurodegeneration independently of cause. NfPs in CSF measured by lumbar puncture are about 40-fold more concentrated than in blood in healthy individuals. New ultra-sensitive methods now allow minimally invasive measurement of these low levels of NfPs in serum or plasma to track disease onset and progression in neurological disorders or nervous system injury and assess responses to therapeutic interventions. Any of the five Nf subunits neurofilament light chain (NfL), neurofilament medium chain (NfM), neurofilament heavy chain $(\mathrm{NfH})$, alpha-internexin (INA) and peripherin (PRPH) may be altered in a given neuropathological condition. In familial and sporadic Alzheimer's disease (AD), plasma NfL levels may rise as early as 22 years before clinical onset in familial AD and 10 years before sporadic AD. The major determinants of elevated levels of NfPs and degradation fragments in CSF and blood are the magnitude of damaged or degenerating axons of fiber tracks, the affected axon caliber sizes and the rate of release of NfP and fragments at different stages of a given neurological disease or condition directly or indirectly affecting central nervous system (CNS) and/or peripheral nervous system (PNS). NfPs are rapidly emerging as transformative blood biomarkers in neurology providing novel 
insights into a wide range of neurological diseases and advancing clinical trials. Here we summarize the current understanding of intracellular NfP physiology, pathophysiology and extracellular kinetics of NfPs in biofluids and review the value and limitations of NfPs and degradation fragments as biomarkers of neurodegeneration and neuronal injury.

Keywords: neurofilament, NFL, pNfH, biomarker, CSF, blood, neurodegeneration, neuronal injury

\section{INTRODUCTION}

It is widely accepted that the pathophysiology underlying many neurodegenerative disorders, such as Alzheimer's disease $(\mathrm{AD})$, originates many years prior to clinical symptoms. $\mathrm{AD}$ evolves through three stages - an early, preclinical stage with no detectable symptoms; a middle stage of mild cognitive impairment; and a late stage marked by symptoms of dementia. The lack of success in identifying treatments that cure $\mathrm{AD}$ or alter its progression has been attributed in part to the implementation of candidate treatments at a disease stage that is too advanced to blunt the disease triggering mechanism(s) or halt early progression before momentum builds to irreversible levels. There is a growing need for reliable noninvasive blood-based biomarkers for $\mathrm{AD}$ that can facilitate diagnosis, predict disease progression, and provide evidence of disease modification.

Neurofilament proteins (NfPs) appeared in the last few years as the most promising blood biomarkers of neuroaxonal integrity or damage. Nfs are classified as a type IV class of intermediate filaments (IFs) specific to neurons (Yuan et al., 2017). They are protein polymers measuring $10 \mathrm{~nm}$ in diameter and many micrometers in length. Together with microtubules $(25 \mathrm{~nm})$ and microfilaments $(7 \mathrm{~nm})$, they form the neuronal cytoskeleton. Much interest in the field has been recently focused on the detection of NfPs and degradation fragments released from neurons into blood as surrogate markers of neuronal damage in neuropathic states. The rationale for NfPs and fragments as biomarkers of neuronal damage is that they are not only responsive to neuronal injury but are also prominent components of abnormal intraneuronal aggregates in varied neurodegenerative diseases, including $\mathrm{AD}$, dementia with Lewy bodies (DLB), Parkinson's disease (PD), frontotemporal dementia (FTD), amyotrophic lateral sclerosis (ALS), Charcot-Marie-Tooth disease (CMT), multiple sclerosis (MS), giant axonal neuropathy (GAN) and toxic neuropathies. Although amyloid-beta and tau proteins are widely regarded as useful diagnostic biomarkers of $\mathrm{AD}$, tau proteins increase only in specific neurodegenerative diseases such as $\mathrm{AD}$ and unaltered in other neurological diseases that are clearly neurodegenerative, such as tau-negative FTD caused by granulin or C9orf72 mutations (Foiani et al., 2018) where, by contrast, CSF and serum neurofilament light chain (NfL) fragment levels are more than 8 times higher in patients than in pre-symptomatic carriers or healthy controls (Meeter et al., 2016). Furthermore, in Huntington disease (HD), CSF NfL fragment levels correlate more strongly with disease progression than do CSF tau levels (Niemela et al., 2017). Moreover, studies using a stable isotope labeling method to investigate tau metabolism demonstrate that the production rate of tau positively correlates with the amount of amyloid plaques, suggesting that increased tau levels in $\mathrm{AD}$ could be due to elevated transcription, synthesis or secretion from neurons in response to amyloid-beta pathology rather than reflect actual neurodegeneration (Sato et al., 2018). Thus, as general neuronal integrity markers, NfPs and their fragments may be more sensitive to neurodegeneration than is tau.

In individuals with inherited forms of $\mathrm{AD}$, levels of $\mathrm{NfL}$ fragments in blood may be altered 22 years before symptoms begin (Quiroz et al., 2020). NfL responds more sensitively to subclinical cognitive decline than amyloid-beta or tau (Bos et al., 2019; Kern et al., 2019; Merluzzi et al., 2019). Moreover, mean NfL fragment plasma levels increased 3.4 times faster in subjects who developed $\mathrm{AD}$ compared to those who remained dementiafree in a trajectory analysis of 4444 non-demented participants in the Rotterdam study at baseline and up to 14 years followup. In this review, we summarize the current understanding of NfPs and fragments as biomarkers in neurodegeneration and neurological injuries and draw attention to important unanswered questions.

\section{PROPERTIES OF NEUROFILAMENTS RELEVANT TO THEIR USE AS BIOMARKERS}

\section{The Physiological Basis of Neurofilament Proteins as Biomarkers of Neuronal Structural Integrity}

For a blood-based biomarker to reflect the structural integrity of neurons in human brains, it has to be a structural constituent of the neuron, impacted by the neuropathological process, and easily detectable in blood. The composition of intermediate filament subunits in neurons varies depending on the nerve cell type and stage of development (Figure 1). At the earliest stage of embryonic development, neural stem cells express nestin (NES), a type VI intermediate filament protein that is down-regulated after differentiation and replaced by cell type-specific intermediate filament proteins (Lendahl et al., 1990). Vimentin (VIM), a type III intermediate filament protein of mesenchymal cells, is also transiently co-expressed with nestin in precursor nerve cells (Yabe et al., 2003). VIM is gradually replaced by peripherin (PRPH), alpha-internexin (INA), neurofilament medium chain (NfM), and NfL during embryonic development. Neurofilament heavy chain $(\mathrm{NfH})$ chain expression is low in developing neurons and increases postnatally (Shaw and Weber, 1982; Pachter and Liem, 1984). 

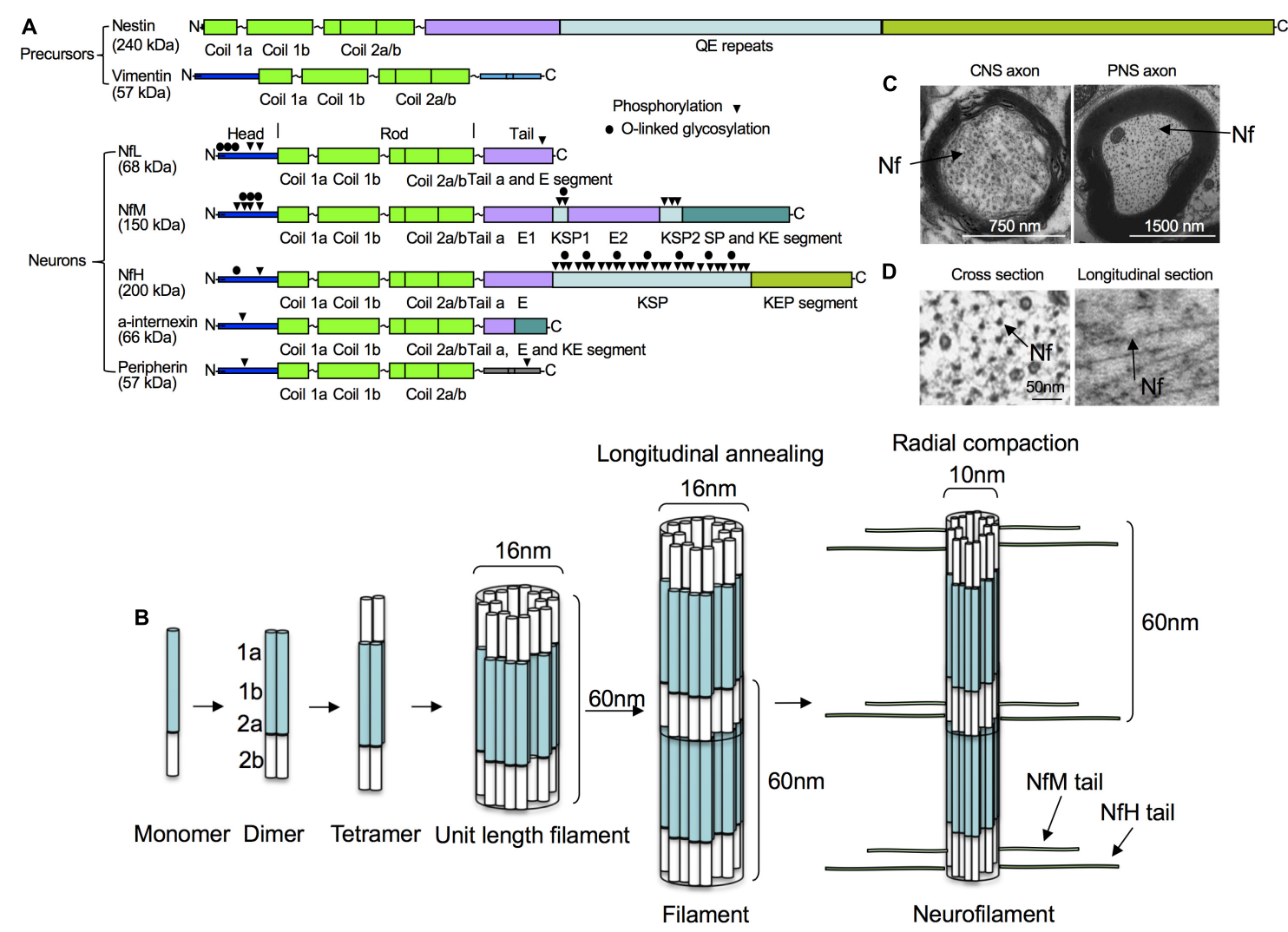

FIGURE 1 | Structure, assembly and cytoarchitecture of Nfs. (A) Domain structure of Nfs in precursor and mature neurons. Precursor neurons contain nestin and vimentin while mature neurons have NfPs consisting of $\mathrm{NfL}, \mathrm{NfM}, \mathrm{NfH}, \mathrm{INA}$, and/or PRPH. All Nf subunits include a conserved alpha-helical rod domain, amino-terminal globular head regions and carboxy-terminal tail domains. Phosphorylation and O-linked glycosylation sites are shown. (B) Nf assembly. Nf monomers form coiled-coil heterodimers, then tetramers and unit-length filaments and gradual end-to-end annealing of which results in filament elongation to form mature Nfs with a diameter of about $10 \mathrm{~nm}$ after radial compaction. (C) Moderate number of Nfs in corpus callosum axons vs. large number of Nfs in sciatic axons in mice.

(D) Ultrastructural representations of Nfs from mouse optic nerves in cross and longitudinal sections.

Mature mammalian neurons usually express five different NfPs: NfL, NfM and NfH chains, as well as INA and PRPH. In mature neurons in the CNS, Nfs are generally composed of NfL, NfM, NfH, and INA (Yuan et al., 2006), whereas, in the peripheral nervous system, they mainly consist of NfL, NfM, NfH and PRPH (Yuan et al., 2012). Like all IF proteins, NfPs all share a common alpha-helical rod domain that assembles to form a filament backbone, flanked by variable amino and carboxy-terminal domains that regulate polymer assembly and interactions. NF heteropolymer assembly starts with the formation of NfP dimers and antiparallel aggregation of these dimers leads to formation of tetramers which are thought to be the basic subunit of NFs during assembly (Mucke et al., 2018) and usually consist of NfL and one or more of the other Nf proteins. NfPs of mature neurons in vivo are mainly stable polymers and the pool of soluble NfP is small.

Neurofilament proteins are mainly synthesized in the cell body and transported as hetero-oligomeric assemblies and short filaments into axons and dendrites (Pachter and Liem, 1984; Yuan et al., 2003, 2009; Yan and Brown, 2005) to establish a highly stable regionally specialized NF network (Nixon and Logvinenko, 1986; Nixon et al., 1994; Sanchez et al., 1996). Nf mRNAs are also transported out of cell bodies into dendrites, spines, and axons and localized NfP synthesis in these cytoplasmic extensions is used to spatially and temporally regulate their protein content in these subcellular domains (Alami et al., 2014). NfPs can be proteolyzed by calpains, the proteasome, and autophagy into many smaller degradation products (Yuan et al., 2017).

\section{The Neuropathological Basis for Neurofilament Proteins as Biomarkers}

Biochemical, genetic, and animal model evidence implicates NfPs as a pathogenic culprit playing primary or secondary roles in nervous system diseases. NfPs are involved in the pathophysiological processes underlying many states of neurological injury and neurodegeneration, reflecting changes in structural integrity and abnormal accumulation or maldistribution of NfPs (Hamberger et al., 2003).

\section{Animal Studies}

Proper levels of NfPs are important for the normal functions of nervous systems in animals. Absence of NfL from neurons reduces axon diameters and causes sensorimotor and cognitive impairments in quails (Yamasaki et al., 1991) and mice (Zhu et al., 1997; Yuan et al., 2018). Single deletion of NfM, NfH or PRPH 
in mice can lead to age-related atrophy of motor axons (Elder et al., 1999), decrease in conduction velocity (Kriz et al., 2000) and reduced numbers of unmyelinated sensory axons (Lariviere et al., 2002), respectively. Deletion of INA in the absence of NfL (Yuan et al., 2003) or both NfL and NfH results in reduced transport of NfM into axons (Yuan et al., 2015b). Overexpression of NfL, $\mathrm{NfM}, \mathrm{NfH}$ or PRPH in animals can produce neuropathology of motor neuron diseases (Cote et al., 1993; Xu et al., 1993; Beaulieu et al., 1999; Gama Sosa et al., 2003) while overexpression of INA leads to motor coordination deficits (Ching et al., 1999). In addition to the importance of NfP levels, expression of an NfL mutation in mice which causes human disease (Zuchner et al., 2004; Filali et al., 2011; Liu et al., 2011; Shen et al., 2011; Pisciotta et al., 2015) also leads to motor neuropathology (Lee et al., 1994) and phenotype of CMT (Filali et al., 2011) probably due to disruption of Nf assembly (Perez-Olle et al., 2002; Tradewell et al., 2009) and transport (Brownlees et al., 2002), and abnormal Nf accumulation (Zhai et al., 2007).

\section{Human Studies}

Clinical studies demonstrate presence, normal structure and assembled network of NfPs are critical for human health. NfL loss of function mutations in cases of human neuropathy which cause markedly lowered NfL protein levels reduce axon diameters and cause sensorimotor and cognitive impairments in humans (Yum et al., 2009; Sainio et al., 2018). NfL and NfH mutations can cause Nf accumulation in CMT type 2E/1F/CMTDIG (Lerat et al., 2019) and CMT2CC (Ikenberg et al., 2019). In AD, NfPs are integral components of neurofibrillary tangles (Rudrabhatla et al., 2011; Figure 2) and NfH and NfM are 4-8-fold more phosphorylated than normal (Rudrabhatla et al., 2010). In PD, Lewy bodies contain NfPs (Goldman et al., 1983) and a cagelike Nf structure encapsulates Lewy bodies (Moors et al., 2019). In Nf inclusion disease, a form of FTD, prominent aggregations of NfPs, especially INA, are the neuropathologic hallmark of the condition (Cairns et al., 2004). Abnormal NfP accumulations are also a hallmark pathologic feature of ALS (Cleveland and Rothstein, 2001). In MS, increased expression of phosphorylated $\mathrm{NfH}$ ( $\mathrm{pNfH}$ ) is observed in spinal motor neuron perikarya (Muller-Wielsch et al., 2017) and Nfs accumulate excessively in axons in GAN (Bomont et al., 2000).

\section{Neurofilament Proteins Released From Neurons Gain Access to Blood Under Physiological and Pathological Conditions \\ Recent Technology Breakthroughs for the Reliable Detection of Neurofilament Proteins in the Peripheral Circulation}

Low levels of NfPs are constantly released from neurons into CSF and blood under physiological conditions and rise above normal in pathological states.

Rosengren et al. (1996) first tested NfPs as possible biomarkers using enzyme-linked immunosorbent assay (ELISA) with polyclonal rabbit antisera specific against the individual NfPs and showed that CSF NfL levels were increased in patients with ALS and AD compared to controls. However, the sensitivity of ELISA and the later developed electrochemiluminescence (ECL) immunoassay does not allow small, disease-related changes to be reliably detected in peripheral circulation. In 2010, single-molecule enzyme-linked immunosorbent assay (Simoa) was initially described (Rissin et al., 2010) which later enabled reliable quantification of NfL in serum or plasma samples (Gisslen et al., 2016) using NfL-specific monoclonal antibodies (mAb47:3) (Norgren et al., 2002). More recently, Meso Scale Discovery, immunomagnetic reduction technologies and the Ella platform based on microfluidic channels have also been developed to detect low NfP levels in blood (Liu H.C. et al., 2020; Lombardi et al., 2020; Gauthier et al., 2021).

\section{Neurofilament Proteins in Exosomes}

The fact that plasma NfL levels are enriched in neuron-derived exosomes compared to total exosomes isolated from blood in healthy individuals (Sun et al., 2017) suggests the NfPs are released from neurons at least in the form of exosomes (Figure 3). Moreover, plasma neuron-derived exosomes contain about 74-fold more NfL than plasma astrocyte-derived exosomes, which have only negligible amounts (Winston et al., 2019). NfP-containing exosomes or NfPs or degradation fragments released into the extracellular space may be eliminated from the CNS along intramural peri-arterial drainage pathway (Engelhardt et al., 2017).

\section{Neurofilament Protein Forms in Peripheral Circulation} Identity of the NfL forms in plasma exosomes is still unclear but a $22 \mathrm{kDa} \mathrm{NfL}$ degradation fragment has been revealed with an anti-NfL antibody and shown to be increased in ALS patients (Lombardi et al., 2020). Also identified are a $30 \mathrm{kDa}$ fragment of NfL in Nf-containing aggregates from human blood (Adiutori et al., 2018) and a $10 \mathrm{kDa}$ fragment of NfL in mouse CSF. Since no full length NfL has been ever reported in CSF or blood (Brureau et al., 2017), the detected Simoa signal is, therefore, NfL immunoreactivity or NfL breakdown product. By contrast, full length $(200 \mathrm{kDa})$ or oligomeric $\mathrm{NfH}$ were predominant in CSF and blood (Petzold et al., 2003; Shaw et al., 2005; Lewis et al., 2008). Recent studies also suggest full length (150 kDa) or trimeric NfM (450 kDa) in blood (Haggmark et al., 2014). A comprehensive list of widely used capture and detection antibodies to NfPs in ELISA is shown in Table 1.

\section{Neurofilament Light Chain Levels in Normal Individuals}

Intracellular NfPs have long half-lives ranging from 55 days in axons (Nixon and Logvinenko, 1986; Yuan et al., 2015a) to 6472 days at synapses (Heo et al., 2018), indicating their slow turnover rates inside neuronal compartments. Upon release into the extracellular space, serum or plasma NfL levels in healthy individuals are about $2.5 \%$ of the levels in CSF and correlate highly with the 40-fold higher NfL concentrations in CSF with typical R values ranging from 0.6 to 0.7 (Disanto et al., 2017; Pereira et al., 2017; Khalil et al., 2020; Alagaratnam et al., 2021), suggesting that most of the NfL signal in blood is CNSderived and could be used as a proxy measure for CSF NfL 

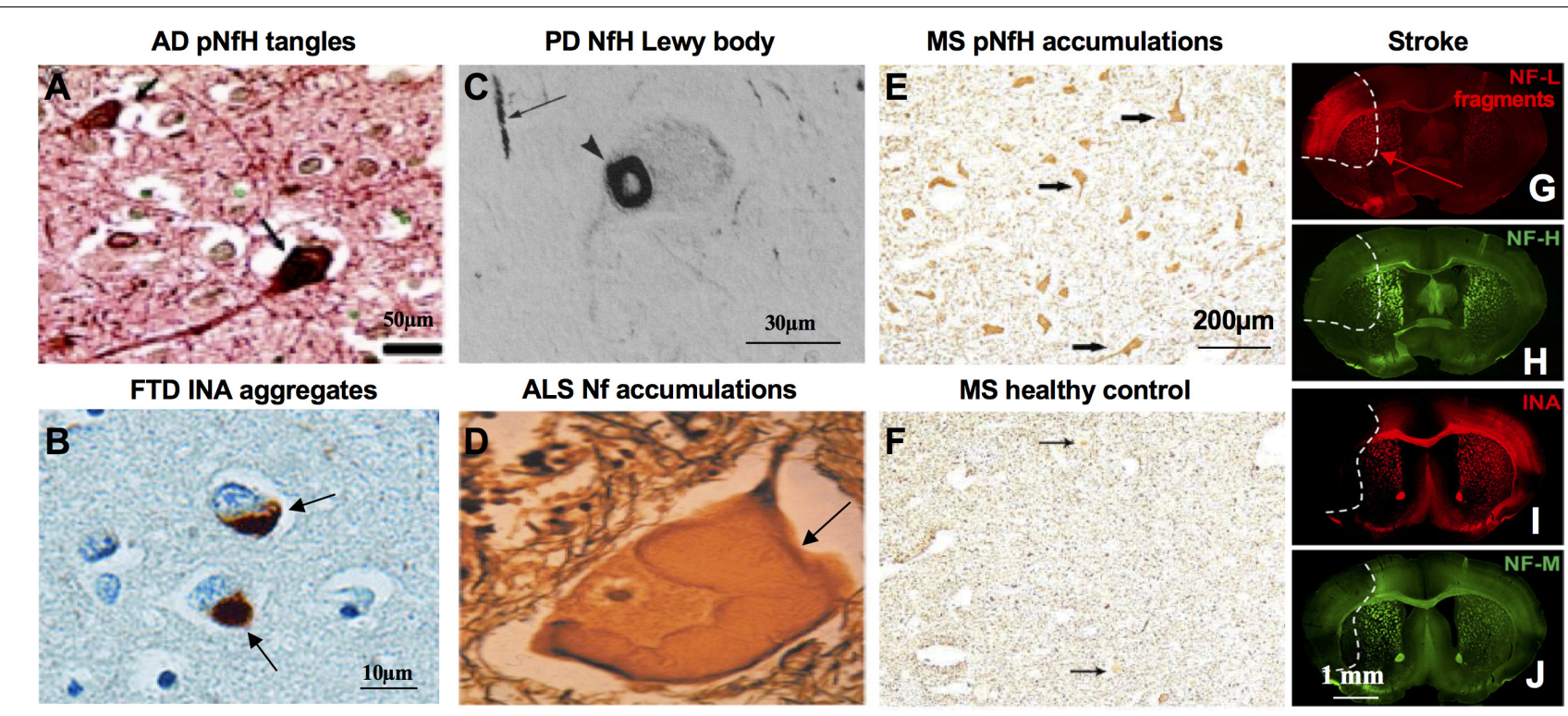

FIGURE 2 | Pathological basis of NfPs as biomarkers in neurologic diseases and neuronal injury. (A) NFTs in AD brain are stained with pNfH with mouse monoclonal phospho-NfH antibody RT97 under the condition it does not cross-react with phosphor-tau (adapted from Rudrabhatla et al., 2010). (B) Cytoplasmic inclusions in NIFID brain, a type of FTD, are stained with antibody to alpha-internexin (adapted from Cairns et al., 2004). (C) Cytoplasmic Lewy bodies in PD brain are stained with antibody to $\mathrm{NfH}$ (adapted from Goldman et al., 1983). (D) Masses of Nf swelling in ALS spinal cord are stained with Silver (adapted from Cleveland and Rothstein, 2001). (E) Anterior horn cell perikarya in MS spinal cord are prominently stained with antibody to pNfH (SMI31) whereas healthy controls remain almost non-reactive (F) (adapted from Muller-Wielsch et al., 2017). Ischemia-affected areas in mouse brain $24 \mathrm{~h}$ after experimental stroke induction are demarcated by an increase of NfL degradation fragments immunoreactivity (G), while the immunosignals for $\mathrm{NfH}(\mathbf{H})$, alpha-internexin (INA) (I), and NfM (J) are decreased (adapted from Mages et al., 2018).

levels (Gisslen et al., 2016). The NfL levels in blood are most often tested in serum and less frequently in EDTA-plasma with serum levels slightly higher than in plasma (Hviid et al., 2020b). Either specimen type is acceptable, however, when used in either research or clinical setting a single specimen should be selected for use. Plasma NfL levels measured in the morning may be more than $10 \%$ higher than those measured in the evening, suggesting that synaptic remodeling during sleep might alter NfL kinetics (Benedict et al., 2020; Thebault et al., 2021). CSF NfL levels in healthy females are about $20 \%$ lower than levels in healthy males (Bridel et al., 2019) although the reverse was true in an ALS cohort (Thouvenot et al., 2020). Concentrations of CSF and serum NfL increase with age in healthy controls (Yilmaz et al., 2017) with an increase in adult control serum NfL levels of $2.2 \%$ per year of age (Disanto et al., 2017; Barro et al., 2018). These increases accompany hippocampal atrophy in cognitively healthy older adults, which has suggested possible $\mathrm{AD}$-independent, ageexpected hippocampal decline (Idland et al., 2017). However, younger children have higher serum NfL levels than older children reaching the lowest level between the age of 10 and 15 years, then increasing in a linear fashion until the age of 60 years and accelerating non-linearly afterward (Evers et al., 2020; Khalil et al., 2020; Reinert et al., 2020). There are various proposed bases for serum NfL elevation in aging, including subclinical senescence with greater neuronal apoptosis (Khalil et al., 2020) and increased disruption of blood-brain barrier (Sweeney et al., 2018). Levels of serum NfL may also be affected by race, systolic blood pressure, decreased renal function, glycemic control measured by hemoglobin A1C (Korley et al., 2019) and pregnancy (Cuello et al., 2019). The multiplicity of influences on these levels prompts caution in controlling stringently for confounding variables in clinical studies.

\section{Contribution of Neurofilament Proteins or Fragments From Different Neuronal Compartments}

Besides calpains, the proteasome and autophagy (Smerjac et al., 2018), other non-specific proteases, including cathepsin D (Nixon and Marotta, 1984) and caspases 6 and 8 (Shabanzadeh et al., 2015) can also trigger $\mathrm{Nf}$ turnover and generate $\mathrm{Nf}$ peptides. $\mathrm{Nf}$ assembly confers significant proteolytic resistance to $\mathrm{Nf}$ subunits: deletion of three $\mathrm{Nf}$ subunits leads to degradation of the fourth subunit (Yuan et al., 2015b). Phosphorylation also protects Nfs against proteolysis (Goldstein et al., 1987; Pant, 1988; Rao et al., 2012). NfPs or their degradation fragments are released into biofluids following any damage to nervous system. Therefore, they are neither able to determine brain region specific alterations nor differentiate disease specific pathophysiological process.

\section{Mechanisms for Neurofilament Protein and Fragment Release From Neurons}

The exact mechanisms governing NfP release into biofluid are not fully understood. Release of NfPs or fragments from neurons may be a direct passive consequence of the loss of membrane integrity or may follow the known pathways for active secretion of other neuronal peptides and proteins. Intracellular endosomal organelles known as multivesicular bodies may play 
A Capture antibodyparamagnetic bead

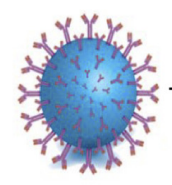

Detection antibody-biotin

Fluogenic resorufin product
Streptavidin-b-galactosidase

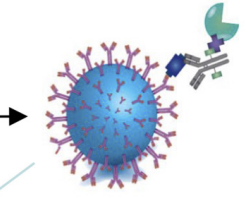

Each bead will contain one bound protein or none

Fluogenic resorufin b-Dgalactopyranoside
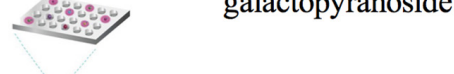

-

The sample is loaded into arrays, in the Simoa disc, consisting of more than 200,000 microwells - each well (4.25 $\mu \mathrm{m}$ width, $3.25 \mu \mathrm{m}$ depth) large enough to hold one bead with a single immunocomplex ( $2.7 \mu \mathrm{m}$ diameter).

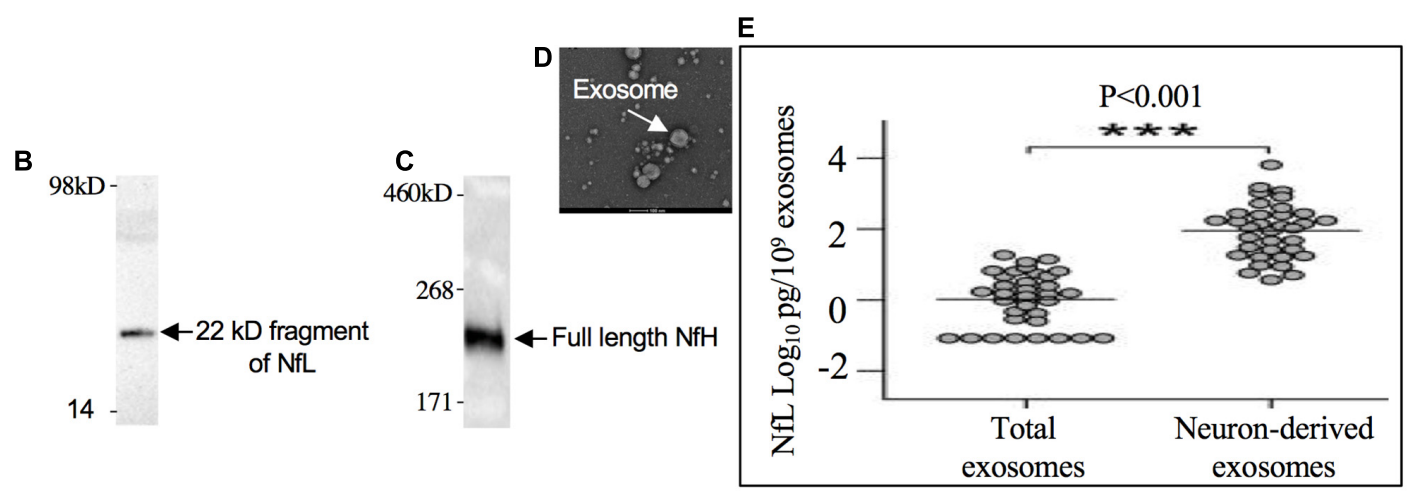

FIGURE 3 | 22 kD fragment of NfL and full length NfH in blood. (A) Low levels of NfPs in blood can be detected with single molecule array technology (Simoa/digital ELISA). A $22 \mathrm{kDa}$ degradation fragment of $\mathrm{NfL}$ (B, adapted from Lombardi et al., 2020) and full length NfH (adapted from Adiutori et al., 2018) were detected in blood (C). (D) Isolated exosomes from blood (adapted from Zhang et al., 2020). (E) NfL signal is enriched in neuron-derived exosomes compared to total or astrocyte-derived exosomes in blood (adapted from Sun et al., 2017). ${ }^{* \star *}$ Indicates highly significant.

critical roles in the release of peptides (Von Bartheld and Altick, 2011). This may happen though "back-fusion" events and budding from the plasma membrane to generate microvesicles (Kleijmeer et al., 2001) or through release of smaller endosomally derived exosomes (Lachenal et al., 2011). Levels of NfL signals in isolated neuron-derived exosomes accounting for a small percentage of total NfL concentration in plasma suggest that active secretion is at least one of the mechanisms for NfP release from neurons. After release from neurons, some NfPs and fragments can be degraded and cleared by varied extracellular proteinases and microglia and these processes may even further generate the fragments from a larger form. Pathways for degradation could be differentially critical in the context of healthy, injured or chronically damaged neurons. Expression of NfP genes is not elevated in ALS (Wong et al., 2000) and neither NfP gene (Robinson et al., 1994) nor protein expression (Ashton et al., 2019) is elevated in AD, suggesting that the increased NfP signal in biofluids is not due to a compensatory overproduction.

\section{Major Determinants of Neurofilament Protein and Fragment Levels in Cerebrospinal Fluid and Blood}

Studies have linked NfP levels in blood to changes in white matter (Moore et al., 2018; Spotorno et al., 2020; Maggi et al., 2021), gray matter (Jakimovski et al., 2019a; Kang et al., 2020), or both (Johnson et al., 2018), yielding a confusing picture of what variables dictate the highly variable levels found in different disorders. Some likely determinants of blood/CSF levels, however, include the composition of the diseased or injured area (relative abundance of large caliber axons that have high Nfcontent) and size of the damaged region. NfL and $\mathrm{NfH}$ content in spinal cord is several fold higher than in corpus callosum (Yuan et al., 2012) and at least 10-fold higher than in cortex (Shaw et al., 2005). Accordingly, a spinal cord injury released 
TABLE 1 | NfP and fragment measurement as biomarkers.

\begin{tabular}{|c|c|c|c|}
\hline & Capture antibodies & Detection antibodies & References \\
\hline \multicolumn{4}{|c|}{ ELISA for measuring Nf subunits as biomarkers } \\
\hline \multirow[t]{4}{*}{ NfL } & Chicken polyclonal anti-NfL & Rabbit polyclonal anti-NfL & Rosengren et al., 1996 \\
\hline & NfL mAb 47:3, core domain (aa92-396) & NfL mAb 2:1 & Norgren et al., 2003 \\
\hline & Polyclonal antibody R61d to NfL, NfM and NfH & $\mathrm{NfL}$ mAb NR4 & Hu et al., 2002 \\
\hline & NfL 21 mAb, core domain (aa93-396) & NfL 23 mAb & Gaetani et al., 2018 \\
\hline \multirow[t]{7}{*}{$\mathrm{NfH}$} & SMI31 mAb anti-NfH and NfM & Anti-NfH NA211 & Hoglund et al., 2012 \\
\hline & $\mathrm{SMI} 34$ mAb anti-NfH & Rabbit polyclonal anti-NfH & Zucchi et al., 2018 \\
\hline & SMl35 mAb anti-NfH & Chicken polyclonal anti-NfH & Petzold et al., 2003 \\
\hline & Chicken polyclonal anti-NfH & Rabbit polyclonal anti-NfH & Shaw et al., 2005 \\
\hline & $\mathrm{AH} 1 \mathrm{mAb}$ anti-NfH & NAP4 mAb anti-NfH & Boylan et al., 2009 \\
\hline & Polyclonal antibody R61d to NfL, NfM and NfH & SMI31, SMI32, SMI33 and SMI34 & Hu et al., 2002 \\
\hline & pNfH mAb 9 C9 & $\mathrm{NfH}$ polyclonal antibody & Koel-Simmelink et al., 2014 \\
\hline \multirow[t]{3}{*}{ NfM } & Polyclonal antibody R61d to NfL, NfM and NfH & SMI31, SMI32 and SMI33 & Hu et al., 2002 \\
\hline & Monoclonal anti-NfM & Monoclonal anti-NfM & Martinez-Morillo et al., 2015 \\
\hline & Polyclonal anti-NfM & Polyclonal anti-NfM & Zucchi et al., 2018 \\
\hline \multirow[t]{2}{*}{$\mathrm{PRPH}$} & Rabbit polyclonal anti-PRPH & Chicken polyclonal anti-PRPH & Finderlater, 2010 \\
\hline & Unknown & Unknown & Sabbatini et al., 2021 \\
\hline \multicolumn{4}{|c|}{ Proteomics for measuring NF subunits as biomarkers } \\
\hline \multicolumn{2}{|c|}{$\mathrm{NfM}$} & & $\begin{array}{l}\text { Haggmark et al., 2014; } \\
\text { Martinez-Morillo et al., 2014; } \\
\text { Remnestal et al., } 2020\end{array}$ \\
\hline \multicolumn{2}{|l|}{ INA } & & Martinez-Morillo et al., 2014 \\
\hline \multicolumn{2}{|l|}{ PRPH } & & Liang et al., 2019 \\
\hline
\end{tabular}

about 12-fold more $\mathrm{NfH}$ into blood than a brain injury of comparable size (Shaw et al., 2005). Demyelinating damage to CNS axons associated with clinical or MRI (magnetic resonance imaging) disease activity in MS can cause a spike of more than 20 -fold in the levels of serum NfL which may be lowered with effective treatment (Akgun et al., 2019). Only about 20\% of the NfL fragment present in blood comes from neuron-derived exosomes (Altick et al., 2009; Winston et al., 2019; Guedes et al., 2020) so the extent of loss of membrane integrity affecting NFrich axons, or even to a lesser extent synapses, is likely the major determinant of NfP and fragment levels in CSF and blood. In a limited region of involvement as in the substantia nigra pars compacta in PD, NfL fragment level increases in CSF and serum are modest. By contrast, in FTD/ALS, widespread degeneration of large caliber Nf-rich axonal fibers in the spinal cord and brain results in one of the highest elevations of NfP and fragment blood levels among neurodegenerative diseases. More studies are warranted to determine the relative gray and white matter contributions to NfP and fragment levels in biofluids at different stage of a specific disease.

\section{Mechanisms of Neurofilament Protein or Peptide Trafficking Between Brain and Blood}

Since the main source of serum NfPs is the CNS, it is not fully clear how NfPs traffic between parenchymal, CSF and blood compartments. NfPs or their degradation fragments could also follow the apparent general pathways by which molecules such as amyloid-beta peptides pass from the interstitial fluid (ISF) of the brain into CSF and blood. Soluble metabolites or peptides from cells in most organ are absorbed directly into the blood or drain via lymphatic vessels to regional lymph nodes (Engelhardt et al., 2017). Soluble tracers such as serum albumin injected into ISF of the brain drain to cervical lymph nodes along the walls of cerebral arteries (Szentistvanyi et al., 1984) through intramural peri-arterial drainage pathway (IPAD) (Albargothy et al., 2018) including initially along basement membranes that surround capillaries and then along the basement membranes between smooth muscle cells in the tunica media of intracerebral and leptomeningeal arteries (Carare et al., 2008). About $85 \%$ of a tracer injected into the cerebral hemispheres passes to cervical lymph nodes via IPAD (Szentistvanyi et al., 1984) while only 10$15 \%$ passes into the CSF (Szentistvanyi et al., 1984; McIntee et al., 2016). Future studies need to measure the proportion of NfPs and degradation fragments released from neurons that reaches the CSF. Drainage of CSF into lymphatic vessels of the nasal mucosa via the cribriform plate appears to be a major lymphatic drainage pathway (Kida et al., 1993; De Leon et al., 2017) and may also include dural lymphatics (Aspelund et al., 2015). The gliallymphatic or glymphatic pathway is recently identified in rodent brain, which sub-serves the flow of CSF into the brain along perivascular spaces and then into the brain interstitium facilitated by aquoporin-4 water channels (Rasmussen et al., 2018). This pathway then directs flow toward the venous perivascular and perineuronal spaces, ultimately clearing solutes from neuropil into meningeal and cervical lymphatic drainage vessels.

\section{Dynamics of Extracellular Neurofilament Proteins and Fragments}

In acute neurological diseases with a known timepoint for neuronal or axonal damage such as traumatic brain injury (TBI) 
(Bergman et al., 2016; Shahim et al., 2017), stroke (Gattringer et al., 2017; Tiedt et al., 2018) and MS (Rosso et al., 2020), CSF and serum NfP signals increased over a few days and remained elevated over many months. It may be difficult to investigate the dynamics of CSF and serum NfPs in chronic neurodegenerative diseases such as $\mathrm{AD}$ and $\mathrm{PD}$ without treatments that can cure them. Because it is suggested that serum NfL fragments may be cleared by the kidneys, renal function ought to be considered when interpreting serum NfL levels (Korley et al., 2019; Van Der Plas et al., 2021).

\section{Neurofilament Proteins as Biomarkers in Animal Models \\ Neurofilament Proteins as Biomarkers in Animal Models of Neurological Diseases}

Increased levels of plasma NfL have been observed in mouse models of PD A53T- alpha-synuclein, tauopathy P301S-Tau and AD APP/PS1 (amyloid precursor protein/presenilin 1) (Bacioglu et al., 2016). Increases in NfL in CSF and blood coincide with the onset and progression of the corresponding proteopathic lesions in brain. Experimental induction of alphasynuclein lesions increase blood NfL levels, while blocking the development of amyloid-beta lesions attenuates NfL increases (Bacioglu et al., 2016). Prolonged expression in mice of p25 (the calpain-mediated truncated product of $\mathrm{p} 35$, the regulatory subunit of Cdk5 - cyclin-dependent-like kinase 5) causes severe synaptic and neuronal loss and brain atrophy which are accompanied by cognitive deficits (Fischer et al., 2005). In these inducible CamKII-TetOp25 transgenic mouse models of neurodegeneration, serum NfL levels increase after induction of neurodegeneration by switching on p 25 transgene expression via removal of doxycycline but do not increase further if induction is stopped by switching off p25 expression. Increased levels of serum NfL correlate with induced neuronal damage in the cortex and hippocampus of CamKII-TetOp25 mice, indicating that NfL levels mirror the ongoing neurodegeneration and neuronal loss and may be used as a dynamic biomarker of neurodegeneration (Brureau et al., 2017). In HD R6/2 mice, increased levels of NfL in CSF and serum is associated with neurodegeneration and disease severity (Soylu-Kucharz et al., 2017). In 304Q knock-in spinocerebellar ataxia type 3 (SCA3) mouse model, serum NfL and $\mathrm{pNfH}$ are elevated at the presymptomatic stage of 6 months of age and correlate with ataxin 3 aggregation and Purkinje cell loss in the brain (Wilke et al., 2020). Increased CSF pNFH levels were also observed in horses with equine neuroaxonal dystrophy/degenerative myeloencephalopathy (Edwards et al., 2021). Plasma pNfH levels also closely reflect later stages of disease progression and therapeutic response in the SOD1 (superoxide dismutase 1) G93A mouse model of ALS (Lu et al., 2012). Recently, serum NfL concentration in sheep with prion disease was more than 15 times higher than that found in control samples (Zetterberg et al., 2019). More recently, plasma NfL levels were also reported to reflect disease severity in mice inoculated with prions and fell significantly in antisense oligonucleotide-treated mice compared to the immediate pre-dose timepoint, suggesting a reversal of pathology driving the $53 \%$ increase in survival time (Minikel et al., 2020).

\section{Neurofilament Proteins as Biomarkers in Animal Models of Neurological Injuries}

Following experimental spinal cord injury (SCI) in adult rats, serum $\mathrm{pNfH}$ showed an initial peak of expression at $16 \mathrm{~h}$ and a second peak at 3 days while no serum $\mathrm{pNfH}$ is detectable in sham control animals (Shaw et al., 2005). The maximum level of $\mathrm{pNfH}$ in these SCI experiments was $250 \mathrm{ng} / \mathrm{ml} \mathrm{pNfH}$ in the 3-5 day post-injury period following injury. Serum pNfH showed a similar trajectory in TBI in adult rats but the average peak level of expression of serum pNfH was only about $20 \mathrm{ng} / \mathrm{ml}$, much lower than that seen in the SCI model (Shaw et al., 2005). Recent studies found serum NfL levels were substantially elevated at all acute and subacute time-points after a single mild TBI (mTBI), peaked at 1-day, and remained elevated 14-days post-injury (O"Brien et al., 2021). Increased serum NfL levels were also mTBI dose-dependent and correlated with the degree of sensorimotor impairment (O"Brien et al., 2021). In more recent studies using an experimental rat model of blast-induced TBI, pNfH levels increased at $24 \mathrm{hr}$, returned to normal levels at 1 month, but increased again at 6 months and 1 year post-blast exposure (Arun et al., 2021). Moreover, the changes in CSF pNfH correlate with $\mathrm{pNfH}$ levels in brain regions and with neurobehavioral function in the rats (Arun et al., 2021).

\section{Neurofilament Proteins as Biomarkers in Neurological Diseases}

Cerebrospinal fluid or serum NfL and $\mathrm{pNfH}$ have been widely studied as biomarkers in a number of neurological diseases (Table 2) or conditions directly or indirectly affecting central and peripheral nervous systems (Table 3). NfPs are not only elevated in neurological diseases but may also track disease progression. Different subunits might reflect different neurodegenerative processes. In addition to commonly used NfL and $\mathrm{pNfH}$, some studies also found potential values of other Nf subunits, i.e., NfM (Hu et al., 2002; Haggmark et al., 2014; Martinez-Morillo et al., 2014; Zucchi et al., 2018; Remnestal et al., 2020), INA (MartinezMorillo et al., 2014) and PRPH (Finderlater, 2010; Liang et al., 2019; Sabbatini et al., 2021) as biomarkers in CSF or serum in neurological diseases or injuries.

\section{Multiple Sclerosis}

Patients with MS have up to $60 \%$ axonal loss at all spinal levels involving all fibers regardless of their diameter (Tallantyre et al., 2009; Petrova et al., 2018). The concentrations of CSF and serum NfPs represent the degree of axonal loss and therefore, could be a biomarker of MS disease activity. Accordingly, CSF NfL levels in relapsing MS were 3-fold higher than in healthy controls (951.8 vs. $284.4 \mathrm{pg} / \mathrm{ml}$ ) and associated with relapse and cortical lesions (Damasceno et al., 2019). Serum NfL levels was first reported to be increased in early relapsing MS and correlated with MRI measures of disease severity using an electrochemiluminescence assay (Kuhle et al., 2016). This finding of serum NfL as a biomarker of MS disease activity was later substantiated with higher sensitivity Simoa digital immunoassay 
TABLE 2 | NfPs and fragments as biomarkers in neurodegeneration and neuronal injuries.

\begin{tabular}{|c|c|c|c|c|c|c|c|c|c|c|c|c|}
\hline \multirow{3}{*}{$\begin{array}{l}\text { Neurological diseases and } \\
\text { injuries }\end{array}$} & \multicolumn{8}{|c|}{ Association of NF subunit level with } & \multicolumn{3}{|c|}{ Association of NF subunit level with } & \multirow[t]{3}{*}{ References } \\
\hline & \multicolumn{2}{|c|}{ NfL } & \multicolumn{2}{|c|}{ pNfH (smi35) } & \multicolumn{2}{|c|}{ NfH (smi34) } & \multicolumn{2}{|c|}{ NfH (smi31 and others) } & \multirow[b]{2}{*}{$\begin{array}{l}\text { Disease } \\
\text { activity }\end{array}$} & \multirow[b]{2}{*}{ Prognosis } & \multirow[b]{2}{*}{$\begin{array}{l}\text { Treatment } \\
\text { response }\end{array}$} & \\
\hline & B & C & B & C & B & C & B & C & & & & \\
\hline $\begin{array}{l}\text { Multiple sclerosis and clinically } \\
\text { isolated syndrome }\end{array}$ & + & + & + & + & + & + & + & + & yes & yes & yes & $\begin{array}{l}\text { Linker et al., 2009; Disanto et al., } \\
\text { 2016, 2017; Herrera et al., 2019; } \\
\text { Calabresi et al., 2020; Saraste } \\
\text { et al., } 2021\end{array}$ \\
\hline Alzheimer's disease & + & + & & + & & & + & + & yes & yes & yes & $\begin{array}{l}\text { Rosengren et al., 1996; Hu et al., } \\
\text { 2002; Kuhle et al., 2010; Hoglund } \\
\text { et al., 2012; Zetterberg et al., 2016; } \\
\text { Mattsson et al., 2017; Gaetani } \\
\text { et al., 2018; Benedet et al., } 2020\end{array}$ \\
\hline Adult Down syndrome & + & & & & & & & & yes & yes & & $\begin{array}{l}\text { Fortea et al., 2018; Strydom et al., } \\
\text { 2018; Shinomoto et al., 2019; } \\
\text { Delaby et al., 2020; Carmona-Iragui } \\
\text { et al., 2021; Petersen et al., } 2021\end{array}$ \\
\hline Mild cognitive impairment & + & + & & & & & & & yes & yes & & $\begin{array}{l}\text { Zhou et al., 2017; Mayeli et al., } \\
\text { 2019; Osborn et al., } 2019\end{array}$ \\
\hline Vascular dementia & & + & & & & + & & + & yes & yes & & $\begin{array}{l}\text { Hu et al., 2002; Skillback et al., } \\
2014\end{array}$ \\
\hline Mixed dementia & & + & & & & & & & yes & yes & & Skillback et al., 2014 \\
\hline Frontal temporal dementia & & + & & & & & & & yes & yes & & $\begin{array}{l}\text { Skillback et al., 2014; Remnestal } \\
\text { et al., } 2020\end{array}$ \\
\hline Dementia with Lewy body & & & & + & & & & & & & & De Jong et al., 2007 \\
\hline HIV-associated dementia & + & & & & & & & & yes & yes & yes & Gisslen et al., 2016 \\
\hline Stroke & + & + & & + & & & & & yes & yes & & $\begin{array}{l}\text { Norgren et al., 2003; Petzold et al., } \\
\text { 2003; Kuhle et al., 2010; } \\
\text { Martinez-Morillo et al., 2014; Tiedt } \\
\text { et al., 2018; Garland et al., 2021; } \\
\text { Peng et al., 2021; Wang Z. et al., } \\
2021\end{array}$ \\
\hline Traumatic brain injury & + & & & & & & & & yes & yes & & $\begin{array}{l}\text { Shahim et al., 2016; Liang et al., } \\
\text { 2019; Yang et al., } 2019\end{array}$ \\
\hline Sport-related concussion & + & & & & & & & & & & & $\begin{array}{l}\text { Shahim et al., 2017; McDonald } \\
\text { et al., } 2021\end{array}$ \\
\hline
\end{tabular}


TABLE 2 | (Continued)

Neurological diseases and injuries

(1)

Spinal cord injury

Amyotrophic lateral sclerosis

$+$

Parkinson's disease

Huntington disease

Bipolar disorder

Autism spectrum disorder

Neuronal ceroid lipofuscinosis type 2 and 3

Spinal muscular atrophy

Cortico-basal degeneration

Multiple system atrophy

Progressive supranuclear palsy

Spinocerebellar ataxia

Friedreich ataxia

Epilepsy

Charcot-Marie-Tooth disease

Hereditary transthyretin amyloidosis

Guillain-Barre syndrome

Chronic inflammatory demyelinating polyneuropathy + Neuromyelitis optica

Creutzfeldt-Jacob disease (prion disease)

Canine cognitive dysfunction syndrome

B, blood; C, CSF

$+$

$+$

$+$
Association of NF subunit level with

Association of NF subunit level with

References

\begin{tabular}{|c|c|c|c|}
\hline NfL & pNfH (smi35) & $\mathrm{NfH}$ (smi34) & $\mathrm{NfH}$ (smi31 and others) \\
\hline
\end{tabular}

B C B

\section{Disease Prognosis Treatment}

activity

yes

yes

yes

yes

yes

$+$

$+$

Yes

yes

yes

yes

Yes

yes
Shaw et al., 2005: Kuhle et at., 2015

Rosengren et al., 1996; Kuhle et al. 2010; Haggmark et al., 2014; Ross et al., 2018; Benatar et al., 2019

Lin et al., 2018, 2019; Backstrom et al., 2020; Ye et al., 2021

Byrne et al., 2017; Rodrigues et al., 2020

Jakobsson et al., 2014

He et al., 2020

yes

Ru et al., 2019; Dang Do et al.,

2020

Olsson et al., 2019

Hansson et al., 2017

Hansson et al., 2017

Hansson et al., 2017

Li et al., 2019; Coarelli et al., 2021

Clay et al., 2020

Rejdak et al., 2012

Sandelius et al., 2018; Millere et al., 2021

Kapoor et al., 2019; Ticau et al.,

2019

Kuhle et al., 2010; Mariotto et al.,

2018

Hayashi et al., 2021

Miyazawa et al., 2007; Liu et al., 2021

Steinacker et al., 2016; Minike et al., 2020; Thompson et al., 2021 Vikartovska et al., 2020 
(Hansson et al., 2017; Novakova et al., 2017; Kuhle et al., 2019; Szilasiova et al., 2021). Increased levels of serum NfL are also associated with MS brain T2 lesion load (Disanto et al., 2017). A recent study showed that serum NfL levels were associated with T1, T2 and gadolinium-enhancing lesion volumes at baseline and higher serum levels of NfL at baseline were associated with greater atrophy of the whole brain, gray matter and deep gray matter nuclei in the long term (Jakimovski et al., 2019a). Serum NfL may also detect MS disease activity that escapes detection in routine MRI (Akgun et al., 2019). The levels of serum NfL increased 6 years before clinical MS onset, indicating MS may have a prodromal phase lasting several years and that neuronal damage occurs already during this phase (Bjornevik et al., 2019). After clinical onset, a 1-point Expanded Disability Status Scale (EDSS) increase corresponds to an serum NfL increase of about 14\% (Disanto et al., 2017).

Serum NfL concentrations have been used to assess disease progression in MS. Clinically isolated syndrome (CIS) is one of the MS disease courses and refers to a first episode of neurological symptoms that last at least $24 \mathrm{~h}$ and is caused by inflammation or demyelination of in the CNS. Elevated NfL levels in both pediatric and adult patients with CIS have been reported to be associated with a shorter time to clinically definite MS diagnosis independent of other prognostic factors (Van Der Vuurst De Vries et al., 2019). In patients with confirmed relapsing or progressive MS, baseline serum NfL can predict short-term outcomes including clinical and cognitive performance (Disanto et al., 2017; Jakimovski et al., 2019b; Filippi et al., 2020). Serum NfL levels sampled within the first 5 years of MS symptom onset was shown to independently predict long-term worsening EDSS score and risk of developing progressive MS in patients followed longitudinally for 15-26 years (Thebault et al., 2020a). Notably, patients with serum NfL levels less than $7.62 \mathrm{pg} / \mathrm{ml}$ were 7.1 times less likely to develop progressive MS (Thebault et al., 2020a).

Serum/plasma or CSF NfPs have potential utility for assessing treatment efficacy in single patients and beginning at an earlier stage in the disease course. Treatment with any diseasemodifying therapy in MS has been reported to be associated with significantly lower serum NfL levels compared to untreated individuals (Disanto et al., 2017; Harris et al., 2021), proving that CSF or serum/plasma NfL is a therapeutic response biomarker in MS that may be related to consequent prevention of ongoing neuronal damage.

Fingolimod significantly reduced plasma NfL levels after 6 months and until the end of the studies (24 months) (Kuhle

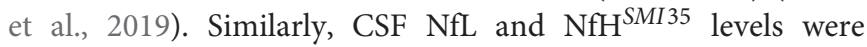
significantly lowered after 12 months of natalizumab treatment. A 4 fold greater reduction of $\mathrm{NfL}$ than of $\mathrm{NfH}^{\text {SMI35 }}$ suggests differential sensitivity to therapeutic changes using different subunits as the biomarker (Kuhle et al., 2013) although $\mathrm{NfH}^{\text {SMI } 35}$ antibodies detect $\mathrm{NfH}$ phosphorylation rather than the protein itself and may reflect different aspects of a given disease. Caution should be taken when MS patient are at risk for other treatmentinduced neurological complications that can cause serum NfL levels to rise, such as natalizumab-induced progressive multifocal leukoencephalopathy (Dalla Costa et al., 2019) and ablative hemopoietic stem cell transplantation (Thebault et al., 2020b).

\section{Amyotrophic Lateral Sclerosis}

Mutation carriers with ALS symptoms have higher NfPs than those without ALS symptoms (CSF NfL 37-fold, 7388 vs. $195.7 \mathrm{pg} / \mathrm{ml}$ ) (Weydt et al., 2016), suggesting that elevated NfP levels are linked to disease progression and the symptomatic disease phase (Benatar et al., 2019; Gille et al., 2019). Moreover, elevated serum NfL levels were observed as far back as 1 to 3.5 years before symptom onset depending on different gene mutations (SOD1, 12 months; FUS, 2 years and C9orf72, 3.5 years) (Benatar et al., 2018, 2019). CSF NfL levels also correlate with the extent of upper motor neuron and lower motor neuron involvement in ALS (Poesen et al., 2017). The time to generalization in ALS is an early clinical parameter of disease progression and CSF NfL concentrations have been shown to predict the conversion from bulbar/spinal to generalized ALS (Tortelli et al., 2015). Levels of NfL and pNfH also correlate with survival length in ALS (Brettschneider et al., 2006; Zetterberg et al., 2007; Lu et al., 2015). Higher serum NfL at diagnosis is also one of several factors that predict time of death in ALS (Thouvenot et al., 2020). In a recent clinical trial, levels of pNfH and NfL in plasma and CSF were largely unchanged in placebo-treated patients due to superoxide dismutase 1 (SOD1) mutations and decreased in patients treated with tofersen administered intrathecally over a period of 12 weeks, an antisense oligonucleotide that mediates the degradation of SOD1 messenger RNA to reduce SOD1 protein synthesis (Miller et al., 2020). Moreover, CSF SOD1 concentration decreased in these tofersen-treated patients with evidence of a slowing in the disease in the total scores on the ALS functional rating scale and the handheld dynamometry megascore.

\section{Alzheimer's Disease}

Plasma NfL is significantly higher in patients with MCI (mild cognitive impairment) $(42.8 \mathrm{pg} / \mathrm{ml})$ and patients with $\mathrm{AD}$ $(51.0 \mathrm{pg} / \mathrm{ml})$ compared with healthy controls $(34.7 \mathrm{pg} / \mathrm{ml})$ (Mattsson et al., 2017). This finding was further confirmed by other studies (Zhou et al., 2017; Lewczuk et al., 2018). Moreover, higher NfL levels were associated with cognitive decline in nondementia older adults (He et al., 2021). Interestingly, elevated plasma NfL is associated with the presence of amyloid-beta plaques in pre-symptomatic individuals whereas NfL levels is associated with the load of tau in symptomatic patients (Benedet et al., 2020). Plasma NfL is also associated with AD progression independent of amyloid-beta (Moscoso et al., 2021a). Plasma NfL levels also correlate with Braak staging and longitudinal increases in plasma NfL are observed in all Braak groupings (Ashton et al., 2019). In addition, normal plasma NfL level $(20.24 \mathrm{pg} / \mathrm{ml})$ is also linked with resistance to PS1 familial AD in apolipoprotein E3 (APOE3) Christchurch mutation (Arboleda-Velasquez et al., 2019). The role of NfL as a potential biomarker for $\mathrm{AD}$ has been extensively reviewed and recent meta-analysis regarding its association with AD can be found elsewhere (Olsson et al., 2016; Khalil et al., 2018; Bridel et al., 2019; Jin et al., 2019). Recent studies further demonstrated plasma NfL levels or together with cognitive testing as predictors of fast progression (Santangelo et al., 2021) and future declines in cognition and function in AD (Li et al., 2021). 
TABLE 3 | NfPs and fragments as biomarkers in conditions affecting nervous system.

\begin{tabular}{|c|c|c|c|c|c|c|c|c|c|c|}
\hline \multirow[t]{3}{*}{ Conditions } & \multicolumn{6}{|c|}{ Association of NF subunit level with } & \multicolumn{3}{|c|}{ Association of NF subunit level with } & \multirow[t]{3}{*}{ References } \\
\hline & \multirow{2}{*}{$\begin{array}{c}\text { NfL } \\
\text { B }\end{array}$} & \multicolumn{3}{|c|}{ pNfH (smi35) } & \multicolumn{2}{|c|}{ NfH (smi31 and others) } & \multirow[b]{2}{*}{ Disease activity } & \multirow[b]{2}{*}{ Prognosis } & \multirow[b]{2}{*}{ Treatment response } & \\
\hline & & C & B & C & B & C & & & & \\
\hline Acute bacterial meningitis & + & & & & & & & & & Gronhoj et al., 2021 \\
\hline Anesthesia and surgery & + & & & & & & & & & Evered et al., 2018 \\
\hline Anorexia nervosa & + & & & & & & & & & Nilsson et al., 2019 \\
\hline Autoimmune encephalitis & & + & & + & & & & & yes & $\begin{array}{l}\text { Kortvelyessy et al., 2018; Fominykh } \\
\text { et al., 2019; Piepgras et al., } 2021\end{array}$ \\
\hline Brain metastasis and glioma & + & & & & & & yes & yes & & Hepner et al., 2019 \\
\hline Cardiac arrest & + & & & & & & yes & yes & & Moseby-Knappe et al., 2019 \\
\hline Cerebral small vessel disease & + & & & & & & yes & yes & & Egle et al., 2021; Qu et al., 2021 \\
\hline $\begin{array}{l}\text { Chemotherapy-induced cognitive } \\
\text { impairment }\end{array}$ & & & & & + & & yes & & & Natori et al., 2015 \\
\hline Chorea-acanthocytosis & + & & & & & & yes & & & Peikert et al., 2020 \\
\hline Diabetic neuropathy & & & & & + & & & & & Qiao et al., 2015 \\
\hline Hypoxic-ischemic encephalopathy & & & & & & + & yes & & & Douglas-Escobar et al., 2010 \\
\hline Idiopathic normal pressure hydrocephalus & & + & & & & & & & & Jeppsson et al., 2013 \\
\hline Intrapartum asphyxia & + & & & & & & yes & & & Toorell et al., 2018 \\
\hline Mcleod syndrome & + & & & & & & & & & Peikert et al., 2020 \\
\hline $\begin{array}{l}\text { Mitochondrial encephalomyopathy, lactic } \\
\text { acidosis, and stroke-like episodes }\end{array}$ & + & & & & & & yes & & & Zheng et al., 2021 \\
\hline Mitochondrial encephalopathy & & + & & & & & yes & yes & & Sofou et al., 2019 \\
\hline MOG-Abs-associated disorders & & & & + & & & & & & Sara et al., 2021 \\
\hline Neurosarcoidosis & + & + & & & & & & & & Byg et al., 2021 \\
\hline Peri/intraventricular hemorrhage & + & + & & & & & yes & yes & & Goeral et al., 2021 \\
\hline Postoperative delirium & + & & & & & & & & & Casey et al., 2019 \\
\hline Preeclampsia & + & & & & & & yes & yes & & Evers et al., 2018 \\
\hline Preterm infants & + & & & & & & & & & Depoorter et al., 2018 \\
\hline Sepsis-associated encephalopathy & + & & & & & & yes & yes & & Ehler et al., 2019 \\
\hline Severe COVID-19 & + & & & & & & & & & Sutter et al., 2021 \\
\hline Thoracolumbar intervertebral disk herniation & & & & & + & & yes & yes & & Nishida et al., 2014 \\
\hline Wilson's disease & + & & & & & & yes & & & Shribman et al., 2021 \\
\hline X-linked adrenoleukodystrophy & + & & & & & & yes & & yes & Weinhofer et al., 2021 \\
\hline
\end{tabular}

B, blood; C, CSF. 
Hyperphosphorylation of tau neurofibrillary tangles is one of the hallmarks in AD. CSF ptau181 levels were first found to be increased significantly in patients with $\mathrm{AD}$ compared to healthy controls over two decades ago (Vanmechelen et al., 2000). This finding was subsequently verified by others (Lewczuk et al., 2004; Fagan et al., 2011; Tang et al., 2014) and later also was confirmed with the measurement of serum ptau181 (Shekhar et al., 2016). Recent studies demonstrated that blood ptau181 can predict cortical brain atrophy (Llibre-Guerra et al., 2019; Tissot et al., 2021), tau and amyloid-beta pathology (Lantero Rodriguez et al., 2020; Clark et al., 2021; Moscoso et al., 2021b), differentiate $\mathrm{AD}$ from other neurodegenerative diseases (Mielke et al., 2018; Thijssen et al., 2020; Grothe et al., 2021) and identify AD across the clinical continuum (Janelidze et al., 2020a; Karikari et al., 2020b, 2021). In familial AD, plasma ptau181 levels may rise as early as 16 years before clinical onset (O'connor et al., 2020). In addition to ptau181, some studies demonstrated ptau217 (Janelidze et al., 2020b; Karikari et al., 2020a; Palmqvist et al., 2020) and ptau231 are also useful biomarkers for AD (Kohnken et al., 2000; Suarez-Calvet et al., 2020; Ashton et al., 2021b). The combined use of these AD-specific biomarkers ptau181, ptau217, ptau231 with NfL as a disease-non-specific biomarker of neuronal integrity could improve prediction and monitoring of disease progression in AD (Moscoso et al., 2021a).

\section{Frontotemporal Dementia}

Serum NfL levels in patients with FTD were about 4-fold higher than in healthy controls (77.9 vs. $19.6 \mathrm{pg} / \mathrm{ml})$ and the elevations correlate with disease severity (Rohrer et al., 2016). Moreover, increased serum NfL levels were observed 1 to 2 years before the clinical onset of symptoms (Van Der Ende et al., 2019), indicating pathophysiology of the disease in the preclinical phase.

\section{Dementia With Lewy Bodies}

Plasma NfL levels in patients with DLB were about 2-fold higher than in healthy controls ( 55.3 vs. $25.7 \mathrm{pg} / \mathrm{ml}$ ) and the elevations correlate with disease severity and plasma NfL is the best predictor of cognitive decline compared to age, sex and baseline severity variables over a follow-up of 2 years (Pilotto et al., 2021).

\section{Peripheral Neuropathy}

Neurofilament proteins are most abundant in peripheral largecaliber myelinated axons such as sciatic nerves (Hoffman et al., 1987). Plasma NfL levels were about 2-fold higher in patients with inherited peripheral neuropathy CMT than in healthy controls (13.2 vs. $5.2 \mathrm{pg} / \mathrm{ml}$ ) and correlated with disease severity (Sandelius et al., 2018; Millere et al., 2021). Serum NfL was also significantly elevated in acquired peripheral neuropathy and their levels correlated not only with disease severity and outcome (Mariotto et al., 2018) but also declined with remission (Bischof et al., 2018). These studies suggest that NfL might be a promising biomarker for disease activity monitoring of peripheral neuropathy.

\section{Parkinson's Disease}

Plasma NfL levels were about 1.6-fold higher in patients with advanced Hoehn-Yahr stage and patients with PD dementia than in healthy controls (17.6 vs. $10.6 \mathrm{pg} / \mathrm{ml}$ ) and correlated with disease severity (Lin et al., 2019). Higher baseline plasma levels of NfL were also associated with greater motor and cognitive decline after a follow-up period of 3 years in patients with PD, suggesting value of $\mathrm{NfL}$ as a predictive biomarker of disease severity and progression in this disease (Lin et al., 2019; Ma et al., 2021; Zhu et al., 2021). A recent study also suggests that higher serum NfL levels were also associated with dopamine transporter concentration (Ye et al., 2021).

\section{Huntington Disease}

Plasma NfL levels were about 3-fold higher in patients with HD than in healthy controls (3.63 vs. $2.68 \mathrm{log} \mathrm{pg} / \mathrm{ml}$ ) and also significantly higher in manifest HD than premanifest HD (Byrne et al., 2017, 2018). Increased CSF and plasma NfL appeared in young adult carriers of HD gene mutation approximately 24 years before the clinical onset of symptoms (Scahill et al., 2020). Each CAG (cytosine, adenine and guanine trinucleotide repeat) increase is associated with higher, more steeply rising NfL levels (Byrne et al., 2017).

\section{Stroke}

Cerebrospinal fluid NfL was first reported to correlate with outcome after aneurysmal subarachnoid hemorrhage (Nylen et al., 2006) followed by the observations of increased CSF pNfH levels in acute ischemic stroke (8-fold at week 3 after stoke, 2.96 vs. $0.35 \mathrm{ng} / \mathrm{ml}$ in controls) (Singh et al., 2011). The findings were replicated with the measurements of serum NfL levels that patients with recent subcortical infarcts had higher NfL baseline levels compared to healthy controls (Gattringer et al., 2017; PujolCalderon et al., 2019; Peters et al., 2020). Elevated plasma NfL was also associated with poor functional outcome and mortality rate after spontaneous subarachnoid hemorrhage (Hviid et al., 2020a). The elevated NfL levels continued at the 3-month followup and seemed to return to normal at 15-month after stroke, indicating that levels of NfL could be a tool for monitoring infarct extent (Tiedt et al., 2018), predicting cognitive function (Peng et al., 2021; Wang J.H. et al., 2021) and mortality in patients with stroke (Gendron et al., 2020). Serum NfL levels also correlate with disease severity, disease progression and 17-year survival in patients with cerebral autosomal dominant arteriopathy with subcortical infarcts and leukoencephalopathy (CADASIL) caused by mutations in the NOTCH3 gene (Gravesteijn et al., 2019). In addition to NfL and pNfH, CSF and serum NfM levels were also elevated in patients with stroke (Martinez-Morillo et al., 2015).

\section{Traumatic Brain Injury and Spinal Cord Injury}

One month after neurosurgical trauma, there was a distinct peak in CSF (6-fold increase, 2460 vs. $409 \mathrm{ng} / \mathrm{ml}$ at baseline) and plasma NfL concentration, which peaked at 1 -month postsurgery, returning to baseline after 6 to 9 months (Bergman et al., 2016). Boxers who received severe head impact ( $>15$ hits to the head or experienced grogginess during or after bout) had elevated plasma NfL at 7-10 days after a bout compared to boxers who received mild head impact ( $<15$ head hits) (Shahim et al., 2017). In TBI, both CSF and serum NfL levels were elevated over the first 1-2 weeks compared to healthy controls (Al Nimer et al., 2015; Shahim et al., 2017; Hossain et al., 2019), 
decreased over 5 years and correlated with measures of functional outcome (Shahim et al., 2020). Similar to TBI, CSF and serum NfL concentrations are also increased in SCI patients compared to healthy controls (Guez et al., 2003), correlated with motor outcome 3-12 months after trauma and minocycline treatment showed decreased NfL levels in a subgroup of injured patients (Kuhle et al., 2015). Care must be taken when TBI patients are over 60 years old or having pre-existing neurological conditions (Iverson et al., 2019). In addition to NfL, serum pNfH was also increased in TBI (Shibahashi et al., 2016) and SCI patients (Hayakawa et al., 2012; Singh et al., 2017) and appears to be a predictive biomarker for outcome.

\section{Spinal Muscular Atrophy}

Spinal Muscular Atrophy (MSA) is a rare neuromuscular disorder due to a mutation of survival of motor neuron 1 gene that results in the loss of motor neurons and progressive muscle wasting. Baseline levels of CSF NfL (31-fold, 4598 vs. $148 \mathrm{pg} / \mathrm{ml}$ ) and tau (2.3-fold, $939 \mathrm{vs.} 404 \mathrm{pg} / \mathrm{ml})$ were significantly higher in children with SMA than in controls (Olsson et al., 2019). Treatment with nusinersen, a drug that increases the level of SMN protein in the CNS normalized NfL and tau levels which correlated with degree of motor improvement in children with SMA (Olsson et al., 2019). Plasma pNFH levels were also observed to correlate with disease activity and treatment response in infants with MSA treated with nusinersen (Darras et al., 2019).

\section{Spinocerebellar Ataxia Type 3}

Spinocerebellar ataxia type 3 is a condition characterized by progressive problems with movement due to mutations in the ataxin 3 gene. Plasma NfL levels were about 4-fold higher in patients with SCA3 than in healthy controls $(34.8 \mathrm{vs} .8 .6 \mathrm{pg} / \mathrm{ml})$ and correlate with disease severity, disease progression and CAG repeat length of ataxin 3 gene mutation (Li et al., 2019; Peng et al., 2020; Wilke et al., 2020). Increased serum NfL appeared in mutation carriers 7.5 years before the clinical onset of symptoms (Wilke et al., 2020).

\section{Human Immunodeficiency Virus Infection}

Human immunodeficiency virus (HIV) invades brain and leads to the CNS injury, most severely manifesting as HIV-associated dementia with high morbidity and mortality (Price and Brew, 1988). CSF and plasma NfL levels were elevated in HIV infection, especially in $\mathrm{HIV}$-associated dementia (44-fold increase for CSF NfL, 16185 vs. $363 \mathrm{nmol} / \mathrm{L}$ in HIV-negative controls), and is markedly reduced after antiretroviral treatment-induced viral suppression (Abdulle et al., 2007; Jessen Krut et al., 2014; Gisslen et al., 2016). Plasma NfL is also negatively associated with neuropsychological performance in HIV-infected individuals and their levels decline with initiation of antiretroviral therapy (Anderson et al., 2018).

\section{Prion Diseases}

Prion diseases are a family of rare progressive neurodegenerative disorders that affect both humans and animals. CSF and blood NfL levels are significantly higher (about 4-fold increase) in both sporadic and genetic prion disease compared to healthy controls (Steinacker et al., 2016; Thompson et al., 2018; Kanata et al., 2019;
Zerr et al., 2021). Increased plasma NfL appeared in adult carriers of prion gene mutation as early as 2 years before the clinical onset of symptoms (Thompson et al., 2021).

\section{Hereditary Transthyretin-Mediated Amyloidosis}

Hereditary transthyretin-mediated amyloidosis is a condition with adult onset caused by mutation of transthyretin and characterized by extracellular deposition of amyloid and destruction of the somatic and autonomic PNS. Plasma NfL levels in patients with hereditary transthyretin-mediated (hATTR) amyloidosis with polyneuropathy were 4-fold higher than in healthy controls (69.4 vs. $16.3 \mathrm{pg} / \mathrm{ml}$ ) (Ticau et al., 2019). Levels of NfL at 18 months increased in placebo-treated patients $(99.5 \mathrm{pg} / \mathrm{ml})$ and decreased in patients treated with patisiran (48.8 $\mathrm{pg} / \mathrm{ml})$, a gene-silencing drug that interferes with the production of an abnormal form of transthyretin (Ticau et al., 2019). The levels of 66 proteins in blood were significant changed following patisiran treatment relative to placebo, with change in NfL being the most significant (Ticau et al., 2019). Moreover, at 18 months, improvement in mNIS +7 (a robust and clinically meaningful measure of neuropathy progression) compared to baseline in patisiran-treated patients significantly correlated with a reduction of plasma NfL levels.

\section{Late Infantile Neuronal Ceroid Lipofuscinosis Type 2}

Ceroid lipofuscinosis type 2 (CLN2) disease is an inherited disorder that primarily affects the nervous system. Before treatment in CLN2 patients, plasma NfL levels were 48-fold higher than in healthy controls (153.2 vs. $3.21 \mathrm{pg} / \mathrm{ml}$ ) and in CLN2 disease, subjects receiving replacement therapy with cerliponase alfa, plasma NfL levels decreased by $50 \%$ each year over 3 years of treatment ( $\mathrm{Ru}$ et al., 2019). Cerliponase alfatreated patients demonstrated fewer declines in motor and language function than that in historical controls (Schulz et al., 2018). The fold change of CSF NfL compared with healthy controls has been shown varied extensively between individual conditions, with the smallest effect sizes observed in subjective cognitive decline and PD, and the largest effect sizes observed in cardiac arrest, HIV-associated dementia, FTD/ALS, ALS and HD (Rosen et al., 2004; Bridel et al., 2019). The pre-treatment plasma NfL levels observed in CLN2 disease patients is at the high end of neurological disease levels - similar to that seen in ALS, FTD/ALS, HIV-associated dementia and higher than many other neurodegenerative diseases. Even within ALS group, the CSF NfL levels in patients with lower motor neuron signs $(346 \mathrm{pg} / \mathrm{ml})$ only had 2.6-fold increase compared with healthy controls $(138 \mathrm{pg} / \mathrm{ml})$ while 17.6-fold increase was observed in those with signs of upper motor neuron disease (2435 pg/ml) (Rosengren et al., 1996). Therefore, the fold change in CSF and serum NfL levels could be due to damage to different neuronal compartments in different nervous system regions.

\section{Brain Cancer}

Neurofilament light chain levels in serum are sensitive to any neuronal damage. As CNS tumors grow bigger and bigger, they could affect function and integrity of neighboring neurons and/or may cause increased intracranial pressure that compromises 
neuronal function. Accordingly, levels of serum NfL in patients with CNS tumors with progressive disease were 33-fold higher than in healthy controls (239.3 vs. $7.2 \mathrm{pg} / \mathrm{ml}$ ) and vary closely with tumor activity (Hepner et al., 2019). Similarly, neurons could be damaged by the infiltration of the brain metastasis in the brain parenchyma, brain compression caused by metastasis, vascular disturbance and toxic products diffusing from tumor cells (Zhang and Olsson, 1997). In fact, serum NfL levels in patients with metastatic solid tumors with known brain metastasis were 19fold higher than in healthy controls (142.3 vs. $7.2 \mathrm{pg} / \mathrm{ml}$ ) (Hepner et al., 2019). This finding was later confirmed and expanded that an increase in serum NfL could be detected 3 months before brain metastasis diagnosis and a high level of NfL at time of brain metastasis correlated with an inferior survival (Winther-Larsen et al., 2020; Lin et al., 2021). These studies imply serum NFL is a potential clinical biomarker for both CNS tumors and metastatic solid tumors with brain metastasis.

\section{Cardiac Arrest}

Neurons in the brain can be damaged due to prolonged oxygen and sugar deprivation within $3 \mathrm{~min}$ of the heart stopping. CSF NfL levels were first reported to be increased in adult patients with cardiac arrest (52-fold, 11,381 vs. $217 \mathrm{pg} / \mathrm{ml}$ in healthy controls) and highly predictive of poor outcome (Rosen et al., 2004). This finding was later confirmed (Rosen et al., 2014) and also with plasma (Wihersaari et al., 2021) or serum NfL levels (Rana et al., 2013; Disanto et al., 2019). Recently, similar findings were also reported in pediatric patients with cardiac arrest (Kirschen et al., 2020). Cardiac arrest over 3 min can lead to not only hypoxic-ischemic brain damage but also reperfusion injury, the restoration of blood flow after resuscitation placing oxidative stress on the brain as pooled toxins flood already-damaged tissues (Sekhon et al., 2017). Future studies in large dedicated cardiac arrest cohorts with serial longitudinal measurements of serum $\mathrm{NfL}$ and parallel analyses to assess changes caused by hypoxia, ischemia and reperfusion in brain are warranted.

\section{Delirium}

Serum NfL levels in delirium in hip fracture patients were 1.7fold higher than in controls (94 vs. 54 pg/ml) (Halaas et al., 2018) and plasma NfL was associated with delirium severity (Fong et al., 2020) independent of changes in inflammation (Casey et al., 2019). In addition to elevated NfL, higher serum pNfH levels also correlated with more severe postoperative delirium (Inoue et al., 2017; Mietani et al., 2019). These results suggests NfPs can be sensitive markers of neuronal injury associated with delirium.

\section{The Value of Neurofilament Proteins in Differential Diagnosis Is Limited}

Although NfPs are not disease-specific, they may have limited utility in differential diagnosis in some cases. Some neurodegenerative diseases share part of their symptomatology and neuropathology, making it difficult to differentiate between them. The differentiation between multiple system atrophy (MSA) and PD is difficult, particularly in early disease stages. Increased CSF NfL may offer clinically relevant, high accuracy discrimination between MSA and PD (Herbert et al., 2015) and also between PD and other atypical parkinsonian disorders including progressive supranuclear palsy and corticobasal degeneration (Constantinescu et al., 2010; Ashton et al., 2021a). The overlap of FTD and ALS has been well documented in FTD patients with co-morbid motor neuron degeneration and in ALS patients with frontotemporal dysfunction (Lomen-Hoerth, 2011). CSF NfL levels are higher in ALS than in FTD (Skillback et al., 2017) and also significantly higher in patients with FTDALS than in patients with FTD without ALS (Pijnenburg et al., 2015). CSF pNfH has also been shown to be a better biomarker than CSF NfL in differentiating ALS from other diseases mimicking ALS symptomatology (Poesen et al., 2017). Early symptoms of patients with FTD typically do not include memory impairment but instead often manifest changes in their behavior, personality and social interaction, which are often confused with symptoms occurring in psychiatric disorders. About 50\% behavioral variant FTD patients received a prior diagnosis of a psychiatric disorder in a large retrospective study (Woolley et al., 2011). Patients with FTD have significantly higher serum NfL levels than patients with psychiatric disorders (Al Shweiki et al., 2019; Katisko et al., 2020), suggesting NfL as a promising tool to help differentially diagnose FTD and psychiatric disorders.

\section{CURRENT RESEARCH GAPS AND POTENTIAL DEVELOPMENT OF NEUROFILAMENTS AS BIOMARKERS}

\section{Blood-Brain and Blood-Cerebrospinal Fluid Barriers}

The effects of blood-brain barrier (BBB) and blood-CSF barrier (BCB) on serum NfP levels are not fully understood. Aging and neurodegenerative disease can cause increased disruption of the BBB (Sweeney et al., 2018) which could contribute to the elevated levels of serum NfP signals observed in these conditions. Recent evidence suggests that serum NfL level does not correlate with opening of the blood brain barrier after cranial irradiation (Kalm et al., 2017). Consistent with this finding, higher CSF/serumalbumin ratios were observed in FTD-3 patients, but this did not affect the significant associations among serum NfL levels and pre-symptomatic, symptomatic CHMP2B (charged multivesicular body protein $2 \mathrm{~B}$ ) mutation carriers and healthy family controls (Toft et al., 2021).

\section{The Exact Form of Extracellular Neurofilament Proteins and Degradation Fragments}

Because full length NfL proteins have never been detected in CSF and blood, it seems likely that most or all of the NfL detected in the CSF or serum are peptides generated from partial degradation of NfL in neurons or after their release. The identity and form(s) of NfPs detected by the commonly used NfL antibodies is not fully clarified. Recent studies suggest that a $22 \mathrm{kDa}$ degradation fragment could be the detected plasma signal of NfL since it is also increased in ALS patients (Lombardi et al., 2020). The peptide species of INA and PRPH in CSF and plasma are not known. If a 
Nf subunit such as INA is fully and rapidly degraded into amino acids upon release from neuronal compartments into blood, then no signals of Simoa assay can be measured and no value of utility as a biomarker. Determination of the form of detected NfP immunosignals (full length or degradation fragments) in blood will not only impact their utility as blood biomarkers but also help to better understanding the pathophysiological process in a given neurological diseases.

\section{The Relationship Among Different Neurofilament Subunits}

Neurofilament proteins are not identical and each has a distinct structure and could potentially have differential diagnostic value as biomarkers. The relationships among NfPs are complex and interrelated. When NfL is absent in mice, NfH levels decline most, followed by the decreased levels of NfM and PRPH (Yuan et al., 2012) and the levels of INA is only marginally declined (Yuan et al., 2003). When NfM is absent in mice, NfL levels decline most, followed by the lowered levels of NfH and INA (Yuan et al., 2006). NfL and NfM are co-regulated in mammalian brain and only marginally affected by the deletion of $\mathrm{NfH}$, INA or both (Yuan et al., 2006). The first ELISA for NfPs was developed (Rosengren et al., 1996) prior to the recognition of INA and PRPH as additional Nf subunits (Yuan et al., 2006, Yuan et al., 2012). NfL is the most intensively studied subunit as a biomarker followed by phosphorylated $\mathrm{NfH}$, especially after introduction of a highly sensitive digital assay (Gisslen et al., 2016).

Despite less attention being paid to NfM, INA and PRPH as biomarkers in neurological diseases, their potential utility is considerable. In addition to the well-established increase of NfL during aging, a highly significant increase in the levels in CSF of both phosphorylated and non-phosphorylated NfM and $\mathrm{NfH}$ are also seen in aged individuals as compared with young controls (Hu et al., 2002). NfPs are an integral part of neurofibrillary tangles in AD brain (Rudrabhatla et al., 2011) and C-terminal phosphorylation sites of both NfM and NfH are 4- to 8-fold more abundant in $\mathrm{AD}$ compared with control brain (Rudrabhatla et al., 2010). Levels of specific phosphorylation sites on NfM and NfH in blood could potentially be used as a biomarker to discriminate $\mathrm{AD}$ from normal brain aging and other neurological conditions.

Alpha-internexin is enriched in CNS and its prominent aggregation in Nf inclusion disease (Cairns et al., 2004) could qualify INA as a CNS-selective biomarker. However, the intact form of INA is difficult to detect in laboratory practice due to its instability. A possible solution could be to test for blood levels of its more stable degradation products. INA was identified by proteomics as a novel biomarker in the CSF of patients with hemorrhagic stroke (Martinez-Morillo et al., 2014). In contrast to INA, PRPH is enriched in PNS (Yuan et al., 2012) and therefore could potentially be developed as a PNS-specific biomarker. Moreover, PRPH is also sensitive to diffuse axonal injury (Liang et al., 2019) and its aggregate-inducing isoform Per 28 is upregulated in ALS and is associated with disease pathology (Xiao et al., 2008). A recent report suggests high serum levels of PRPH might be a general biomarker of axon disorders of lower motor neurons (Sabbatini et al., 2021). Future studies should therefore aim to develop assays of appropriate specificity for each of the NfP subunits or degradation fragments to explore the complementary information they may contribute to NfP pathobiology and use as biomarkers.

\section{Stable Isotope Labeling Kinetics Coupled With Mass Spectrometry}

The levels of NfP and peptide in CSF and blood depend on the rates of synthesis of NfPs or mechanism and rates of NfP peptide release. A recently developed stable isotope labeling method coupled with mass spectrometry may be useful to define the kinetics of NfP turnover in healthy individuals, with aging and in patients with neurological conditions associated with elevated NfP signals in CSF and blood. Special attention should be paid to the extremely slow turnover of NfPs incorporated into the filamentous lattice in axons (Nixon and Logvinenko, 1986; Yuan et al., 2015a). This method uses hours-long infusions of ${ }^{13} \mathrm{C}$ and ${ }^{15} \mathrm{~N}$ stable isotopes before measuring the labeled proteins in CSF, blood or brain tissue samples (Bateman et al., 2006; Paterson et al., 2019). The incorporation of newly synthesized labeled proteins gradually increases until a steady state is reached. Following stop of infusions, the proportion of the labeled amino acid in the target protein gradually declines as a result of protein clearance or degradation. Alterations in the isotopic enrichment of the target proteins allow the calculation of protein synthesis and clearance rates from the ratio of labeled to non-labeled protein. This method was used to measure the kinetics of tau isoforms and fragments in human CNS (Sato et al., 2018). The elevated CNS tau levels in AD patients was initially interpreted as resulting from passive release of this protein by degenerative neurons. However, results from stable isotope labeling kinetics (SILK) studies suggest that the bulk of tau in human CSF is released by an active process that is stimulated by neuronal exposure to aggregated amyloid-beta. On the one hand, the concentration of NfPs in CSF or serum measured at a given time represents a static biomarker whose equilibrium could be affected by various factors. On the other hand, NfP-SILK can provide dynamic measure of production and clearance of newly synthesized NfPs that might provide a more detailed understanding of the mechanisms underlying these alterations in NfP levels.

\section{Confounding Factors}

Since there are significant variations of measured blood NfL levels among different methods and labs, standardization of blood NfL measurement globally is needed. Care must be taken when interpreting results obtained in different studies. Community-based large populations of healthy individuals are required to generate normative data for reference intervals. As discussed earlier, there are numerous demographic, life style, and comorbidity factors that potentially influence NfP levels in biological samples. With the increasing use of blood assays, variables such as exercise (Joisten et al., 2021), blood volume, body mass index need to be considered (Manouchehrinia et al., 2020; Perino et al., 2021). Trace amounts of NfPs relative to those in neurons have been reported 
in erythrocytes (Granger and Lazarides, 1983; Terasawa et al., 2006), T lymphocytes (Murphy et al., 1993), podocytes (Wang et al., 2018), and oocytes (Takahashi and Ishizuka, 2012), which could be confounds in certain disease conditions. Because blood $\mathrm{NfL}$ alteration is associated with aging, future studies are also needed to establish the age-adjusted normal values of serum NfL levels across all age groups. The recent establishment of reference intervals of serum NfL in 342 Scandinavian reference subjects from 18 to 87 years of age is a step in the right direction (Hviid et al., 2020b). Comparative studies of two or more neurological disorders will be valuable to clarify the relative magnitude of change and its disease significance using the same methodologies. Sporadic AD patients are often older individuals associated with higher prevalence of cardiovascular conditions that is also associated with CNS ischemic damage and subsequent release of NfPs into blood (Gattringer et al., 2017). Co-existing peripheral neuropathy with CNS diseases may also weaken the correlation between CSF and serum NfP signals. Longitudinal measurements should also be encouraged to minimize intra- and inter-individual variation due to transient confounding variables and emerging co-morbidities (Khalil et al., 2020; Liu S. et al., 2020).

\section{CONCLUSION}

The development of minimally invasive ultrasensitive assays of NfPs released from neurons into in blood has increased the potential use of NfPs as biomarkers especially for repeated measurements during longitudinal studies such as in MS. The degree of elevation of NfPs in serum could easily differentiate behavioral FTD from primary psychiatric disorders where significant clinical overlaps of these two conditions exist and the sensitivity and specificity of structural and functional imaging methods remain imperfect. Monitoring the kinetics

\section{REFERENCES}

Abdulle, S., Mellgren, A., Brew, B. J., Cinque, P., Hagberg, L., Price, R. W., et al. (2007). CSF neurofilament protein (NFL) - a marker of active HIVrelated neurodegeneration. J. Neurol. 254, 1026-1032. doi: 10.1007/s00415-0060481-8

Adiutori, R., Aarum, J., Zubiri, I., Bremang, M., Jung, S., Sheer, D., et al. (2018). The proteome of neurofilament-containing protein aggregates in blood. Biochem. Biophys. Rep. 14, 168-177. doi: 10.1016/j.bbrep.2018.04.010

Akgun, K., Kretschmann, N., Haase, R., Proschmann, U., Kitzler, H. H., Reichmann, H., et al. (2019). Profiling individual clinical responses by highfrequency serum neurofilament assessment in MS. Neurol. Neuroimmunol. Neuroinflamm. 6:e555. doi: 10.1212/NXI.0000000000000555

Al Nimer, F., Thelin, E., Nystrom, H., Dring, A. M., Svenningsson, A., Piehl, F., et al. (2015). Comparative Assessment of the Prognostic Value of Biomarkers in Traumatic Brain Injury Reveals an Independent Role for Serum Levels of Neurofilament Light. PLoS One 10:e0132177. doi: 10.1371/journal.pone. 0132177

Al Shweiki, M. R., Steinacker, P., Oeckl, P., Hengerer, B., Danek, A., Fassbender, K., et al. (2019). Neurofilament light chain as a blood biomarker to differentiate psychiatric disorders from behavioural variant frontotemporal dementia. J. Psychiatr. Res. 113, 137-140. doi: 10.1016/j.jpsychires.2019.03.019

Alagaratnam, J., Von Widekind, S., De Francesco, D., Underwood, J., Edison, P., Winston, A., et al. (2021). Correlation between CSF and blood neurofilament of NfPs in blood can increase our ability to assess disease activity, neuronal injury, and neurodegeneration in real time and to measure treatment effectiveness. Much interest has been focused on the detection of blood NfPs by high-sensitivity assays as a surrogate marker of neuronal structural damage and degeneration. However, the majority of these reports are crosssectional, more longitudinal data are required to better elucidate the place of NfPs in the clinical settings. Due to their lack of specificity for a given disease, NfPs will most likely be of limited value as a diagnostic tool except when levels drastically differ between two conditions with similar clinical presentations. No single test or value of NfPs can currently be used to rule in or exclude the diagnosis of a specific disease. Nevertheless, NfPs can potentially be used to monitor disease progression and the effects of therapeutic intervention in combination with clinical judgment in almost any neuronal injury and neurological diseases. Serum NfPs are relatively easily measured. Treatmentinduced decrease in blood NfPs levels as a complement to the more lengthy process of measuring clinical outcomes may, in the future, be more important in the validation and regulatory approval of new drugs for neurological conditions.

\section{AUTHOR CONTRIBUTIONS}

$\mathrm{AY}$ and RN wrote the manuscript and have approved it for publication. Both authors contributed to the article and approved the submitted version.

\section{FUNDING}

Investigations by $\mathrm{AY}$ and $\mathrm{RN}$ have been supported by the National Institute on Aging (Grant 5R01AG005604).

light chain protein: a systematic review and meta-analysis. BMJ Neurol. Open 3:e000143. doi: 10.1136/bmjno-2021-000143

Alami, N. H., Smith, R. B., Carrasco, M. A., Williams, L. A., Winborn, C. S., Han, S. S. W., et al. (2014). Axonal transport of TDP-43 mRNA granules is impaired by ALS-causing mutations. Neuron 81, 536-543. doi: 10.1016/j.neuron.2013.12. 018

Albargothy, N. J., Johnston, D. A., Macgregor-Sharp, M., Weller, R. O., Verma, A., Hawkes, C. A., et al. (2018). Convective influx/glymphatic system: tracers injected into the CSF enter and leave the brain along separate periarterial basement membrane pathways. Acta Neuropathol. 136, 139-152. doi: 10.1007/ s00401-018-1862-7

Altick, A. L., Baryshnikova, L. M., Vu, T. Q., and Von Bartheld, C. S. (2009). Quantitative analysis of multivesicular bodies (MVBs) in the hypoglossal nerve: evidence that neurotrophic factors do not use MVBs for retrograde axonal transport. J. Comp. Neurol. 514, 641-657. doi: 10.1002/cne.22047

Anderson, A. M., Easley, K. A., Kasher, N., Franklin, D., Heaton, R. K., Zetterberg, H., et al. (2018). Neurofilament light chain in blood is negatively associated with neuropsychological performance in HIV-infected adults and declines with initiation of antiretroviral therapy. J. Neurovirol. 24, 695-701. doi: 10.1007/ s13365-018-0664-y

Arboleda-Velasquez, J. F., Lopera, F., O’hare, M., Delgado-Tirado, S., Marino, C., Chmielewska, N., et al. (2019). Resistance to autosomal dominant Alzheimer's disease in an APOE3 Christchurch homozygote: a case report. Nat. Med. 25, 1680-1683. doi: 10.1038/s41591-019-0611-3 
Arun, P., Rossetti, F., Eken, O., Wilder, D., Wang, Y., and Long, J. (2021). Phosphorylated neurofilament heavy chain in the cerebrospinal fluid is a suitable biomarker of acute and chronic blast-induced traumatic brain injury. J. Neurotrauma. [Preprint]. doi: 10.1089/neu.2021.0144

Ashton, N. J., Janelidze, S., Al Khleifat, A., Leuzy, A., Van Der Ende, E. L., Karikari, T. K., et al. (2021a). A multicentre validation study of the diagnostic value of plasma neurofilament light. Nat. Commun. 12:3400.

Ashton, N. J., Leuzy, A., Lim, Y. M., Troakes, C., Hortobagyi, T., Hoglund, $\mathrm{K}$., et al. (2019). Increased plasma neurofilament light chain concentration correlates with severity of post-mortem neurofibrillary tangle pathology and neurodegeneration. Acta Neuropathol. Commun. 7:5. doi: 10.1186/s40478-0180649-3

Ashton, N. J., Pascoal, T. A., Karikari, T. K., Benedet, A. L., Lantero-Rodriguez, J., Brinkmalm, G., et al. (2021b). Plasma p-tau231: a new biomarker for incipient Alzheimer's disease pathology. Acta Neuropathol. 141, 709-724. doi: 10.1007/ s00401-021-02275-6

Aspelund, A., Antila, S., Proulx, S. T., Karlsen, T. V., Karaman, S., Detmar, M., et al. (2015). A dural lymphatic vascular system that drains brain interstitial fluid and macromolecules. J. Exp. Med. 212, 991-999. doi: 10.1084/jem.20142290

Bacioglu, M., Maia, L. F., Preische, O., Schelle, J., Apel, A., Kaeser, S. A., et al. (2016). Neurofilament Light Chain in Blood and CSF as Marker of Disease Progression in Mouse Models and in Neurodegenerative Diseases. Neuron 91, 494-496. doi: 10.1016/j.neuron.2016.07.007

Backstrom, D., Linder, J., Jakobson, Mo, S., Riklund, K., Zetterberg, H., et al. (2020). $\mathrm{NfL}$ as a biomarker for neurodegeneration and survival in Parkinson disease. Neurology 95, e827-e838. doi: 10.1212/WNL.0000000000010084

Barro, C., Benkert, P., Disanto, G., Tsagkas, C., Amann, M., Naegelin, Y., et al. (2018). Serum neurofilament as a predictor of disease worsening and brain and spinal cord atrophy in multiple sclerosis. Brain 141, 2382-2391. doi: 10.1093/ brain/awy154

Bateman, R. J., Munsell, L. Y., Morris, J. C., Swarm, R., Yarasheski, K. E., and Holtzman, D. M. (2006). Human amyloid-beta synthesis and clearance rates as measured in cerebrospinal fluid in vivo. Nat. Med. 12, 856-861. doi: 10.1038/ nm1438

Beaulieu, J. M., Nguyen, M. D., and Julien, J. P. (1999). Late onset of motor neurons in mice overexpressing wild-type peripherin. J. Cell Biol. 147, 531-544. doi: $10.1083 /$ jcb.147.3.531

Benatar, M., Wuu, J., Andersen, P. M., Lombardi, V., and Malaspina, A. (2018). Neurofilament light: A candidate biomarker of presymptomatic amyotrophic lateral sclerosis and phenoconversion. Ann. Neurol. 84, 130-139. doi: 10.1002/ ana. 25276

Benatar, M., Wuu, J., Lombardi, V., Jeromin, A., Bowser, R., Andersen, P. M., et al. (2019). Neurofilaments in pre-symptomatic ALS and the impact of genotype. Amyotroph. Lateral Scler. Frontotemporal Degener. 20, 538-548. doi: 10.1080/ 21678421.2019.1646769

Benedet, A. L., Leuzy, A., Pascoal, T. A., Ashton, N. J., Mathotaarachchi, S., Savard, M., et al. (2020). Stage-specific links between plasma neurofilament light and imaging biomarkers of Alzheimer's disease. Brain 143, 3793-3804. doi: 10.1093/brain/awaa342

Benedict, C., Blennow, K., Zetterberg, H., and Cedernaes, J. (2020). Effects of acute sleep loss on diurnal plasma dynamics of CNS health biomarkers in young men. Neurology 94, e1181-e1189. doi: 10.1212/WNL.0000000000008866

Bergman, J., Dring, A., Zetterberg, H., Blennow, K., Norgren, N., Gilthorpe, J., et al. (2016). Neurofilament light in CSF and serum is a sensitive marker for axonal white matter injury in MS. Neurol. Neuroimmunol. Neuroinflamm. 3:e271. doi: 10.1212/NXI.0000000000000271

Bischof, A., Manigold, T., Barro, C., Heijnen, I., Berger, C. T., Derfuss, T., et al. (2018). Serum neurofilament light chain: a biomarker of neuronal injury in vasculitic neuropathy. Ann. Rheum. Dis. 77, 1093-1094. doi: 10.1136/ annrheumdis-2017-212045

Bjornevik, K., Munger, K. L., Cortese, M., Barro, C., Healy, B. C., Niebuhr, D. W., et al. (2019). Serum Neurofilament Light Chain Levels in Patients With Presymptomatic Multiple Sclerosis. JAMA Neurol. 77, 58-64. doi: 10.1001/ jamaneurol.2019.3238

Bomont, P., Cavalier, L., Blondeau, F., Ben Hamida, C., Belal, S., Tazir, M., et al. (2000). The gene encoding gigaxonin, a new member of the cytoskeletal BTB/kelch repeat family, is mutated in giant axonal neuropathy. Nat. Genet. 26, 370-374. doi: $10.1038 / 81701$
Bos, I., Vos, S., Verhey, F., Scheltens, P., Teunissen, C., Engelborghs, S., et al. (2019). Cerebrospinal fluid biomarkers of neurodegeneration, synaptic integrity, and astroglial activation across the clinical Alzheimer's disease spectrum. Alzheimers Dement. 15, 644-654. doi: 10.1016/j.jalz.2019.01.004

Boylan, K., Yang, C., Crook, J., Overstreet, K., Heckman, M., Wang, Y., et al. (2009). Immunoreactivity of the phosphorylated axonal neurofilament $\mathrm{H}$ subunit (pNF-H) in blood of ALS model rodents and ALS patients: evaluation of blood pNF-H as a potential ALS biomarker. J. Neurochem. 111, 1182-1191. doi: 10.1111/j.1471-4159.2009.06386.x

Brettschneider, J., Petzold, A., Sussmuth, S. D., Ludolph, A. C., and Tumani, H. (2006). Axonal damage markers in cerebrospinal fluid are increased in ALS. Neurology 66, 852-856. doi: 10.1212/01.wnl.0000203120.85850.54

Bridel, C., Van Wieringen, W. N., Zetterberg, H., Tijms, B. M., Teunissen, C. E., And The, N. F. L. G., et al. (2019). Diagnostic Value of Cerebrospinal Fluid Neurofilament Light Protein in Neurology: A Systematic Review and Metaanalysis. JAMA Neurol. 76, 1035-1048. doi: 10.1001/jamaneurol.2019.1534

Brownlees, J., Ackerley, S., Grierson, A. J., Jacobsen, N. J., Shea, K., Anderton, B. H., et al. (2002). Charcot-Marie-Tooth disease neurofilament mutations disrupt neurofilament assembly and axonal transport. Hum. Mol. Genet. 11, 2837-2844. doi: $10.1093 / \mathrm{hmg} / 11.23 .2837$

Brureau, A., Blanchard-Bregeon, V., Pech, C., Hamon, S., Chaillou, P., Guillemot, J. C., et al. (2017). NF-L in cerebrospinal fluid and serum is a biomarker of neuronal damage in an inducible mouse model of neurodegeneration. Neurobiol. Dis. 104, 73-84. doi: 10.1016/j.nbd.2017.04.007

Byg, K. E., Nielsen, H. H., Sejbaek, T., Madsen, J. S., Olsen, D. A., Nguyen, N., et al. (2021). Elevated Neurofilament Light Chain in Cerebrospinal Fluid and Plasma Reflect Inflammatory MRI Activity in Neurosarcoidosis. Brain Sci. 11:238. doi: 10.3390/brainsci11020238

Byrne, L. M., Rodrigues, F. B., Blennow, K., Durr, A., Leavitt, B. R., Roos, R. A. C., et al. (2017). Neurofilament light protein in blood as a potential biomarker of neurodegeneration in Huntington's disease: a retrospective cohort analysis. Lancet Neurol. 16, 601-609. doi: 10.1016/S1474-4422(17)30124-2

Byrne, L. M., Rodrigues, F. B., Johnson, E. B., Wijeratne, P. A., De Vita, E., Alexander, D. C., et al. (2018). Evaluation of mutant huntingtin and neurofilament proteins as potential markers in Huntington's disease. Sci. Transl. Med. 10:eaat7108. doi: 10.1126/scitranslmed.aat7108

Cairns, N. J., Zhukareva, V., Uryu, K., Zhang, B., Bigio, E., Mackenzie, I. R., et al. (2004). alpha-internexin is present in the pathological inclusions of neuronal intermediate filament inclusion disease. Am. J. Pathol. 164, 2153-2161. doi: 10.1016/S0002-9440(10)63773-X

Calabresi, P. A., Arnold, D. L., Sangurdekar, D., Singh, C. M., Altincatal, A., De Moor, C., et al. (2020). Temporal profile of serum neurofilament light in multiple sclerosis: Implications for patient monitoring. Mult. Scler. 2020:1352458520972573. doi: 10.1177/1352458520972573

Carare, R. O., Bernardes-Silva, M., Newman, T. A., Page, A. M., Nicoll, J. A., Perry, V. H., et al. (2008). Solutes, but not cells, drain from the brain parenchyma along basement membranes of capillaries and arteries: significance for cerebral amyloid angiopathy and neuroimmunology. Neuropathol. Appl. Neurobiol. 34, 131-144. doi: 10.1111/j.1365-2990.2007.00926.x

Carmona-Iragui, M., Alcolea, D., Barroeta, I., Videla, L., Munoz, L., Van Pelt, K., et al. (2021). Diagnostic and prognostic performance and longitudinal changes in plasma neurofilament light chain concentrations in adults with Down syndrome: a cohort study. Lancet Neurol. 20, 605-614. doi: 10.1016/ S1474-4422(21)00129-0

Casey, C. P., Lindroth, H., Mohanty, R., Farahbakhsh, Z., Ballweg, T., Twadell, S., et al. (2019). Postoperative delirium is associated with increased plasma neurofilament light. Brain 143, 47-54. doi: 10.1093/brain/awz354

Ching, G. Y., Chien, C. L., Flores, R., and Liem, R. K. (1999). Overexpression of alpha-internexin causes abnormal neurofilamentous accumulations and motor coordination deficits in transgenic mice. J. Neurosci. 19, 2974-2986. doi: 10. 1523/JNEUROSCI.19-08-02974.1999

Clark, C., Lewczuk, P., Kornhuber, J., Richiardi, J., Marechal, B., Karikari, T. K., et al. (2021). Plasma neurofilament light and phosphorylated tau 181 as biomarkers of Alzheimer's disease pathology and clinical disease progression. Alzheimers Res. Ther. 13:65. doi: 10.1186/s13195-021-00805-8

Clay, A., Obrochta, K. M., Soon, R. K. Jr., Russell, C. B., and Lynch, D. R. (2020). Neurofilament light chain as a potential biomarker of disease status in Friedreich ataxia. J. Neurol. 267, 2594-2598. doi: 10.1007/s00415-020-09868-3 
Cleveland, D. W., and Rothstein, J. D. (2001). From Charcot to Lou Gehrig: deciphering selective motor neuron death in ALS. Nat. Rev. Neurosci. 2, 806819. doi: $10.1038 / 35097565$

Coarelli, G., Darios, F., Petit, E., Dorgham, K., Adanyeguh, I., Petit, E., et al. (2021). Plasma neurofilament light chain predicts cerebellar atrophy and clinical progression in spinocerebellar ataxia. Neurobiol. Dis. 2021:105311. doi: 10.1016/ j.nbd.2021.105311

Constantinescu, R., Rosengren, L., Johnels, B., Zetterberg, H., and Holmberg, B. (2010). Consecutive analyses of cerebrospinal fluid axonal and glial markers in Parkinson's disease and atypical Parkinsonian disorders. Parkinsonism Relat. Disord. 16, 142-145. doi: 10.1016/j.parkreldis.2009.07.007

Cote, F., Collard, J. F., and Julien, J. P. (1993). Progressive neuronopathy in transgenic mice expressing the human neurofilament heavy gene: a mouse model of amyotrophic lateral sclerosis. Cell 73, 35-46. doi: 10.1016/00928674(93)90158-M

Cuello, J. P., Martinez Gines, M. L., Kuhle, J., Garcia Dominguez, J. M., Lozano Ros, A., Romero Delgado, F., et al. (2019). Neurofilament light chain levels in pregnant multiple sclerosis patients: a prospective cohort study. Eur. J. Neurol. 26, 1200-1204. doi: 10.1111/ene.13965

Dalla Costa, G., Martinelli, V., Moiola, L., Sangalli, F., Colombo, B., Finardi, A., et al. (2019). Serum neurofilaments increase at progressive multifocal leukoencephalopathy onset in natalizumab-treated multiple sclerosis patients. Ann. Neurol. 85, 606-610. doi: 10.1002/ana.25437

Damasceno, A., Dias-Carneiro, R. P. C., Moraes, A. S., Boldrini, V. O., Quintiliano, R. P. S., Da Silva, V., et al. (2019). Clinical and MRI correlates of CSF neurofilament light chain levels in relapsing and progressive MS. Mult. Scler. Relat. Disord. 30, 149-153. doi: 10.1016/j.msard.2019.02.004

Dang Do, A. N., Sinaii, N., Masvekar, R. R., Baker, E. H., Thurm, A. E., et al. (2020). Neurofilament light chain levels correlate with clinical measures in CLN3 disease. Genet. Med. 23, 751-757. doi: 10.1038/s41436-020-01035-3

Darras, B. T., Crawford, T. O., Finkel, R. S., Mercuri, E., De Vivo, D. C., Oskoui, M., et al. (2019). Neurofilament as a potential biomarker for spinal muscular atrophy. Ann. Clin. Transl. Neurol. 6, 932-944. doi: 10.1002/acn3.779

De Jong, D., Jansen, R. W., Pijnenburg, Y. A., Van Geel, W. J., Borm, G. F., Kremer, H. P., et al. (2007). CSF neurofilament proteins in the differential diagnosis of dementia. J. Neurol. Neurosurg. Psychiatry 78, 936-938. doi: 10.1136/jnnp. 2006. 107326

De Leon, M. J., Li, Y., Okamura, N., Tsui, W. H., Saint-Louis, L. A., Glodzik, L., et al. (2017). Cerebrospinal Fluid Clearance in Alzheimer Disease Measured with Dynamic PET. J. Nucl. Med. 58, 1471-1476. doi: 10.2967/jnumed.116.187211

Delaby, C., Alcolea, D., Carmona-Iragui, M., Illan-Gala, I., Morenas-Rodriguez, E., Barroeta, I., et al. (2020). Differential levels of Neurofilament Light protein in cerebrospinal fluid in patients with a wide range of neurodegenerative disorders. Sci. Rep. 10:9161.

Depoorter, A., Neumann, R. P., Barro, C., Fisch, U., Weber, P., Kuhle, J., et al. (2018). Neurofilament Light Chain: Blood Biomarker of Neonatal Neuronal Injury. Front. Neurol. 9:984. doi: 10.3389/fneur.2018.00984

Disanto, G., Adiutori, R., Dobson, R., Martinelli, V., Dalla Costa, G., Runia, T., et al. (2016). Serum neurofilament light chain levels are increased in patients with a clinically isolated syndrome. J. Neurol. Neurosurg. Psychiatry 87, 126-129. doi: 10.1136/jnnp-2014-309690

Disanto, G., Barro, C., Benkert, P., Naegelin, Y., Schadelin, S., Giardiello, A., et al. (2017). Serum Neurofilament light: A biomarker of neuronal damage in multiple sclerosis. Ann. Neurol. 81, 857-870. doi: 10.1002/ana.24954

Disanto, G., Prosperetti, C., Gobbi, C., Barro, C., Michalak, Z., Cassina, T., et al. (2019). Serum neurofilament light chain as a prognostic marker in postanoxic encephalopathy. Epilepsy Behav. 101, 106432. doi: 10.1016/j.yebeh.2019.07.033

Douglas-Escobar, M., Yang, C., Bennett, J., Shuster, J., Theriaque, D., Leibovici, A., et al. (2010). A pilot study of novel biomarkers in neonates with hypoxic-ischemic encephalopathy. Pediatr. Res. 68, 531-536. doi: 10.1203/PDR. 0b013e3181f85a03

Edwards, L. A., Donnelly, C. G., Reed, S. M., Valberg, S., Chigerwe, M., Johnson, A. L., et al. (2021). Serum and cerebrospinal fluid phosphorylated neurofilament heavy protein concentrations in equine neurodegenerative diseases. Equine Vet. J. doi: $10.1111 /$ evj.13452

Egle, M., Loubiere, L., Maceski, A., Kuhle, J., Peters, N., and Markus, H. S. (2021). Neurofilament light chain predicts future dementia risk in cerebral small vessel disease. J. Neurol. Neurosurg. Psychiatry. 92, 582-589. doi: 10.1136/jnnp-2020325681

Ehler, J., Petzold, A., Wittstock, M., Kolbaske, S., Gloger, M., Henschel, J., et al. (2019). The prognostic value of neurofilament levels in patients with sepsisassociated encephalopathy - A prospective, pilot observational study. PLoS One 14:e0211184. doi: 10.1371/journal.pone.0211184

Elder, G. A., Friedrich, V. L. Jr., Margita, A., and Lazzarini, R. A. (1999). Agerelated atrophy of motor axons in mice deficient in the mid-sized neurofilament subunit. J. Cell Biol. 146, 181-192. doi: 10.1083/jcb.146.1.181

Engelhardt, B., Vajkoczy, P., and Weller, R. O. (2017). The movers and shapers in immune privilege of the CNS. Nat. Immunol. 18, 123-131. doi: 10.1038/ni.3666

Evered, L., Silbert, B., Scott, D. A., Zetterberg, H., and Blennow, K. (2018). Association of Changes in Plasma Neurofilament Light and Tau Levels With Anesthesia and Surgery: Results From the CAPACITY and ARCADIAN Studies. JAMA Neurol. 75, 542-547. doi: 10.1001/jamaneurol.2017.4913

Evers, K. S., Atkinson, A., Barro, C., Fisch, U., Pfister, M., Huhn, E. A., et al. (2018). Neurofilament as Neuronal Injury Blood Marker in Preeclampsia. Hypertension 71, 1178-1184. doi: 10.1161/HYPERTENSIONAHA.117.10314

Evers, K. S., Hugli, M., Fouzas, S., Kasser, S., Pohl, C., Stoecklin, B., et al. (2020). Serum Neurofilament Levels in Children With Febrile Seizures and in Controls. Front. Neurosci. 14:579958. doi: 10.3389/fnins.2020.579958

Fagan, A. M., Shaw, L. M., Xiong, C., Vanderstichele, H., Mintun, M. A., Trojanowski, J. Q., et al. (2011). Comparison of analytical platforms for cerebrospinal fluid measures of beta-amyloid 1-42, total tau, and p-tau181 for identifying Alzheimer disease amyloid plaque pathology. Arch. Neurol. 68, 1137-1144. doi: 10.1001/archneurol.2011.105

Filali, M., Dequen, F., Lalonde, R., and Julien, J. P. (2011). Sensorimotor and cognitive function of a NEFL(P22S) mutant model of Charcot-Marie-Tooth disease type 2E. Behav. Brain Res. 219, 175-180. doi: 10.1016/j.bbr.2010.12.022

Filippi, P., Vestenicka, V., Siarnik, P., Sivakova, M., Copikova-Cudrakova, D., Belan, V., et al. (2020). Neurofilament light chain and MRI volume parameters as markers of neurodegeneration in multiple sclerosis. Neuro Endocrinol. Lett. 41, 17-26.

Finderlater, J. (2010). Peripherin-28 as a biomarker of ALS: A methodological study. Toronto: University of Toronto.

Fischer, A., Sananbenesi, F., Pang, P. T., Lu, B., and Tsai, L. H. (2005). Opposing roles of transient and prolonged expression of p25 in synaptic plasticity and hippocampus-dependent memory. Neuron 48, 825-838. doi: 10.1016/j.neuron. 2005.10.033

Foiani, M. S., Woollacott, I. O., Heller, C., Bocchetta, M., Heslegrave, A., Dick, K. M., et al. (2018). Plasma tau is increased in frontotemporal dementia. J. Neurol. Neurosurg. Psychiatry 89, 804-807. doi: 10.1136/jnnp-2017-317260

Fominykh, V., Brylev, L., Gaskin, V., Luzin, R., Yakovlev, A., Komoltsev, I., et al. (2019). Neuronal damage and neuroinflammation markers in patients with autoimmune encephalitis and multiple sclerosis. Metab. Brain Dis. 34, 1473-1485. doi: 10.1007/s11011-019-00452-x

Fong, T. G., Vasunilashorn, S. M., Ngo, L., Libermann, T. A., Dillon, S. T., Schmitt, E. M., et al. (2020). Association of Plasma Neurofilament Light with Postoperative Delirium. Ann. Neurol. 88, 984-994. doi: 10.1002/ana.25889

Fortea, J., Carmona-Iragui, M., Benejam, B., Fernandez, S., Videla, L., Barroeta, I., et al. (2018). Plasma and CSF biomarkers for the diagnosis of Alzheimer's disease in adults with Down syndrome: a cross-sectional study. Lancet Neurol. 17, 860-869. doi: 10.1016/S1474-4422(18)30285-0

Gaetani, L., Hoglund, K., Parnetti, L., Pujol-Calderon, F., Becker, B., Eusebi, P., et al. (2018). A new enzyme-linked immunosorbent assay for neurofilament light in cerebrospinal fluid: analytical validation and clinical evaluation. Alzheimers Res. Ther. 10:8. doi: 10.1186/s13195-018-0339-1

Gama Sosa, M. A., Friedrich, V. L. Jr., Degasperi, R., Kelley, K., Wen, P. H., Senturk, E., et al. (2003). Human midsized neurofilament subunit induces motor neuron disease in transgenic mice. Exp. Neurol. 184, 408-419. doi: 10.1016/S00144886(03)00206- 1

Garland, P., Morton, M., Zolnourian, A., Durnford, A., Gaastra, B., Toombs, J., et al. (2021). Neurofilament light predicts neurological outcome after subarachnoid haemorrhage. Brain. [Preprint]. doi: 10.1093/brain/awaa451

Gattringer, T., Pinter, D., Enzinger, C., Seifert-Held, T., Kneihsl, M., Fandler, S., et al. (2017). Serum neurofilament light is sensitive to active cerebral small vessel disease. Neurology 89, 2108-2114. doi: 10.1212/WNL.0000000000004645 
Gauthier, A., Viel, S., Perret, M., Brocard, G., Casey, R., Lombard, C., et al. (2021). Comparison of Simoa(TM) and Ella(TM) to assess serum neurofilament-light chain in multiple sclerosis. Ann. Clin. Transl. Neurol. 8, 1141-1150. doi: 10. $1002 / \mathrm{acn} 3.51355$

Gendron, T. F., Badi, M. K., Heckman, M. G., Jansen-West, K. R., Vilanilam, G. K., Johnson, P. W., et al. (2020). Plasma neurofilament light predicts mortality in patients with stroke. Sci. Transl. Med. 12:eaay1913. doi: 10.1126/scitranslmed. aay 1913

Gille, B., De Schaepdryver, M., Goossens, J., Dedeene, L., De Vocht, J., Oldoni, E., et al. (2019). Serum neurofilament light chain levels as a marker of upper motor neuron degeneration in patients with Amyotrophic Lateral Sclerosis. Neuropathol. Appl. Neurobiol. 45, 291-304. doi: 10.1111/nan. 12511

Gisslen, M., Price, R. W., Andreasson, U., Norgren, N., Nilsson, S., Hagberg, L., et al. (2016). Plasma Concentration of the Neurofilament Light Protein (NFL) is a Biomarker of CNS Injury in HIV Infection: A Cross-Sectional Study. EBioMed. 3, 135-140. doi: 10.1016/j.ebiom.2015.11.036

Goeral, K., Hauck, A., Atkinson, A., Wagner, M. B., Pimpel, B., Fuiko, R., et al. (2021). Early life serum neurofilament dynamics predict neurodevelopmental outcome of preterm infants. J. Neurol. 268, 2570-2577. doi: 10.1007/s00415021-10429-5

Goldman, J. E., Yen, S. H., Chiu, F. C., and Peress, N. S. (1983). Lewy bodies of Parkinson's disease contain neurofilament antigens. Science 221, 1082-1084. doi: 10.1126/science.6308771

Goldstein, M. E., Sternberger, N. H., and Sternberger, L. A. (1987). Phosphorylation protects neurofilaments against proteolysis. J. Neuroimmunol. 14, 149-160. doi: 10.1016/0165-5728(87)90049-X

Granger, B. L., and Lazarides, E. (1983). Expression of the major neurofilament subunit in chicken erythrocytes. Science 221, 553-556. doi: 10.1126/science. 6346488

Gravesteijn, G., Rutten, J. W., Verberk, I. M. W., Bohringer, S., Liem, M. K., Van Der Grond, J., et al. (2019). Serum Neurofilament light correlates with CADASIL disease severity and survival. Ann. Clin. Transl. Neurol. 6, 46-56. doi: $10.1002 / \operatorname{acn} 3.678$

Gronhoj, M. H., Sejbaek, T., Hansen, R. W., Larsen, L., Dahl, M., Schierbeck, J., et al. (2021). Serum levels of neurofilament light chain, neuron-specific enolase and S100 calcium-binding protein B during acute bacterial meningitis: a prospective cohort study. Infect. Dis. 2021, 1-11. doi: 10.1080/23744235.2021. 1883730

Grothe, M. J., Moscoso, A., Ashton, N. J., Karikari, T. K., Lantero-Rodriguez, J., Snellman, A., et al. (2021). Associations of Fully Automated CSF and Novel Plasma Biomarkers With Alzheimer Disease Neuropathology at Autopsy. Neurology. [Preprint]. doi: 10.1212/WNL.0000000000012513

Guedes, V. A., Kenney, K., Shahim, P., Qu, B. X., Lai, C., Devoto, C., et al. (2020). Exosomal neurofilament light: A prognostic biomarker for remote symptoms after mild traumatic brain injury? Neurology 94, e2412-e2423. doi: 10.1212/ WNL.0000000000009577

Guez, M., Hildingsson, C., Rosengren, L., Karlsson, K., and Toolanen, G. (2003). Nervous tissue damage markers in cerebrospinal fluid after cervical spine injuries and whiplash trauma. J. Neurotrauma 20, 853-858. doi: 10.1089/ 089771503322385782

Haggmark, A., Mikus, M., Mohsenchian, A., Hong, M. G., Forsstrom, B., Gajewska, B., et al. (2014). Plasma profiling reveals three proteins associated to amyotrophic lateral sclerosis. Ann. Clin. Transl. Neurol. 1, 544-553. doi: $10.1002 / \operatorname{acn} 3.83$

Halaas, N. B., Blennow, K., Idland, A. V., Wyller, T. B., Raeder, J., Frihagen, F., et al. (2018). Neurofilament Light in Serum and Cerebrospinal Fluid of Hip Fracture Patients with Delirium. Dement. Geriatr. Cogn. Disord. 46, 346-357. doi: 10.1159/000494754

Hamberger, A., Huang, Y. L., Zhu, H., Bao, F., Ding, M., Blennow, K., et al. (2003). Redistribution of neurofilaments and accumulation of beta-amyloid protein after brain injury by rotational acceleration of the head. J. Neurotrauma 20, 169-178. doi: 10.1089/08977150360547080

Hansson, O., Janelidze, S., Hall, S., Magdalinou, N., Lees, A. J., Andreasson, U., et al. (2017). Blood-based NfL: A biomarker for differential diagnosis of parkinsonian disorder. Neurology 88, 930-937. doi: 10.1212/WNL.0000000000003680

Harris, S., Comi, G., Cree, B. A. C., Arnold, D. L., Steinman, L., Sheffield, J. K., et al. (2021). Plasma neurofilament light chain concentrations as a biomarker of clinical and radiologic outcomes in relapsing multiple sclerosis: Post hoc analysis of phase 3 ozanimod trials. Eur. J. Neurol. [Preprint]. doi: 10.1111/ene. 15009

Hayakawa, K., Okazaki, R., Ishii, K., Ueno, T., Izawa, N., Tanaka, Y., et al. (2012). Phosphorylated neurofilament subunit NF-H as a biomarker for evaluating the severity of spinal cord injury patients, a pilot study. Spinal Cord 50, 493-496. doi: $10.1038 /$ sc. 2011.184

Hayashi, T., Nukui, T., Piao, J. L., Sugimoto, T., Anada, R., Matsuda, N., et al. (2021). Serum neurofilament light chain in chronic inflammatory demyelinating polyneuropathy. Brain Behav. 2021:e02084. doi: 10.1002/brb3. 2084

He, L., Morley, J. E., Aggarwal, G., Nguyen, A. D., Vellas, B., De Souto Barreto, P., et al. (2021). Plasma neurofilament light chain is associated with cognitive decline in non-dementia older adults. Sci. Rep. 11:13394. doi: 10.1186/s13195020-00697-0

He, W. C., Zhang, X. J., Zhang, Y. Q., and Zhang, W. J. (2020). Elevated serum neurofilament light chain in children autism spectrum disorder: a case control study. Neurotoxicology 80, 87-92. doi: 10.1016/j.neuro.2020.06.012

Heo, S., Diering, G. H., Na, C. H., Nirujogi, R. S., Bachman, J. L., Pandey, A., et al. (2018). Identification of long-lived synaptic proteins by proteomic analysis of synaptosome protein turnover. Proc. Natl. Acad. Sci. U S A. 115, E3827-E3836. doi: 10.1073/pnas.1720956115

Hepner, A., Porter, J., Hare, F., Nasir, S. S., Zetterberg, H., Blennow, K., et al. (2019). Serum Neurofilament Light, Glial Fibrillary Acidic Protein and Tau Are Possible Serum Biomarkers for Activity of Brain Metastases and Gliomas. World J. Oncol. 10, 169-175. doi: 10.14740/wjon1228

Herbert, M. K., Aerts, M. B., Beenes, M., Norgren, N., Esselink, R. A., Bloem, B. R., et al. (2015). CSF Neurofilament Light Chain but not FLT3 Ligand Discriminates Parkinsonian Disorders. Front. Neurol. 6:91. doi: 10.3389/fneur. 2015.00091

Herrera, M. I., Kolliker-Frers, R. A., Otero-Losada, M., Perez Lloret, S., Filippo, M., Tau, J., et al. (2019). A Pilot Cross-Sectional Study to Investigate the Biomarker Potential of Phosphorylated Neurofilament-H and Immune Mediators of Disability in Patients With 5 Year Relapsing-Remitting Multiple Sclerosis. Front. Neurol. 10:1046. doi: 10.3389/fneur.2019.01046

Hoffman, P. N., Cleveland, D. W., Griffin, J. W., Landes, P. W., Cowan, N. J., and Price, D. L. (1987). Neurofilament gene expression: a major determinant of axonal caliber. Proc. Natl. Acad. Sci. U S A. 84, 3472-3476. doi: 10.1073/pnas. 84.10.3472

Hoglund, K., Bogstedt, A., Fabre, S., Aziz, A., Annas, P., Basun, H., et al. (2012). Longitudinal stability evaluation of biomarkers and their correlation in cerebrospinal fluid and plasma from patients with Alzheimer's disease. J. Alzheimers. Dis. 32, 939-947. doi: 10.3233/JAD-2012-120976

Hossain, I., Mohammadian, M., Takala, R. S. K., Tenovuo, O., Lagerstedt, L., AlaSeppala, H., et al. (2019). Early Levels of Glial Fibrillary Acidic Protein and Neurofilament Light Protein in Predicting the Outcome of Mild Traumatic Brain Injury. J. Neurotrauma 36, 1551-1560. doi: 10.1089/neu.2018.5952

Hu, Y. Y., He, S. S., Wang, X. C., Duan, Q. H., Khatoon, S., Iqbal, K., et al. (2002). Elevated levels of phosphorylated neurofilament proteins in cerebrospinal fluid of Alzheimer disease patients. Neurosci. Lett. 320, 156-160. doi: 10.1016/S03043940(02)00047-2

Hviid, C. V. B., Gyldenholm, T., Lauridsen, S. V., Hjort, N., Hvas, A. M. and Parkner, T. (2020a). Plasma neurofilament light chain is associated with mortality after spontaneous intracerebral hemorrhage. Clin. Chem. Lab. Med. 58, 261-267. doi: 10.1515/cclm-2019-0532

Hviid, C. V. B., Knudsen, C. S., and Parkner, T. (2020b). Reference interval and preanalytical properties of serum neurofilament light chain in Scandinavian adults. Scand. J. Clin. Lab. Invest. 2020, 1-5.

Idland, A. V., Sala-Llonch, R., Borza, T., Watne, L. O., Wyller, T. B., Braekhus, A., et al. (2017). CSF neurofilament light levels predict hippocampal atrophy in cognitively healthy older adults. Neurobiol. Aging 49, 138-144. doi: 10.1016/j. neurobiolaging.2016.09.012

Ikenberg, E., Reilich, P., Abicht, A., Heller, C., Schoser, B., and Walter, M. C. (2019). Charcot-Marie-Tooth disease type 2CC due to a frameshift mutation of the neurofilament heavy polypeptide gene in an Austrian family. Neuromuscul. Disord. 29, 392-397. doi: 10.1016/j.nmd.2019.02.007

Inoue, R., Sumitani, M., Ogata, T., Chikuda, H., Matsubara, T., Kato, S., et al. (2017). Direct evidence of central nervous system axonal damage in patients 
with postoperative delirium: A preliminary study of $\mathrm{pNF}-\mathrm{H}$ as a promising serum biomarker. Neurosci. Lett. 653, 39-44. doi: 10.1016/j.neulet.2017.05.023

Iverson, G. L., Reddi, P. J., Posti, J. P., Kotilainen, A. K., Tenovuo, O., Ohman, J., et al. (2019). Serum Neurofilament Light Is Elevated Differentially in Older Adults with Uncomplicated Mild Traumatic Brain Injuries. J. Neurotrauma 36, 2400-2406. doi: 10.1089/neu.2018.6341

Jakimovski, D., Kuhle, J., Ramanathan, M., Barro, C., Tomic, D., Hagemeier, J., et al. (2019a). Serum neurofilament light chain levels associations with gray matter pathology: a 5-year longitudinal study. Ann. Clin. Transl. Neurol. 6, 1757-1770. doi: $10.1002 / \operatorname{acn} 3.50872$

Jakimovski, D., Zivadinov, R., Ramanthan, M., Hagemeier, J., Weinstock-Guttman, B., Tomic, D., et al. (2019b). Serum neurofilament light chain level associations with clinical and cognitive performance in multiple sclerosis: A longitudinal retrospective 5-year study. Mult. Scler. 2019:1352458519881428. doi: 10.1177/ 1352458519881428

Jakobsson, J., Bjerke, M., Ekman, C. J., Sellgren, C., Johansson, A. G., Zetterberg, H., et al. (2014). Elevated concentrations of neurofilament light chain in the cerebrospinal fluid of bipolar disorder patients. Neuropsychopharmacology 39, 2349-2356. doi: 10.1038/npp.2014.81

Janelidze, S., Mattsson, N., Palmqvist, S., Smith, R., Beach, T. G., Serrano, G. E., et al. (2020a). Plasma P-tau181 in Alzheimer's disease: relationship to other biomarkers, differential diagnosis, neuropathology and longitudinal progression to Alzheimer's dementia. Nat. Med. 26, 379-386. doi: 10.1038/ s41591-020-0755-1

Janelidze, S., Stomrud, E., Smith, R., Palmqvist, S., Mattsson, N., Airey, D. C., et al. (2020b). Cerebrospinal fluid p-tau217 performs better than p-tau181 as a biomarker of Alzheimer's disease. Nat. Commun. 11:1683. doi: 10.1038/s41467020-15436-0

Jeppsson, A., Zetterberg, H., Blennow, K., and Wikkelso, C. (2013). Idiopathic normal-pressure hydrocephalus: pathophysiology and diagnosis by CSF biomarkers. Neurol. 80, 1385-1392. doi: 10.1212/WNL.0b013e31828c2fda

Jessen Krut, J., Mellberg, T., Price, R. W., Hagberg, L., Fuchs, D., Rosengren, L., et al. (2014). Biomarker evidence of axonal injury in neuroasymptomatic HIV-1 patients. PLoS One 9:e88591. doi: 10.1371/journal.pone.0088591

Jin, M., Cao, L., and Dai, Y. P. (2019). Role of Neurofilament Light Chain as a Potential Biomarker for Alzheimer's Disease: A Correlative Meta-Analysis. Front. Aging Neurosci. 11:254. doi: 10.3389/fnagi.2019.00254

Johnson, E. B., Byrne, L. M., Gregory, S., Rodrigues, F. B., Blennow, K., Durr, A., et al. (2018). Neurofilament light protein in blood predicts regional atrophy in Huntington disease. Neurology 90, e717-e723. doi: 10.1212/WNL. 0000000000005005

Joisten, N., Rademacher, A., Warnke, C., Proschinger, S., Schenk, A., Walzik, D., et al. (2021). Exercise Diminishes Plasma Neurofilament Light Chain and Reroutes the Kynurenine Pathway in Multiple Sclerosis. Neurol. Neuroimmunol. Neuroinflamm. 8:e982. doi: 10.1212/NXI.0000000000000982

Kalm, M., Bostrom, M., Sandelius, A., Eriksson, Y., Ek, C. J., Blennow, K., et al. (2017). Serum concentrations of the axonal injury marker neurofilament light protein are not influenced by blood-brain barrier permeability. Brain Res. 1668, 12-19. doi: 10.1016/j.brainres.2017.05.011

Kanata, E., Golanska, E., Villar-Pique, A., Karsanidou, A., Dafou, D., Xanthopoulos, K., et al. (2019). Cerebrospinal fluid neurofilament light in suspected sporadic Creutzfeldt-Jakob disease. J. Clin. Neurosci. 60, 124-127. doi: 10.1016/j.jocn.2018.09.031

Kang, M. S., Aliaga, A. A., Shin, M., Mathotaarachchi, S., Benedet, A. L., Pascoal, T. A., et al. (2020). Amyloid-beta modulates the association between neurofilament light chain and brain atrophy in Alzheimer's disease. Mol. Psychiatry. [Preprint]. doi: 10.1038/s41380-020-0818-1

Kapoor, M., Foiani, M., Heslegrave, A., Zetterberg, H., Lunn, M. P., Malaspina, A., et al. (2019). Plasma neurofilament light chain concentration is increased and correlates with the severity of neuropathy in hereditary transthyretin amyloidosis. J. Peripher. Nerv. Syst. 24, 314-319. doi: 10.1111/jns. 12350

Karikari, T. K., Benedet, A. L., Ashton, N. J., Lantero Rodriguez, J., Snellman, A., Suarez-Calvet, M., et al. (2021). Diagnostic performance and prediction of clinical progression of plasma phospho-tau181 in the Alzheimer's Disease Neuroimaging Initiative. Mol. Psychiatry 26, 429-442. doi: 10.1038/s41380020-00923-z

Karikari, T. K., Emersic, A., Vrillon, A., Lantero-Rodriguez, J., Ashton, N. J., Kramberger, M. G., et al. (2020a). Head-to-head comparison of clinical performance of CSF phospho-tau T181 and T217 biomarkers for Alzheimer's disease diagnosis. Alzheimers Dement. 17, 755-767. doi: 10.1002/alz.12236

Karikari, T. K., Pascoal, T. A., Ashton, N. J., Janelidze, S., Benedet, A. L., Rodriguez, J. L., et al. (2020b). Blood phosphorylated tau 181 as a biomarker for Alzheimer's disease: a diagnostic performance and prediction modelling study using data from four prospective cohorts. Lancet Neurol. 19, 422-433. doi: 10.1016/S14744422(20)30071-5

Katisko, K., Cajanus, A., Jaaskelainen, O., Kontkanen, A., Hartikainen, P., Korhonen, V. E., et al. (2020). Serum neurofilament light chain is a discriminative biomarker between frontotemporal lobar degeneration and primary psychiatric disorders. J. Neurol. 267, 162-167. doi: 10.1007/s00415019-09567-8

Kern, S., Syrjanen, J. A., Blennow, K., Zetterberg, H., Skoog, I., Waern, M., et al. (2019). Association of Cerebrospinal Fluid Neurofilament Light Protein With Risk of Mild Cognitive Impairment Among Individuals Without Cognitive Impairment. JAMA Neurol. 76, 187-193. doi: 10.1001/jamaneurol.2018.3459

Khalil, M., Pirpamer, L., Hofer, E., Voortman, M. M., Barro, C., Leppert, D., et al. (2020). Serum neurofilament light levels in normal aging and their association with morphologic brain changes. Nat. Commun. 11:812. doi: 10.1038/s41467020-14612-6

Khalil, M., Teunissen, C. E., Otto, M., Piehl, F., Sormani, M. P., Gattringer, T., et al. (2018). Neurofilaments as biomarkers in neurological disorders. Nat. Rev. Neurol. 14, 577-589. doi: 10.1038/s41582-018-0058-z

Kida, S., Pantazis, A., and Weller, R. O. (1993). CSF drains directly from the subarachnoid space into nasal lymphatics in the rat. Anatomy, histology and immunological significance. Neuropathol. Appl. Neurobiol. 19, 480-488. doi: 10.1111/j.1365-2990.1993.tb00476.x

Kirschen, M. P., Yehya, N., Graham, K., Kilbaugh, T., Berg, R. A., Topjian, A., et al. (2020). Circulating Neurofilament Light Chain Is Associated With Survival After Pediatric Cardiac Arrest. Pediatr. Crit. Care Med. 21, 656-661. doi: 10. 1097/PCC.0000000000002294

Kleijmeer, M., Ramm, G., Schuurhuis, D., Griffith, J., Rescigno, M., RicciardiCastagnoli, P., et al. (2001). Reorganization of multivesicular bodies regulates MHC class II antigen presentation by dendritic cells. J. Cell Biol. 155, 53-63. doi: $10.1083 /$ jcb.200103071

Koel-Simmelink, M. J., Vennegoor, A., Killestein, J., Blankenstein, M. A., Norgren, N., Korth, C., et al. (2014). The impact of pre-analytical variables on the stability of neurofilament proteins in CSF, determined by a novel validated SinglePlex Luminex assay and ELISA. J. Immunol. Methods 402, 43-49. doi: 10.1016/j.jim. 2013.11.008

Kohnken, R., Buerger, K., Zinkowski, R., Miller, C., Kerkman, D., Debernardis, J., et al. (2000). Detection of tau phosphorylated at threonine 231 in cerebrospinal fluid of Alzheimer's disease patients. Neurosci. Lett. 287, 187-190. doi: 10.1016/ S0304-3940(00)01178-2

Korley, F. K., Goldstick, J., Mastali, M., Van Eyk, J. E., Barsan, W., Meurer, W. J., et al. (2019). Serum NfL (Neurofilament Light Chain) Levels and Incident Stroke in Adults With Diabetes Mellitus. Stroke 50, 1669-1675. doi: 10.1161/ STROKEAHA.119.024941

Kortvelyessy, P., Pruss, H., Thurner, L., Maetzler, W., Vittore-Welliong, D., Schultze-Amberger, J., et al. (2018). Biomarkers of Neurodegeneration in Autoimmune-Mediated Encephalitis. Front. Neurol. 9:668. doi: 10.3389/fneur. 2018.00668

Kriz, J., Zhu, Q., Julien, J. P., and Padjen, A. L. (2000). Electrophysiological properties of axons in mice lacking neurofilament subunit genes: disparity between conduction velocity and axon diameter in absence of NF-H. Brain Res. 885, 32-44. doi: 10.1016/S0006-8993(00)02899-7

Kuhle, J., Barro, C., Disanto, G., Mathias, A., Soneson, C., Bonnier, G., et al. (2016). Serum neurofilament light chain in early relapsing remitting MS is increased and correlates with CSF levels and with MRI measures of disease severity. Mult. Scler. 22, 1550-1559. doi: 10.1177/1352458515623365

Kuhle, J., Gaiottino, J., Leppert, D., Petzold, A., Bestwick, J. P., Malaspina, A., et al. (2015). Serum neurofilament light chain is a biomarker of human spinal cord injury severity and outcome. J. Neurol. Neurosurg. Psychiatry 86, 273-279. doi: 10.1136/jnnp-2013-307454

Kuhle, J., Kropshofer, H., Haering, D. A., Kundu, U., Meinert, R., Barro, C., et al. (2019). Blood neurofilament light chain as a biomarker of MS disease activity and treatment response. Neurol. 92, e1007-e1015. doi: 10.1212/WNL. 0000000000007032 
Kuhle, J., Malmestrom, C., Axelsson, M., Plattner, K., Yaldizli, O., Derfuss, T., et al. (2013). Neurofilament light and heavy subunits compared as therapeutic biomarkers in multiple sclerosis. Acta Neurol. Scand. 128, e33-e36. doi: 10. 1111 /ane. 12151

Kuhle, J., Regeniter, A., Leppert, D., Mehling, M., Kappos, L., Lindberg, R. L., et al. (2010). A highly sensitive electrochemiluminescence immunoassay for the neurofilament heavy chain protein. J. Neuroimmunol. 220, 114-119. doi: 10.1016/j.jneuroim.2010.01.004

Lachenal, G., Pernet-Gallay, K., Chivet, M., Hemming, F. J., Belly, A., Bodon, G., et al. (2011). Release of exosomes from differentiated neurons and its regulation by synaptic glutamatergic activity. Mol. Cell Neurosci. 46, 409-418. doi: 10.1016/j.mcn.2010.11.004

Lantero Rodriguez, J., Karikari, T. K., Suarez-Calvet, M., Troakes, C., King, A., Emersic, A., et al. (2020). Plasma p-tau181 accurately predicts Alzheimer's disease pathology at least 8 years prior to post-mortem and improves the clinical characterisation of cognitive decline. Acta Neuropathol. 140, 267-278. doi: 10.1007/s00401-020-02195-x

Lariviere, R. C., Nguyen, M. D., Ribeiro-Da-Silva, A., and Julien, J. P. (2002). Reduced number of unmyelinated sensory axons in peripherin null mice. J. Neurochem. 81, 525-532. doi: 10.1046/j.1471-4159.2002.00853.x

Lee, M. K., Marszalek, J. R., and Cleveland, D. W. (1994). A mutant neurofilament subunit causes massive, selective motor neuron death: implications for the pathogenesis of human motor neuron disease. Neuron 13, 975-988. doi: 10. 1016/0896-6273(94)90263-1

Lendahl, U., Zimmerman, L. B., and Mckay, R. D. (1990). CNS stem cells express a new class of intermediate filament protein. Cell 60, 585-595. doi: 10.1016/00928674(90)90662-X

Lerat, J., Magdelaine, C., Beauvais-Dzugan, H., Espil, C., Ghorab, K., Latour, P., et al. (2019). A novel pathogenic variant of NEFL responsible for deafness associated with peripheral neuropathy discovered through next-generation sequencing and review of the literature. J. Peripher. Nerv. Syst. 24, 139-144. doi: $10.1111 /$ jns. 12310

Lewczuk, P., Ermann, N., Andreasson, U., Schultheis, C., Podhorna, J., Spitzer, P., et al. (2018). Plasma neurofilament light as a potential biomarker of neurodegeneration in Alzheimer's disease. Alzheimers Res. Ther. 10:71. doi: 10.1186/s13195-018-0404-9

Lewczuk, P., Esselmann, H., Bibl, M., Beck, G., Maler, J. M., Otto, M., et al. (2004). Tau protein phosphorylated at threonine 181 in CSF as a neurochemical biomarker in Alzheimer's disease: original data and review of the literature. J. Mol. Neurosci. 23, 115-122. doi: 10.1385/JMN:23:1-2:115

Lewis, S. B., Wolper, R. A., Miralia, L., Yang, C., and Shaw, G. (2008). Detection of phosphorylated NF-H in the cerebrospinal fluid and blood of aneurysmal subarachnoid hemorrhage patients. J. Cereb. Blood Flow Metab. 28, 1261-1271. doi: $10.1038 /$ jcbfm.2008.12

Li, D., Zhang, L., Nelson, N. W., Mielke, M. M., and Yu, F. (2021). Plasma neurofilament light and future declines in cognition and function in Alzheimer's disease in the FIT-AD trial. J. Alzheimers Dis. Rep. 5, 601-611. doi: 10.3233/ ADR-210302

Li, Q. F., Dong, Y., Yang, L., Xie, J. J., Ma, Y., Du, Y. C., et al. (2019). Neurofilament light chain is a promising serum biomarker in spinocerebellar ataxia type 3 . Mol. Neurodegener. 14:39. doi: 10.1186/s13024-019-0338-0

Liang, Y., Tong, F., Zhang, L., Zhu, L., Li, W., Huang, W., et al. (2019). iTRAQbased proteomic analysis discovers potential biomarkers of diffuse axonal injury in rats. Brain Res. Bull. 153, 289-304. doi: 10.1016/j.brainresbull.2019.09.004

Lin, C. H., Li, C. H., Yang, K. C., Lin, F. J., Wu, C. C., Chieh, J. J., et al. (2019). Blood NfL: A biomarker for disease severity and progression in Parkinson disease. Neurology 93, e1104-e1111. doi: 10.1212/WNL.0000000000008088

Lin, X., Lu, T., Deng, H., Liu, C., Yang, Y., Chen, T., et al. (2021). Serum neurofilament light chain or glial fibrillary acidic protein in the diagnosis and prognosis of brain metastases. J. Neurol. [Preprint]. doi: 10.1007/s00415-02110660-0

Lin, Y. S., Lee, W. J., Wang, S. J., and Fuh, J. L. (2018). Levels of plasma neurofilament light chain and cognitive function in patients with Alzheimer or Parkinson disease. Sci. Rep. 8:17368. doi: 10.1038/s41598-018-35766-w

Linker, R. A., Brechlin, P., Jesse, S., Steinacker, P., Lee, D. H., Asif, A. R., et al. (2009). Proteome profiling in murine models of multiple sclerosis: identification of stage specific markers and culprits for tissue damage. PLoS One 4:e7624. doi: 10.1371/journal.pone.0007624
Liu, C., Zhao, L., Fan, P., Ko, H., Au, C., Ng, A., et al. (2021). High serum neurofilament levels among Chinese patients with aquaporin-4-IgGseropositive neuromyelitis optica spectrum disorders. J. Clin. Neurosci. 83, 108-111. doi: 10.1016/j.jocn.2020.11.016

Liu, H. C., Lin, W. C., Chiu, M. J., Lu, C. H., Lin, C. Y., and Yang, S. Y. (2020). Development of an assay of plasma neurofilament light chain utilizing immunomagnetic reduction technology. PLoS One 15:e0234519. doi: 10.1371/ journal.pone.0234519

Liu, Q., Xie, F., Alvarado-Diaz, A., Smith, M. A., Moreira, P. I., Zhu, X., et al. (2011). Neurofilamentopathy in neurodegenerative diseases. Open Neurol. J. 5, 58-62. doi: 10.2174/1874205X01105010058

Liu, S., Huang, Z., Zhang, L., Pan, J., Lei, Q., Meng, Y., et al. (2020). Plasma Neurofilament Light Chain May Be a Biomarker for the Inverse Association Between Cancers and Neurodegenerative Diseases. Front. Aging Neurosci. 12:10. doi: 10.3389/fnagi.2020.00010

Llibre-Guerra, J. J., Li, Y., Schindler, S. E., Gordon, B. A., Fagan, A. M., Morris, J. C., et al. (2019). Association of Longitudinal Changes in Cerebrospinal Fluid Total Tau and Phosphorylated Tau 181 and Brain Atrophy With Disease Progression in Patients With Alzheimer Disease. JAMA Netw. Open 2:e1917126. doi: 10.1001/jamanetworkopen.2019.17126

Lombardi, V., Carassiti, D., Giovannoni, G., Lu, C. H., Adiutori, R., and Malaspina, A. (2020). The potential of neurofilaments analysis using dry-blood and plasma spots. Sci. Rep. 10:97. doi: 10.1038/s41598-019-54310-y

Lomen-Hoerth, C. (2011). Clinical phenomenology and neuroimaging correlates in ALS-FTD. J. Mol. Neurosci. 45, 656-662. doi: 10.1007/s12031-011-9636-x

Lu, C. H., Macdonald-Wallis, C., Gray, E., Pearce, N., Petzold, A., Norgren, N., et al. (2015). Neurofilament light chain: A prognostic biomarker in amyotrophic lateral sclerosis. Neurology 84, 2247-2257. doi: 10.1212/WNL. 0000000000001642

Lu, C. H., Petzold, A., Kalmar, B., Dick, J., Malaspina, A., and Greensmith, L. (2012). Plasma neurofilament heavy chain levels correlate to markers of late stage disease progression and treatment response in SOD1(G93A) mice that model ALS. PLoS One 7:e40998. doi: 10.1371/journal.pone.0040998

Ma, L. Z., Zhang, C., Wang, H., Ma, Y. H., Shen, X. N., Wang, J., et al. (2021). Serum Neurofilament Dynamics Predicts Cognitive Progression in de novo Parkinson's Disease. J. Parkinsons Dis. [Preprint]. doi: 10.3233/JPD-212535

Mages, B., Aleithe, S., Altmann, S., Blietz, A., Nitzsche, B., Barthel, H., et al. (2018). Impaired Neurofilament Integrity and Neuronal Morphology in Different Models of Focal Cerebral Ischemia and Human Stroke Tissue. Front. Cell Neurosci. 12:161. doi: 10.3389/fncel.2018.00161

Maggi, P., Kuhle, J., Schadelin, S., Van Der Meer, F., Weigel, M., Galbusera, R., et al. (2021). Chronic White Matter Inflammation and Serum Neurofilament Levels in Multiple Sclerosis. Neurology 97, e543-e553. doi: 10.1212/WNL. 0000000000012326

Manouchehrinia, A., Piehl, F., Hillert, J., Kuhle, J., Alfredsson, L., Olsson, T., et al. (2020). Confounding effect of blood volume and body mass index on blood neurofilament light chain levels. Ann. Clin. Transl. Neurol. 7, 139-143. doi: 10.1002/acn3.50972

Mariotto, S., Farinazzo, A., Magliozzi, R., Alberti, D., Monaco, S., and Ferrari, S. (2018). Serum and cerebrospinal neurofilament light chain levels in patients with acquired peripheral neuropathies. J. Peripher. Nerv. Syst. 23, 174-177. doi: $10.1111 /$ jns. 12279

Martinez-Morillo, E., Childs, C., Garcia, B. P., Alvarez Menendez, F. V., Romaschin, A. D., Cervellin, G., et al. (2015). Neurofilament medium polypeptide (NFM) protein concentration is increased in CSF and serum samples from patients with brain injury. Clin. Chem. Lab. Med. 53, 1575-1584. doi: $10.1515 /$ cclm-2014-0908

Martinez-Morillo, E., Garcia Hernandez, P., Begcevic, I., Kosanam, H., Prieto Garcia, B., Alvarez Menendez, F. V., et al. (2014). Identification of novel biomarkers of brain damage in patients with hemorrhagic stroke by integrating bioinformatics and mass spectrometry-based proteomics. J. Proteome Res. 13, 969-981. doi: 10.1021/pr401111h

Mattsson, N., Andreasson, U., Zetterberg, H., Blennow, K., Alzheimer's Disease, and Neuroimaging, I. (2017). Association of Plasma Neurofilament Light With Neurodegeneration in Patients With Alzheimer Disease. JAMA Neurol. 74, 557-566. doi: 10.1001/jamaneurol.2016.6117

Mayeli, M., Mirshahvalad, S. M., Aghamollaii, V., Tafakhori, A., Abdolalizadeh, A., and Rahmani, F. (2019). Plasma Neurofilament Light Chain Levels Are 
Associated With Cortical Hypometabolism in Alzheimer Disease Signature Regions. J. Neuropathol. Exp. Neurol. [Preprint]. doi: 10.1093/jnen/nlz054

McDonald, S. J., O’brien, W. T., Symons, G. F., Chen, Z., Bain, J., Major, B. P., et al. (2021). Prolonged elevation of serum neurofilament light after concussion in male Australian football players. Biomark Res. 9:4. doi: 10.1186/s40364-02000256-7

McIntee, F. L., Giannoni, P., Blais, S., Sommer, G., Neubert, T. A., Rostagno, A., et al. (2016). In vivo Differential Brain Clearance and Catabolism of Monomeric and Oligomeric Alzheimer's Abeta protein. Front. Aging Neurosci. 8:223. doi: 10.3389/fnagi.2016.00223

Meeter, L. H., Dopper, E. G., Jiskoot, L. C., Sanchez-Valle, R., Graff, C., Benussi, L., et al. (2016). Neurofilament light chain: a biomarker for genetic frontotemporal dementia. Ann. Clin. Transl. Neurol. 3, 623-636. doi: 10.1002/acn3.325

Merluzzi, A. P., Vogt, N. M., Norton, D., Jonaitis, E., Clark, L. R., Carlsson, C. M., et al. (2019). Differential effects of neurodegeneration biomarkers on subclinical cognitive decline. Alzheimers Dement. 5, 129-138. doi: 10.1016/j.trci.2019.02. 004

Mielke, M. M., Hagen, C. E., Xu, J., Chai, X., Vemuri, P., Lowe, V. J., et al. (2018). Plasma phospho-tau181 increases with Alzheimer's disease clinical severity and is associated with tau- and amyloid-positron emission tomography. Alzheimers Dement. 14, 989-997. doi: 10.1016/j.jalz.2018.02.013

Mietani, K., Sumitani, M., Ogata, T., Shimojo, N., Inoue, R., Abe, H., et al. (2019). Dysfunction of the blood-brain barrier in postoperative delirium patients, referring to the axonal damage biomarker phosphorylated neurofilament heavy subunit. PLoS One 14:e0222721. doi: 10.1371/journal.pone.0222721

Miller, T., Cudkowicz, M., Shaw, P. J., Andersen, P. M., Atassi, N., Bucelli, R. C., et al. (2020). Phase 1-2 Trial of Antisense Oligonucleotide Tofersen for SOD1 ALS. N. Engl. J. Med. 383, 109-119. doi: 10.1056/NEJMoa2003715

Millere, E., Rots, D., Simren, J., Ashton, N. J., Kupats, E., Micule, I., et al. (2021). Plasma neurofilament light chain as a potential biomarker in Charcot-MarieTooth disease. Eur. J. Neurol. 28, 974-981. doi: 10.1111/ene.14689

Minikel, E. V., Zhao, H. T., Le, J., O'moore, J., Pitstick, R., Graffam, S., et al. (2020). Prion protein lowering is a disease-modifying therapy across prion disease stages, strains and endpoints. Nucleic Acids Res. 48, 10615-10631. doi: 10.1093/nar/gkaa616

Miyazawa, I., Nakashima, I., Petzold, A., Fujihara, K., Sato, S., and Itoyama, Y. (2007). High CSF neurofilament heavy chain levels in neuromyelitis optica. Neurology 68, 865-867. doi: 10.1212/01.wnl.0000256820.26489.17

Moore, E. E., Hohman, T. J., Badami, F. S., Pechman, K. R., Osborn, K. E., Acosta, L. M. Y., et al. (2018). Neurofilament relates to white matter microstructure in older adults. Neurobiol. Aging 70, 233-241. doi: 10.1016/j.neurobiolaging.2018. 06.023

Moors, T. E., Maat, C. A., Niedieker, D., Mona, D., Petersen, D., TimmernansHuisman, E., et al. (2019). Subcellular orchestration of alpha-synuclein variants in Parkinson's disease brain revealed by 3D multicolor STED microscopy. bioRxiv [Preprint]. doi: 10.1101/470476

Moscoso, A., Grothe, M. J., Ashton, N. J., Karikari, T. K., Lantero Rodriguez, J., Snellman, A., et al. (2021a). Longitudinal Associations of Blood Phosphorylated Tau181 and Neurofilament Light Chain With Neurodegeneration in Alzheimer Disease. JAMA Neurol. 78, 396-406.

Moscoso, A., Grothe, M. J., Ashton, N. J., Karikari, T. K., Rodriguez, J. L., Snellman, A., et al. (2021b). Time course of phosphorylated-tau181 in blood across the Alzheimer's disease spectrum. Brain 144, 325-339. doi: 10.1093/brain/awaa399

Moseby-Knappe, M., Mattsson, N., Nielsen, N., Zetterberg, H., Blennow, K., Dankiewicz, J., et al. (2019). Serum Neurofilament Light Chain for Prognosis of Outcome After Cardiac Arrest. JAMA Neurol. 76, 64-71. doi: 10.1001/ jamaneurol.2018.3223

Mucke, N., Kammerer, L., Winheim, S., Kirmse, R., Krieger, J., Mildenberger, M., et al. (2018). Assembly Kinetics of Vimentin Tetramers to Unit-Length Filaments: A Stopped-Flow Study. Biophys. J. 114, 2408-2418. doi: 10.1016/j. bpj.2018.04.032

Muller-Wielsch, K., Cannella, B., and Raine, C. S. (2017). Multiple sclerosis: neurofilament pathology in spinal motor neurons. J. Mult. Scler. 04:1000207. doi: 10.4172/2376-0389.1000207

Murphy, A., Breen, K. C., Long, A., Feighery, C., Casey, E. B., and Kelleher, D. (1993). Neurofilament expression in human T lymphocytes. Immunology 79, $167-170$.
Natori, A., Ogata, T., Sumitani, M., Kogure, T., Yamauchi, T., and Yamauchi, H. (2015). Potential role of pNF-H, a biomarker of axonal damage in the central nervous system, as a predictive marker of chemotherapy-induced cognitive impairment. Clin. Cancer Res. 21, 1348-1352. doi: 10.1158/1078-0432.CCR-142775

Niemela, V., Landtblom, A. M., Blennow, K., and Sundblom, J. (2017). Tau or neurofilament light-Which is the more suitable biomarker for Huntington's disease? PLoS One 12:e0172762. doi: 10.1371/journal.pone.0172762

Nilsson, I. A. K., Millischer, V., Karrenbauer, V. D., Jureus, A., Salehi, A. M., Norring, C., et al. (2019). Plasma neurofilament light chain concentration is increased in anorexia nervosa. Transl. Psychiatry 9:180. doi: 10.1038/s41398019-0518-2

Nishida, H., Nakayama, M., Tanaka, H., Kamishina, H., Izawa, T., Hatoya, S., et al. (2014). Evaluation of serum phosphorylated neurofilament subunit NF-H as a prognostic biomarker in dogs with thoracolumbar intervertebral disc herniation. Vet. Surg. 43, 289-293. doi: 10.1111/j.1532-950X.2014.12 144.x

Nixon, R. A., and Logvinenko, K. B. (1986). Multiple fates of newly synthesized neurofilament proteins: evidence for a stationary neurofilament network distributed nonuniformly along axons of retinal ganglion cell neurons. J. Cell Biol. 102, 647-659. doi: 10.1083/jcb.102.2.647

Nixon, R. A., and Marotta, C. A. (1984). Degradation of neurofilament proteins by purified human brain cathepsin D. J. Neurochem. 43, 507-516. doi: 10.1111/j. 1471-4159.1984.tb00928.x

Nixon, R. A., Paskevich, P. A., Sihag, R. K., and Thayer, C. Y. (1994). Phosphorylation on carboxyl terminus domains of neurofilament proteins in retinal ganglion cell neurons in vivo: influences on regional neurofilament accumulation, interneurofilament spacing, and axon caliber. J. Cell Biol. 126, 1031-1046. doi: 10.1083/jcb.126.4.1031

Norgren, N., Karlsson, J. E., Rosengren, L., and Stigbrand, T. (2002). Monoclonal antibodies selective for low molecular weight neurofilaments. Hybrid Hybridomics 21, 53-59. doi: 10.1089/15368590252917647

Norgren, N., Rosengren, L., and Stigbrand, T. (2003). Elevated neurofilament levels in neurological diseases. Brain Res. 987, 25-31. doi: 10.1016/S0006-8993(03) 03219-0

Novakova, L., Zetterberg, H., Sundstrom, P., Axelsson, M., Khademi, M., Gunnarsson, M., et al. (2017). Monitoring disease activity in multiple sclerosis using serum neurofilament light protein. Neurology 89, 2230-2237. doi: 10. 1212/WNL.0000000000004683

Nylen, K., Csajbok, L. Z., Ost, M., Rashid, A., Karlsson, J. E., Blennow, K., et al. (2006). CSF -neurofilament correlates with outcome after aneurysmal subarachnoid hemorrhage. Neurosci. Lett. 404, 132-136. doi: 10.1016/j.neulet. 2006.05.029

O'connor, A., Karikari, T. K., Poole, T., Ashton, N. J., Lantero Rodriguez, J., Khatun, A., et al. (2020). Plasma phospho-tau181 in presymptomatic and symptomatic familial Alzheimer's disease: a longitudinal cohort study. Mol. Psychiatry [Preprint]. doi: 10.1038/s41380-020-0838-x

O”Brien, W. T., Pham, L., Brady, R. D., Bain, J., Yamakawa, G. R., Sun, M., et al. (2021). Temporal profile and utility of serum neurofilament light in a rat model of mild traumatic brain injury. Exp. Neurol. 341:113698. doi: 10.1016/j. expneurol.2021.113698

Olsson, B., Alberg, L., Cullen, N. C., Michael, E., Wahlgren, L., Kroksmark, A. K., et al. (2019). NFL is a marker of treatment response in children with SMA treated with nusinersen. J. Neurol. 266, 2129-2136. doi: 10.1007/s00415-01909389-8

Olsson, B., Lautner, R., Andreasson, U., Ohrfelt, A., Portelius, E., Bjerke, M., et al. (2016). CSF and blood biomarkers for the diagnosis of Alzheimer's disease: a systematic review and meta-analysis. Lancet Neurol. 15, 673-684. doi: 10.1016/ S1474-4422(16)00070-3

Osborn, K. E., Khan, O. A., Kresge, H. A., Bown, C. W., Liu, D., Moore, E. E., et al. (2019). Cerebrospinal fluid and plasma neurofilament light relate to abnormal cognition. Alzheimers Dement. 11, 700-709. doi: 10.1016/j.dadm.2019.08.008

Pachter, J. S., and Liem, R. K. (1984). The differential appearance of neurofilament triplet polypeptides in the developing rat optic nerve. Dev. Biol. 103, 200-210. doi: 10.1016/0012-1606(84)90021-6

Palmqvist, S., Janelidze, S., Quiroz, Y. T., Zetterberg, H., Lopera, F., Stomrud, E., et al. (2020). Discriminative Accuracy of Plasma Phospho-tau217 for Alzheimer 
Disease vs Other Neurodegenerative Disorders. JAMA 324, 772-781. doi: 10 . 1001/jama.2020.12134

Pant, H. C. (1988). Dephosphorylation of neurofilament proteins enhances their susceptibility to degradation by calpain. Biochem. J. 256, 665-668. doi: 10.1042/ bj 2560665

Paterson, R. W., Gabelle, A., Lucey, B. P., Barthelemy, N. R., Leckey, C. A., Hirtz, C., et al. (2019). SILK studies - capturing the turnover of proteins linked to neurodegenerative diseases. Nat. Rev. Neurol. 15, 419-427. doi: 10.1038/s41582019-0222-0

Peikert, K., Akgun, K., Beste, C., Ziemssen, T., Buhmann, C., Danek, A., et al. (2020). Neurofilament light chain in serum is significantly increased in choreaacanthocytosis. Parkinsonism Relat. Disord. 80, 28-31. doi: 10.1016/j.parkreldis. 2020.09.004

Peng, Y., Li, Q., Qin, L., He, Y., Luo, X., Lan, Y., et al. (2021). Combination of Serum Neurofilament Light Chain Levels and MRI Markers to Predict Cognitive Function in Ischemic Stroke. Neurorehabil. Neural Repair 2021:1545968321989354. doi: 10.1177/1545968321989354

Peng, Y., Zhang, Y., Chen, Z., Peng, H., Wan, N., Zhang, J., et al. (2020). Association of serum neurofilament light and disease severity in patients with spinocerebellar ataxia type 3. Neurology 95, e2977-e2987. doi: 10.1212/WNL. 0000000000010671

Pereira, J. B., Westman, E., Hansson, O., Alzheimer's Disease, and Neuroimaging, I. (2017). Association between cerebrospinal fluid and plasma neurodegeneration biomarkers with brain atrophy in Alzheimer's disease. Neurobiol. Aging 58, 14-29. doi: 10.1016/j.neurobiolaging.2017.06.002

Perez-Olle, R., Leung, C. L., and Liem, R. K. (2002). Effects of Charcot-MarieTooth-linked mutations of the neurofilament light subunit on intermediate filament formation. J. Cell Sci. 115, 4937-4946. doi: 10.1242/jcs.00148

Perino, J., Patterson, M., Momen, M., Borisova, M., Heslegrave, A., Zetterberg, H., et al. (2021). Neurofilament light plasma concentration positively associates with age and negatively associates with weight and height in the dog. Neurosci. Lett. 744:135593. doi: 10.1016/j.neulet.2020.135593

Peters, N., Van Leijsen, E., Tuladhar, A. M., Barro, C., Konieczny, M. J., Ewers, M., et al. (2020). Serum Neurofilament Light Chain Is Associated with Incident Lacunes in Progressive Cerebral Small Vessel Disease. J. Stroke 22, 369-376. doi: $10.5853 /$ jos.2019.02845

Petersen, M. E., Rafii, M. S., Zhang, F., Hall, J., Julovich, D., Ances, B. M., et al. (2021). Plasma Total-Tau and Neurofilament Light Chain as Diagnostic Biomarkers of Alzheimer's Disease Dementia and Mild Cognitive Impairment in Adults with Down Syndrome. J. Alzheimers Dis. 79, 671-681. doi: 10.3233/ JAD-201167

Petrova, N., Carassiti, D., Altmann, D. R., Baker, D., and Schmierer, K. (2018). Axonal loss in the multiple sclerosis spinal cord revisited. Brain Pathol. 28, 334-348. doi: 10.1111/bpa.12516

Petzold, A., Keir, G., Green, A. J., Giovannoni, G., and Thompson, E. J. (2003). A specific ELISA for measuring neurofilament heavy chain phosphoforms. J. Immunol. Methods 278, 179-190. doi: 10.1016/S0022-1759(03)00189-3

Piepgras, J., Muller, A., Steffen, F., Lotz, J., Loquai, C., Zipp, F., et al. (2021). Neurofilament light chain levels reflect outcome in a patient with glutamic acid decarboxylase 65 antibody-positive autoimmune encephalitis under immune checkpoint inhibitor therapy. Eur. J. Neurol. 28, 1086-1089. doi: 10.1111/ene. 14692

Pijnenburg, Y. A., Verwey, N. A., Van Der Flier, W. M., Scheltens, P., and Teunissen, C. E. (2015). Discriminative and prognostic potential of cerebrospinal fluid phosphoTau/tau ratio and neurofilaments for frontotemporal dementia subtypes. Alzheimers Dement. 1, 505-512. doi: 10.1016/j.dadm.2015.11.001

Pilotto, A., Imarisio, A., Carrarini, C., Russo, M., Masciocchi, S., Gipponi, S., et al. (2021). Plasma Neurofilament Light Chain Predicts Cognitive Progression in Prodromal and Clinical Dementia with Lewy Bodies. J. Alzheimers Dis. 82, 913-919. doi: 10.3233/JAD-210342

Pisciotta, C., Bai, Y., Brennan, K. M., Wu, X., Grider, T., Feely, S., et al. (2015). Reduced neurofilament expression in cutaneous nerve fibers of patients with CMT2E. Neurology 85, 228-234. doi: 10.1212/WNL.0000000000001773

Poesen, K., De Schaepdryver, M., Stubendorff, B., Gille, B., Muckova, P., Wendler, S., et al. (2017). Neurofilament markers for ALS correlate with extent of upper and lower motor neuron disease. Neurology 88, 2302-2309. doi: 10.1212/WNL. 0000000000004029
Price, R. W., and Brew, B. J. (1988). The AIDS dementia complex. J. Infect Dis. 158, 1079-1083. doi: 10.1093/infdis/158.5.1079

Pujol-Calderon, F., Portelius, E., Zetterberg, H., Blennow, K., Rosengren, L. E., and Hoglund, K. (2019). Neurofilament changes in serum and cerebrospinal fluid after acute ischemic stroke. Neurosci. Lett. 698, 58-63. doi: 10.1016/j.neulet. 2018.12.042

Qiao, X., Zhang, S., Zhao, W., Ye, H., Yang, Y., Zhang, Z., et al. (2015). Serum Phosphorylated Neurofilament-Heavy Chain, a Potential Biomarker, is Associated With Peripheral Neuropathy in Patients With Type 2 Diabetes. Medicine 94:e1908. doi: 10.1097/MD.0000000000001908

Qu, Y., Tan, C. C., Shen, X. N., Li, H. Q., Cui, M., Tan, L., et al. (2021). Association of Plasma Neurofilament Light With Small Vessel Disease Burden in Nondemented Elderly: A Longitudinal Study. Stroke 2021:STROKEAHA120030302. doi: 10.1161/STROKEAHA.120.030302

Quiroz, Y. T., Zetterberg, H., Reiman, E. M., Chen, Y., Su, Y., Fox-Fuller, J. T., et al. (2020). Plasma neurofilament light chain in the presenilin 1 E280A autosomal dominant Alzheimer's disease kindred: a cross-sectional and longitudinal cohort study. Lancet Neurol. 19, 513-521. doi: 10.1016/S1474-4422(20)30137-X

Rana, O. R., Schroder, J. W., Baukloh, J. K., Saygili, E., Mischke, K., Schiefer, J., et al. (2013). Neurofilament light chain as an early and sensitive predictor of long-term neurological outcome in patients after cardiac arrest. Int. J. Cardiol. 168, 1322-1327. doi: 10.1016/j.ijcard.2012.12.016

Rao, M. V., Yuan, A., Campbell, J., Kumar, A., and Nixon, R. A. (2012) The C-terminal domains of NF-H and NF-M subunits maintain axonal neurofilament content by blocking turnover of the stationary neurofilament network. PLoS One 7:e44320. doi: 10.1371/journal.pone.0044320

Rasmussen, M. K., Mestre, H., and Nedergaard, M. (2018). The glymphatic pathway in neurological disorders. Lancet Neurol. 17, 1016-1024. doi: 10.1016/ S1474-4422(18)30318-1

Reinert, M. C., Benkert, P., Wuerfel, J., Michalak, Z., Ruberte, E., Barro, C., et al. (2020). Serum neurofilament light chain is a useful biomarker in pediatric multiple sclerosis. Neurol. Neuroimmunol. Neuroinflamm. 7:e749. doi: 10.1212/ NXI.0000000000000749

Rejdak, K., Kuhle, J., Ruegg, S., Lindberg, R. L., Petzold, A., Sulejczak, D., et al. (2012). Neurofilament heavy chain and heat shock protein 70 as markers of seizure-related brain injury. Epilepsia 53, 922-927. doi: 10.1111/j.1528-1167. 2012.03459.x

Remnestal, J., Oijerstedt, L., Ullgren, A., Olofsson, J., Bergstrom, S., Kultima, K., et al. (2020). Altered levels of CSF proteins in patients with FTD, presymptomatic mutation carriers and non-carriers. Transl. Neurodegener. 9:27. doi: 10.1186/s40035-020-00198-y

Rissin, D. M., Kan, C. W., Campbell, T. G., Howes, S. C., Fournier, D. R., Song, L., et al. (2010). Single-molecule enzyme-linked immunosorbent assay detects serum proteins at subfemtomolar concentrations. Nat. Biotechnol. 28, 595-599. doi: $10.1038 /$ nbt.1641

Robinson, C. A., Clark, A. W., Parhad, I. M., Fung, T. S., and Bou, S. S. (1994). Gene expression in Alzheimer neocortex as a function of age and pathologic severity. Neurobiol. Aging 15, 681-690. doi: 10.1016/0197-4580(94)90049-3

Rodrigues, F. B., Byrne, L. M., Tortelli, R., Johnson, E. B., Wijeratne, P. A., Arridge, M., et al. (2020). Mutant huntingtin and neurofilament light have distinct longitudinal dynamics in Huntington's disease. Sci. Transl. Med. 12:eabc2888. doi: 10.1126 /scitranslmed.abc 2888

Rohrer, J. D., Woollacott, I. O., Dick, K. M., Brotherhood, E., Gordon, E., Fellows, A., et al. (2016). Serum neurofilament light chain protein is a measure of disease intensity in frontotemporal dementia. Neurology 87, 1329-1336. doi: 10.1212/WNL.0000000000003154

Rosen, C., Rosen, H., Andreasson, U., Bremell, D., Bremler, R., Hagberg, L., et al. (2014). Cerebrospinal fluid biomarkers in cardiac arrest survivors. Resuscitation 85, 227-232. doi: 10.1016/j.resuscitation.2013.10.032

Rosen, H., Karlsson, J. E., and Rosengren, L. (2004). CSF levels of neurofilament is a valuable predictor of long-term outcome after cardiac arrest. J. Neurol. Sci. 221, 19-24. doi: 10.1016/j.jns.2004.03.003

Rosengren, L. E., Karlsson, J. E., Karlsson, J. O., Persson, L. I., and Wikkelso, C. (1996). Patients with amyotrophic lateral sclerosis and other neurodegenerative diseases have increased levels of neurofilament protein in CSF. J. Neurochem. 67, 2013-2018. doi: 10.1046/j.1471-4159.1996.67052013.x

Rossi, D., Volanti, P., Brambilla, L., Colletti, T., Spataro, R., and La Bella, V. (2018). CSF neurofilament proteins as diagnostic and prognostic biomarkers 
for amyotrophic lateral sclerosis. J. Neurol. 265, 510-521. doi: 10.1007/s00415017-8730-6

Rosso, M., Gonzalez, C. T., Healy, B. C., Saxena, S., Paul, A., Bjornevik, K., et al. (2020). Temporal association of sNfL and gad-enhancing lesions in multiple sclerosis. Ann. Clin. Transl. Neurol. 7, 945-955. doi: 10.1002/acn3.51060

Ru, Y., Corado, C., Soon, R. K. Jr., Melton, A. C., Harris, A., Yu, G. K., et al. (2019). Neurofilament light is a treatment-responsive biomarker in CLN2 disease. Ann Clin. Transl. Neurol. 6, 2437-2447. doi: 10.1002/acn3.50942

Rudrabhatla, P., Grant, P., Jaffe, H., Strong, M. J., and Pant, H. C. (2010) Quantitative phosphoproteomic analysis of neuronal intermediate filament proteins (NF-M/H) in Alzheimer's disease by iTRAQ. FASEB J. 24, 4396-4407. doi: 10.1096/fj.10-157859

Rudrabhatla, P., Jaffe, H., and Pant, H. C. (2011). Direct evidence of phosphorylated neuronal intermediate filament proteins in neurofibrillary tangles (NFTs): phosphoproteomics of Alzheimer's NFTs. FASEB J. 25, 3896-3905. doi: 10.1096/ fj.11-181297

Sabbatini, D., Raggi, F., Ruggero, S., Seguso, M., Mandrioli, J., Cagnin, A., et al. (2021). Evaluation of peripherin in biofluids of patients with motor neuron diseases. Ann. Clin. Transl. Neurol. 8, 1750-1754. doi: 10.1002/acn3.51419

Sainio, M. T., Ylikallio, E., Maenpaa, L., Lahtela, J., Mattila, P., Auranen, M., et al. (2018). Absence of NEFL in patient-specific neurons in early-onset Charcot-Marie-Tooth neuropathy. Neurol. Genet. 4:e244. doi: 10.1212/NXG. 0000000000000244

Sanchez, I., Hassinger, L., Paskevich, P. A., Shine, H. D., and Nixon, R. A. (1996). Oligodendroglia regulate the regional expansion of axon caliber and local accumulation of neurofilaments during development independently of myelin formation. J. Neurosci. 16, 5095-5105. doi: 10.1523/JNEUROSCI.16-16-05095 1996

Sandelius, A., Zetterberg, H., Blennow, K., Adiutori, R., Malaspina, A., Laura, M., et al. (2018). Plasma neurofilament light chain concentration in the inherited peripheral neuropathies. Neurology 90, e518-e524. doi: 10.1212/ WNL.0000000000004932

Santangelo, R., Agosta, F., Masi, F., Spinelli, E. G., Cecchetti, G., Caso, F., et al. (2021). Plasma neurofilament light chain levels and cognitive testing as predictors of fast progression in Alzheimer's disease. Eur. J. Neurol. 28, 2980-2988. doi: 10.1111/ene.14999

Sara, M., Matteo, G., Luisa, G., Chiara, M., Ruggero, C., Romain, M., et al. (2021). NfL levels predominantly increase at disease onset in MOG-Abs-associated disorders. Mult. Scler. Relat. Disord. 50:102833. doi: 10.1016/j.msard.2021. 102833

Saraste, M., Bezukladova, S., Matilainen, M., Tuisku, J., Rissanen, E., Sucksdorff, M., et al. (2021). High serum neurofilament associates with diffuse white matter damage in MS. Neurol. Neuroimmunol. Neuroinflamm. 8:e926. doi: 10.1212/ NXI.0000000000000926

Sato, C., Barthelemy, N. R., Mawuenyega, K. G., Patterson, B. W., Gordon, B. A., and Jockel-Balsarotti, J. (2018). Tau Kinetics in Neurons and the Human Central Nervous System. Neuron 98, 861-864. doi: 10.1016/j.neuron.2018.04. 035

Scahill, R. I., Zeun, P., Osborne-Crowley, K., Johnson, E. B., Gregory, S., Parker, C., et al. (2020). Biological and clinical characteristics of gene carriers far from predicted onset in the Huntington's disease Young Adult Study (HD-YAS): a cross-sectional analysis. Lancet Neurol. 19, 502-512. doi: 10.1016/S14744422(20)30143-5

Schulz, A., Ajayi, T., Specchio, N., De Los Reyes, E., Gissen, P., Ballon, D., et al. (2018). Study of Intraventricular Cerliponase Alfa for CLN2 Disease. N. Engl. J. Med. 378, 1898-1907. doi: 10.1056/NEJMoa1712649

Sekhon, M. S., Ainslie, P. N., and Griesdale, D. E. (2017). Clinical pathophysiology of hypoxic ischemic brain injury after cardiac arrest: a "two-hit" model. Crit. Care 21:90. doi: 10.1186/s13054-017-1670-9

Shabanzadeh, A. P., D’onofrio, P. M., Monnier, P. P., and Koeberle, P. D. (2015). Targeting caspase- 6 and caspase- 8 to promote neuronal survival following ischemic stroke. Cell Death Dis. 6:e1967. doi: 10.1038/cddis.2015.272

Shahim, P., Gren, M., Liman, V., Andreasson, U., Norgren, N., Tegner, Y., et al. (2016). Serum neurofilament light protein predicts clinical outcome in traumatic brain injury. Sci. Rep. 6:36791. doi: 10.1038/srep36791

Shahim, P., Politis, A., Van Der Merwe, A., Moore, B., Chou, Y. Y., Pham, D. L., et al. (2020). Neurofilament light as a biomarker in traumatic brain injury. Neurology 95, e610-e622. doi: 10.1212/WNL.0000000000009983
Shahim, P., Zetterberg, H., Tegner, Y., and Blennow, K. (2017). Serum neurofilament light as a biomarker for mild traumatic brain injury in contact sports. Neurology 88, 1788-1794. doi: 10.1212/WNL.0000000000003912

Shaw, G., and Weber, K. (1982). Differential expression of neurofilament triplet proteins in brain development. Nature 298, 277-279. doi: 10.1038/298277a0

Shaw, G., Yang, C., Ellis, R., Anderson, K., Parker Mickle, J., Scheff, S., et al. (2005). Hyperphosphorylated neurofilament NF-H is a serum biomarker of axonal injury. Biochem. Biophys. Res. Commun. 336, 1268-1277. doi: 10.1016/j.bbrc. 2005.08.252

Shekhar, S., Kumar, R., Rai, N., Kumar, V., Singh, K., Upadhyay, A. D., et al. (2016). Estimation of Tau and Phosphorylated Tau181 in Serum of Alzheimer's Disease and Mild Cognitive Impairment Patients. PLoS One 11:e0159099. doi: 10.1371/journal.pone.0159099

Shen, H., Barry, D. M., Dale, J. M., Garcia, V. B., Calcutt, N. A., and Garcia, M. L. (2011). Muscle pathology without severe nerve pathology in a new mouse model of Charcot-Marie-Tooth disease type 2E. Hum. Mol. Genet. 20, 2535-2548. doi: 10.1093/hmg/ddr152

Shibahashi, K., Doi, T., Tanaka, S., Hoda, H., Chikuda, H., Sawada, Y., et al. (2016). The Serum Phosphorylated Neurofilament Heavy Subunit as a Predictive Marker for Outcome in Adult Patients after Traumatic Brain Injury. J. Neurotrauma 33, 1826-1833. doi: 10.1089/neu.2015.4237

Shinomoto, M., Kasai, T., Tatebe, H., Kondo, M., Ohmichi, T., Morimoto, M., et al. (2019). Plasma neurofilament light chain: A potential prognostic biomarker of dementia in adult Down syndrome patients. PLoS One 14:e0211575. doi: 10.1371/journal.pone.0211575

Shribman, S., Heller, C., Burrows, M., Heslegrave, A., Swift, I., Foiani, M. S., et al. (2021). Plasma Neurofilament Light as a Biomarker of Neurological Involvement in Wilson's Disease. Mov. Disord. 36, 503-508. doi: 10.1002/mds. 28333

Singh, A., Kumar, V., Ali, S., Mahdi, A. A., and Srivastava, R. N. (2017). Phosphorylated neurofilament heavy: A potential blood biomarker to evaluate the severity of acute spinal cord injuries in adults. Int. J. Crit. Illn. Inj. Sci. 7, 212-217. doi: 10.4103/IJCIIS.IJCIIS_73_16

Singh, P., Yan, J., Hull, R., Read, S., O’sullivan, J., Henderson, R. D., et al. (2011). Levels of phosphorylated axonal neurofilament subunit $\mathrm{H}(\mathrm{pNfH})$ are increased in acute ischemic stroke. J. Neurol. Sci. 304, 117-121. doi: 10.1016/j.jns.2011.01. 025

Skillback, T., Farahmand, B., Bartlett, J. W., Rosen, C., Mattsson, N., Nagga, K., et al. (2014). CSF neurofilament light differs in neurodegenerative diseases and predicts severity and survival. Neurology 83, 1945-1953. doi: 10.1212/WNL. 0000000000001015

Skillback, T., Mattsson, N., Blennow, K., and Zetterberg, H. (2017). Cerebrospinal fluid neurofilament light concentration in motor neuron disease and frontotemporal dementia predicts survival. Amyotroph. Lateral Scler. Frontotemporal Degener. 18, 397-403. doi: 10.1080/21678421.2017.12 81962

Smerjac, S. M., Zheng, J., Hu, C. L., and Bizzozero, O. A. (2018). The Role of Calpain and Proteasomes in the Degradation of Carbonylated Neuronal Cytoskeletal Proteins in Acute Experimental Autoimmune Encephalomyelitis. Neurochem. Res. 43, 2277-2287. doi: 10.1007/s11064-018-2648-y

Sofou, K., Shahim, P., Tulinius, M., Blennow, K., Zetterberg, H., Mattsson, N., et al. (2019). Cerebrospinal fluid neurofilament light is associated with survival in mitochondrial disease patients. Mitochondrion 46, 228-235. doi: 10.1016/j.mito. 2018.07.002

Soylu-Kucharz, R., Sandelius, A., Sjogren, M., Blennow, K., Wild, E. J., Zetterberg, H., et al. (2017). Neurofilament light protein in CSF and blood is associated with neurodegeneration and disease severity in Huntington's disease R6/2 mice. Sci. Rep. 7:14114. doi: 10.1038/s41598-017-14179-1

Spotorno, N., Lindberg, O., Nilsson, C., Landqvist Waldo, M., Van Westen, D., Nilsson, K., et al. (2020). Plasma neurofilament light protein correlates with diffusion tensor imaging metrics in frontotemporal dementia. PLoS One 15:e0236384. doi: 10.1371/journal.pone.0236384

Steinacker, P., Blennow, K., Halbgebauer, S., Shi, S., Ruf, V., Oeckl, P., et al. (2016). Neurofilaments in blood and CSF for diagnosis and prediction of onset in Creutzfeldt-Jakob disease. Sci. Rep. 6:38737. doi: 10.1038/srep38737

Strydom, A., Heslegrave, A., Startin, C. M., Mok, K. Y., Hardy, J., Groet, J., et al. (2018). Neurofilament light as a blood biomarker for neurodegeneration in Down syndrome. Alzheimers Res. Ther. 10:39. doi: 10.1186/s13195-018-0367-x 
Suarez-Calvet, M., Karikari, T. K., Ashton, N. J., Lantero Rodriguez, J., MilaAloma, M., and Gispert, J. D. (2020). Novel tau biomarkers phosphorylated at T181, T217 or T231 rise in the initial stages of the preclinical Alzheimer's continuum when only subtle changes in Abeta pathology are detected. EMBO Mol. Med. 12:e12921.

Sun, B., Dalvi, P., Abadjian, L., Tang, N., and Pulliam, L. (2017). Blood neuronderived exosomes as biomarkers of cognitive impairment in HIV. AIDS 31, F9-F17. doi: 10.1097/QAD.0000000000001595

Sutter, R., Hert, L., De Marchis, G. M., Twerenbold, R., Kappos, L., Naegelin, Y., et al. (2021). Serum Neurofilament Light Chain Levels in the Intensive Care Unit: Comparison between Severely Ill Patients with and without Coronavirus Disease 2019. Ann. Neurol. 89, 610-616. doi: 10.1002/ana. 26004

Sweeney, M. D., Sagare, A. P., and Zlokovic, B. V. (2018). Blood-brain barrier breakdown in Alzheimer disease and other neurodegenerative disorders. Nat. Rev. Neurol. 14, 133-150. doi: 10.1038/nrneurol.2017.188

Szentistvanyi, I., Patlak, C. S., Ellis, R. A., and Cserr, H. F. (1984). Drainage of interstitial fluid from different regions of rat brain. Am. J. Physiol. 246, F835-F844. doi: 10.1152/ajprenal.1984.246.6.F835

Szilasiova, J., Mikula, P., Rosenberger, J., Fedicova, M., Gdovinova, Z., Urban, P., et al. (2021). Plasma neurofilament light chain levels are predictors of disease activity in multiple sclerosis as measured by four-domain NEDA status, including brain volume loss. Mult. Scler. 2021:1352458521998039. doi: 10.1177/ 1352458521998039

Takahashi, N., and Ishizuka, B. (2012). The involvement of neurofilament heavy chain phosphorylation in the maturation and degeneration of rat oocytes. Endocrinology 153, 1990-1998. doi: 10.1210/en.2011-2026

Tallantyre, E. C., Bo, L., Al-Rawashdeh, O., Owens, T., Polman, C. H., Lowe, J., et al. (2009). Greater loss of axons in primary progressive multiple sclerosis plaques compared to secondary progressive disease. Brain 132, 1190-1199. doi: 10.1093/brain/awp106

Tang, W., Huang, Q., Yao, Y. Y., Wang, Y., Wu, Y. L., and Wang, Z. Y. (2014). Does CSF p-tau181 help to discriminate Alzheimer's disease from other dementias and mild cognitive impairment? A meta-analysis of the literature. J. Neural. Transm. 121, 1541-1553. doi: 10.1007/s00702-014-1226-y

Terasawa, K., Taguchi, T., Momota, R., Naito, I., Murakami, T., and Ohtsuka, A. (2006). Human erythrocytes possess a cytoplasmic endoskeleton containing beta-actin and neurofilament protein. Arch. Histol. Cytol. 69, 329-340. doi: 10.1679/aohc.69.329

Thebault, S., Abdoli, M., Fereshtehnejad, S. M., Tessier, D., Tabard-Cossa, V., and Freedman, M. S. (2020a). Serum neurofilament light chain predicts long term clinical outcomes in multiple sclerosis. Sci. Rep. 10:10381. doi: 10.1038/s41598020-67504-6

Thebault, S., Booth, R. A., Rush, C. A., Maclean, H., and Freedman, M. S. (2021). Serum Neurofilament Light Chain Measurement in MS: Hurdles to Clinical Translation. Front. Neurosci. 15:654942. doi: 10.3389/fnins.2021.65 4942

Thebault, S., Lee, H., Bose, G., Tessier, D., Abdoli, M., Bowman, M., et al. (2020b). Neurotoxicity after hematopoietic stem cell transplant in multiple sclerosis. Ann. Clin. Transl. Neurol. 7, 767-775. doi: 10.1002/acn3.51045

Thijssen, E. H., La Joie, R., Wolf, A., Strom, A., Wang, P., Iaccarino, L., et al. (2020). Diagnostic value of plasma phosphorylated tau181 in Alzheimer's disease and frontotemporal lobar degeneration. Nat. Med. 26, 387-397. doi: 10.1038/s41591-020-0762-2

Thompson, A. G. B., Anastasiadis, P., Druyeh, R., Whitworth, I., Nayak, A., Nihat, A., et al. (2021). Evaluation of plasma tau and neurofilament light chain biomarkers in a 12-year clinical cohort of human prion diseases. Mol. Psychiatry [Preprint]. doi: 10.1038/s41380-021-01045-w

Thompson, A. G. B., Luk, C., Heslegrave, A. J., Zetterberg, H., Mead, S. H., Collinge, J., et al. (2018). Neurofilament light chain and tau concentrations are markedly increased in the serum of patients with sporadic Creutzfeldt-Jakob disease, and tau correlates with rate of disease progression. J. Neurol. Neurosurg. Psychiatry 89, 955-961. doi: 10.1136/jnnp-2017-317793

Thouvenot, E., Demattei, C., Lehmann, S., Maceski-Maleska, A., Hirtz, C., JuntasMorales, R., et al. (2020). Serum neurofilament light chain at time of diagnosis is an independent prognostic factor of survival in amyotrophic lateral sclerosis. Eur. J. Neurol. 27, 251-257. doi: 10.1111/ene.14063
Ticau, S., Sridharan, G. V., Tsour, S., Cantley, W. L., Chan, A., Gilbert, J. A., et al. (2019). Palsma proeome analysis of patients with hereditary transthyretinmediated (hATTR) amyloidosis establishes neurofilament light chain (NfL) as a bimarker of disease and treatment response. medRxiv [Preprint]. doi: 10.1101/ 19011155

Tiedt, S., Duering, M., Barro, C., Kaya, A. G., Boeck, J., Bode, F. J., et al. (2018). Serum neurofilament light: A biomarker of neuroaxonal injury after ischemic stroke. Neurology 91, e1338-e1347. doi: 10.1212/WNL.0000000000006282

Tissot, C., Benedet, A. L., Therriault, J., Pascoal, T. A., Lussier, F. Z., SahaChaudhuri, P., et al. (2021). Plasma pTau181 predicts cortical brain atrophy in aging and Alzheimer's disease. Alzheimers Res. Ther. 13:69. doi: 10.1186/s13195021-00802-x

Toft, A., Roos, P., Jaaskelainen, O., Musaeus, C. S., Henriksen, E. E., Johannsen, P., et al. (2021). Serum Neurofilament Light in Patients with Frontotemporal Dementia Caused by CHMP2B Mutation. Dement. Geriatr. Cogn. Disord. 2021, 1-6. doi: $10.1159 / 000513877$

Toorell, H., Zetterberg, H., Blennow, K., Savman, K., and Hagberg, H. (2018). Increase of neuronal injury markers Tau and neurofilament light proteins in umbilical blood after intrapartum asphyxia. J. Matern Fetal Neonatal. Med. 31, 2468-2472. doi: 10.1080/14767058.2017.1344964

Tortelli, R., Copetti, M., Ruggieri, M., Cortese, R., Capozzo, R., Leo, A., et al. (2015). Cerebrospinal fluid neurofilament light chain levels: marker of progression to generalized amyotrophic lateral sclerosis. Eur. J. Neurol. 22, 215-218. doi: 10.1111/ene.12421

Tradewell, M. L., Durham, H. D., Mushynski, W. E., and Gentil, B. J. (2009). Mitochondrial and axonal abnormalities precede disruption of the neurofilament network in a model of charcot-marie-tooth disease type $2 \mathrm{E}$ and are prevented by heat shock proteins in a mutant-specific fashion. J. Neuropathol. Exp. Neurol. 68, 642-652. doi: 10.1097/NEN.0b013e3181a 5 deeb

Van Der Ende, E. L., Meeter, L. H., Poos, J. M., Panman, J. L., Jiskoot, L. C., Dopper, E. G. P., et al. (2019). Serum neurofilament light chain in genetic frontotemporal dementia: a longitudinal, multicentre cohort study. Lancet Neurol. 18, 1103-1111. doi: 10.1016/S1474-4422(19)30354-0

Van Der Plas, E., Lullmann, O., Hopkins, L., Schultz, J. L., Nopoulos, P. C., and Harshman, L. A. (2021). Associations between neurofilament light-chain protein, brain structure, and chronic kidney disease. Pediatr. Res. [Preprint]. doi: 10.1038/s41390-021-01649-6

Van Der Vuurst De Vries, R. M., Wong, Y. Y. M., Mescheriakova, J. Y., Van Pelt, E. D., Runia, T. F., et al. (2019). High neurofilament levels are associated with clinically definite multiple sclerosis in children and adults with clinically isolated syndrome. Mult. Scler. 25, 958-967. doi: 10.1177/13524585187 75303

Vanmechelen, E., Vanderstichele, H., Davidsson, P., Van Kerschaver, E., Van Der Perre, B., Sjogren, M., et al. (2000). Quantification of tau phosphorylated at threonine 181 in human cerebrospinal fluid: a sandwich ELISA with a synthetic phosphopeptide for standardization. Neurosci. Lett. 285, 49-52. doi: 10.1016/ S0304-3940(00)01036-3

Vikartovska, Z., Farbakova, J., Smolek, T., Hanes, J., Zilka, N., Hornakova, L., et al. (2020). Novel Diagnostic Tools for Identifying Cognitive Impairment in Dogs: Behavior, Biomarkers, and Pathology. Front. Vet. Sci. 7:551895. doi: 10.3389/fvets.2020.551895

Von Bartheld, C. S., and Altick, A. L. (2011). Multivesicular bodies in neurons: distribution, protein content, and trafficking functions. Prog. Neurobiol. 93, 313-340. doi: 10.1016/j.pneurobio.2011.01.003

Wang, J., Hidaka, T., Sasaki, Y., Tanaka, E., Takagi, M., Shibata, T., et al. (2018). Neurofilament heavy polypeptide protects against reduction in synaptopodin expression and prevents podocyte detachment. Sci. Rep. 8:17157. doi: 10.1038/ s41598-018-35465-6

Wang, J. H., Huang, J., Guo, F. Q., Wang, F., Yang, S., Yu, N. W., et al. (2021). Circulating Neurofilament Light Predicts Cognitive Decline in Patients With Post-stroke Subjective Cognitive Impairment. Front. Aging Neurosci. 13:665981. doi: 10.3389/fnagi.2021.665981

Wang, Z., Wang, R., Li, Y., Li, M., Zhang, Y., Jiang, L., et al. (2021). Plasma Neurofilament Light Chain as a Predictive Biomarker for Post-stroke Cognitive Impairment: A Prospective Cohort Study. Front. Aging Neurosci. 13:631738. doi: 10.3389/fnagi.2021.631738 
Weinhofer, I., Rommer, P., Zierfuss, B., Altmann, P., Foiani, M., Heslegrave, A., et al. (2021). Neurofilament light chain as a potential biomarker for monitoring neurodegeneration in X-linked adrenoleukodystrophy. Nat. Commun. 12:1816. doi: 10.1038/s41467-021-22114-2

Weydt, P., Oeckl, P., Huss, A., Muller, K., Volk, A. E., Kuhle, J., et al. (2016). Neurofilament levels as biomarkers in asymptomatic and symptomatic familial amyotrophic lateral sclerosis. Ann. Neurol. 79, 152-158. doi: 10.1002/ana. 24552

Wihersaari, L., Ashton, N. J., Reinikainen, M., Jakkula, P., Pettila, V., Hastbacka, J., et al. (2021). Neurofilament light as an outcome predictor after cardiac arrest: a post hoc analysis of the COMACARE trial. Intensive Care Med. 47, 39-48. doi: 10.1007/s00134-020-06218-9

Wilke, C., Haas, E., Reetz, K., Faber, J., Garcia-Moreno, H., Santana, M. M., et al. (2020). Neurofilaments in spinocerebellar ataxia type 3: blood biomarkers at the preataxic and ataxic stage in humans and mice. EMBO Mol. Med. 12: e11803.

Winston, C. N., Romero, H. K., Ellisman, M., Nauss, S., Julovich, D. A., Conger, T., et al. (2019). Assessing Neuronal and Astrocyte Derived Exosomes From Individuals With Mild Traumatic Brain Injury for Markers of Neurodegeneration and Cytotoxic Activity. Front. Neurosci. 13:1005. doi: 10. 3389/fnins.2019.01005

Winther-Larsen, A., Hviid, C. V. B., Meldgaard, P., Sorensen, B. S., and SandfeldPaulsen, B. (2020). Neurofilament Light Chain as A Biomarker for Brain Metastases. Cancers 12:2852. doi: 10.3390/cancers 12102852

Wong, N. K., He, B. P., and Strong, M. J. (2000). Characterization of neuronal intermediate filament protein expression in cervical spinal motor neurons in sporadic amyotrophic lateral sclerosis (ALS). J. Neuropathol. Exp. Neurol. 59, 972-982. doi: 10.1093/jnen/59.11.972

Woolley, J. D., Khan, B. K., Murthy, N. K., Miller, B. L., and Rankin, K. P. (2011). The diagnostic challenge of psychiatric symptoms in neurodegenerative disease: rates of and risk factors for prior psychiatric diagnosis in patients with early neurodegenerative disease. J. Clin. Psychiatry 72, 126-133. doi: 10.4088/JCP. 10m06382oli

Xiao, S., Tjostheim, S., Sanelli, T., Mclean, J. R., Horne, P., Fan, Y., et al. (2008). An aggregate-inducing peripherin isoform generated through intron retention is upregulated in amyotrophic lateral sclerosis and associated with disease pathology. J. Neurosci. 28, 1833-1840. doi: 10.1523/JNEUROSCI.3222-07. 2008

Xu, Z., Cork, L. C., Griffin, J. W., and Cleveland, D. W. (1993). Increased expression of neurofilament subunit NF-L produces morphological alterations that resemble the pathology of human motor neuron disease. Cell 73, 23-33. doi: 10.1016/0092-8674(93)90157-L

Yabe, J. T., Chan, W. K., Wang, F. S., Pimenta, A., Ortiz, D. D., and Shea, T. B. (2003). Regulation of the transition from vimentin to neurofilaments during neuronal differentiation. Cell Motil. Cytoskeleton 56, 193-205. doi: 10.1002/cm. 10137

Yamasaki, H., Itakura, C., and Mizutani, M. (1991). Hereditary hypotrophic axonopathy with neurofilament deficiency in a mutant strain of the Japanese quail. Acta Neuropathol. 82, 427-434. doi: 10.1007/BF00293376

Yan, Y., and Brown, A. (2005). Neurofilament polymer transport in axons. J. Neurosci. 25, 7014-7021. doi: 10.1523/JNEUROSCI.2001-05. 2005

Yang, Z., Zhu, T., Mondello, S., Akel, M., Wong, A. T., Kothari, I. M., et al. (2019). Serum-Based Phospho-Neurofilament-Heavy Protein as Theranostic Biomarker in Three Models of Traumatic Brain Injury: An Operation Brain Trauma Therapy Study. J. Neurotrauma 36, 348-359. doi: 10.1089/neu.2017. 5586

Ye, R., Locascio, J. J., Goodheart, A. E., Quan, M., Zhang, B., and Gomperts, S. N. (2021). Serum NFL levels predict progression of motor impairment and reduction in putamen dopamine transporter binding ratios in de novo Parkinson's disease: An 8-year longitudinal study. Parkinsonism Relat. Disord. 85, 11-16. doi: 10.1016/j.parkreldis.2021.02.008

Yilmaz, A., Blennow, K., Hagberg, L., Nilsson, S., Price, R. W., Schouten, J., et al. (2017). Neurofilament light chain protein as a marker of neuronal injury: review of its use in HIV-1 infection and reference values for HIV-negative controls. Expert Rev. Mol. Diagn. 17, 761-770. doi: 10.1080/14737159.2017.13 41313
Yuan, A., Hassinger, L., Rao, M. V., Julien, J. P., Miller, C. C., and Nixon, R. A. (2015a). Dissociation of Axonal Neurofilament Content from Its Transport Rate. PLoS One 10:e0133848. doi: 10.1371/journal.pone.0133848

Yuan, A., Rao, M. V., Kumar, A., Julien, J. P., and Nixon, R. A. (2003). Neurofilament transport in vivo minimally requires hetero-oligomer formation. J. Neurosci. 23, 9452-9458. doi: 10.1523/JNEUROSCI.23-28-09452.2003

Yuan, A., Rao, M. V., Sasaki, T., Chen, Y., Kumar, A., Veeranna, et al. (2006). Alpha-internexin is structurally and functionally associated with the neurofilament triplet proteins in the mature CNS. J. Neurosci. 26, 10006-10019. doi: 10.1523/JNEUROSCI.2580-06.2006

Yuan, A., Rao, M. V., Veeranna, and Nixon, R. A. (2017). Neurofilaments and Neurofilament Proteins in Health and Disease. Cold Spring Harb. Perspect. Biol. 9:a018309. doi: 10.1101/cshperspect.a018309

Yuan, A., Sasaki, T., Kumar, A., Peterhoff, C. M., Rao, M. V., Liem, R. K., et al. (2012). Peripherin is a subunit of peripheral nerve neurofilaments: implications for differential vulnerability of CNS and peripheral nervous system axons. J. Neurosci. 32, 8501-8508. doi: 10.1523/JNEUROSCI.1081-12. 2012

Yuan, A., Sasaki, T., Rao, M. V., Kumar, A., Kanumuri, V., Dunlop, D. S., et al. (2009). Neurofilaments form a highly stable stationary cytoskeleton after reaching a critical level in axons. J. Neurosci. 29, 11316-11329. doi: 10.1523/ JNEUROSCI.1942-09.2009

Yuan, A., Sershen, H., Veeranna, Basavarajappa, B. S., Kumar, A., Hashim, A., et al. (2015b). Neurofilament subunits are integral components of synapses and modulate neurotransmission and behavior in vivo. Mol. Psychiatry 20, 986-994. doi: $10.1038 / \mathrm{mp} .2015 .45$

Yuan, A., Veeranna, Sershen, H., Basavarajappa, B. S., Smiley, J. F., Hashim, A., et al. (2018). Neurofilament light interaction with GluN1 modulates neurotransmission and schizophrenia-associated behaviors. Transl. Psychiatry 8:167. doi: 10.1038/s41398-018-0194-7

Yum, S. W., Zhang, J., Mo, K., Li, J., and Scherer, S. S. (2009). A novel recessive Nefl mutation causes a severe, early-onset axonal neuropathy. Ann. Neurol. 66, 759-770. doi: 10.1002/ana.21728

Zerr, I., Villar-Pique, A., Hermann, P., Schmitz, M., Varges, D., Ferrer, I., et al. (2021). Diagnostic and prognostic value of plasma neurofilament light and total-tau in sporadic Creutzfeldt-Jakob disease. Alzheimers Res. Ther. 13:86. doi: 10.1186/s13195-021-00815-6

Zetterberg, H., Bozzetta, E., Favole, A., Corona, C., Cavarretta, M. C., Ingravalle, F., et al. (2019). Neurofilaments in blood is a new promising preclinical biomarker for the screening of natural scrapie in sheep. PLoS One 14:e0226697. doi: 10. 1371/journal.pone.0226697

Zetterberg, H., Jacobsson, J., Rosengren, L., Blennow, K., and Andersen, P. M. (2007). Cerebrospinal fluid neurofilament light levels in amyotrophic lateral sclerosis: impact of SOD1 genotype. Eur. J. Neurol. 14, 1329-1333. doi: 10.1111/ j.1468-1331.2007.01972.x

Zetterberg, H., Skillback, T., Mattsson, N., Trojanowski, J. Q., Portelius, E., Shaw, L. M., et al. (2016). Association of Cerebrospinal Fluid Neurofilament Light Concentration With Alzheimer Disease Progression. JAMA Neurol. 73, 60-67. doi: 10.1001/jamaneurol.2015.3037

Zhai, J., Lin, H., Julien, J. P., and Schlaepfer, W. W. (2007). Disruption of neurofilament network with aggregation of light neurofilament protein: a common pathway leading to motor neuron degeneration due to CharcotMarie-Tooth disease-linked mutations in NFL and HSPB1. Hum. Mol. Genet. 16, 3103-3116. doi: $10.1093 / \mathrm{hmg} / \mathrm{ddm} 272$

Zhang, M., and Olsson, Y. (1997). Hematogenous metastases of the human braincharacteristics of peritumoral brain changes: a review. J. Neurooncol. 35, 81-89. doi: 10.1023/A:1005799805335

Zhang, N., Gu, D., Meng, M., and Gordon, M. L. (2020). TDP-43 Is Elevated in Plasma Neuronal-Derived Exosomes of Patients With Alzheimer's Disease. Front. Aging Neurosci. 12:166. doi: 10.3389/fnagi.2020.00166

Zheng, Y. S., Sun, C., Wang, R., Chen, N., Luo, S. S., Xi, J. Y., et al. (2021). Neurofilament light is a novel biomarker for mitochondrial encephalomyopathy, lactic acidosis, and stroke-like episodes. Sci. Rep. 11:2001. doi: 10.1038/s41598-021-81721-7

Zhou, W., Zhang, J., Ye, F., Xu, G., Su, H., Su, Y., et al. (2017). Plasma neurofilament light chain levels in Alzheimer's disease. Neurosci. Lett. 650, 60-64. doi: 10.1016/ j.neulet.2017.04.027 
Zhu, Q., Couillard-Despres, S., and Julien, J. P. (1997). Delayed maturation of regenerating myelinated axons in mice lacking neurofilaments. Exp. Neurol. 148, 299-316. doi: 10.1006/exnr.1997.6654

Zhu, Y., Yang, B., Wang, F., Liu, B., Li, K., Yin, K., et al. (2021). Association between plasma neurofilament light chain levels and cognitive function in patients with Parkinson's disease. J. Neuroimmunol. 358:577662. doi: 10.1016/j. jneuroim.2021.577662

Zucchi, E., Lu, C. H., Cho, Y., Chang, R., Adiutori, R., Zubiri, I., et al. (2018). A motor neuron strategy to save time and energy in neurodegeneration: adaptive protein stoichiometry. J. Neurochem. 146, 631-641. doi: 10.1111/jnc. 14542

Zuchner, S., Vorgerd, M., Sindern, E., and Schroder, J. M. (2004). The novel neurofilament light (NEFL) mutation Glu397Lys is associated with a clinically and morphologically heterogeneous type of Charcot-Marie-Tooth neuropathy. Neuromuscul. Disord. 14, 147-157. doi: 10.1016/j.nmd.2003. 10.003
Conflict of Interest: The authors declare that the research was conducted in the absence of any commercial or financial relationships that could be construed as a potential conflict of interest.

Publisher's Note: All claims expressed in this article are solely those of the authors and do not necessarily represent those of their affiliated organizations, or those of the publisher, the editors and the reviewers. Any product that may be evaluated in this article, or claim that may be made by its manufacturer, is not guaranteed or endorsed by the publisher.

Copyright (c) 2021 Yuan and Nixon. This is an open-access article distributed under the terms of the Creative Commons Attribution License (CC BY). The use, distribution or reproduction in other forums is permitted, provided the original author(s) and the copyright owner(s) are credited and that the original publication in this journal is cited, in accordance with accepted academic practice. No use, distribution or reproduction is permitted which does not comply with these terms. 